\title{
A Multi-Layered Ceramic Composite for Impermeable Fuel Cladding for Commercial Water Reactors
}

Final Technical Report for Phase 2 SBIR Project

Work Performed from May, 2003 to November, 2006

\author{
Revision 2 - March 3, 2008 \\ Principal Investigator - Herbert Feinroth \\ Gamma Engineering Corporation \\ 15815 Crabbs Branch Way \\ Rockville, Maryland 20855 \\ hfeinroth@gamma-eng.com \\ Contributing Researchers:
Gamma Engineering Corporation
Bernard Hao
Denwood Ross
Carmine Smedira
Zia Faizthompkins \\ NovaTech International \\ Matt Ales, \\ Eric Barringer
Massachusetts Institute of Technology
Dr. Gordon Kohse
Dr. Yaakov Ostrowsky
David Carpenter
Ceramic Composites Inc
Larry Fehrenbacher
Mark Patterson
Steve Seghi


Researchers from the following National Laboratories, Private Corporations, and Universities also provided engineering and testing services in support of the work reported herein:

\author{
Argonne National Laboratory \\ Idaho National Laboratory \\ MER Corporation \\ NASA Glenn \\ Oak Ridge National Laboratory \\ Pacific Northwest National Laboratory \\ Starfire Enterprises \\ Synterials Corporation \\ TREX Corporation \\ University of Wisconsin \\ Westinghouse Electric Corporation
}

Work Performed for US Department of Energy Office of Science, and Office of Nuclear Energy under Financial Assistance Award - DE-FG02-01ER83194

This report was prepared as an account of work sponsored by an agency of the United States Government. Neither the United States Government nor any agency thereof, nor any of their employees, nor any of their contractors, subcontractors, or their employees, makes any warranty, express or implied, or assumes any legal liability or responsibility for the accuracy, completeness, or any third party's use or the results of such use of any information, apparatus, product, or process disclosed, or represents that its use would not infringe privately owned rights. Reference herein to any specific commercial product, process, or service by trade name, trademark, manufacturer, or otherwise, does not necessarily constitute or imply its endorsement, recommendation, or favoring by the United States Government or any agency thereof or its contractors or subcontractors. The views and opinions of authors expressed herein do not necessarily state or reflect those of the United States Government or any agency thereof.

SBIR/STTR Rights Notice: These SBIR/STTR data are furnished with SBIR/STTR rights under Grant No. DE-FG02-02-01ER83194. For a period of 4 years after acceptance of all items delivered under this grant, the Government agrees to use these data for Government purposes only, and they shall not be disclosed outside the Government (including disclosure for procurement purposes) during such period without permission of the grantee, except that, subject to the foregoing use and disclosure prohibitions, such data may be disclosed for use by support contractors. After the aforesaid 4 - year period the Government has a royalty free license to use, and to authorize others to use on its behalf, these data for Government purposes, but is relieved of all disclosure prohibitions and assumes no liability for unauthorized use of these data by third parties. This Notice shall be affixed to any reproductions of these data in whole or in part. (End of Notice)

PATENT CAUTION CAUTION - Restricted Distribution Data Under 35 U.S.C. Sec. 205. USDOE Docket No. S-108,844.

DISTRIBUTION B Further dissemination authorized to US Government Agencies only; other requests shall be approved by the originating facility or higher DOE programmatic authority. 


\section{$\underline{\text { Table of Contents }}$}

List of Tables $\quad 4$

List of Figures $\quad 4$

Abstract 6

$\begin{array}{lll}1.0 & \text { Introduction } & 7\end{array}$

2.0 Early Research on Ceramic Fuel Cladding 8

3.0 Phase 1 SBIR Research 8

4.0 Phase 2 Development - Rounds 2-5 17

5.0 Application to Super-Critical Water Reactors (Gen IV Program) 30

6.0 Out of Pile Corrosion Tests 44

7.0 Mechanical and Permeability Testing of Early Round Duplex Tubes $\quad 50$

8.0 Design and Fabrication of the Round 6 Tubes 53

9.0 Design, Fabrication and Assembly of MIT Irradiation Test 59

10.0 ORNL Pre-Irradiation Strength Testing of Round 6 Tubes 63

11.0 Private Funded Irradiation Tests at MIT 66

12.0 Summary and Future Plans $\quad 69$

$\begin{array}{lll}13.0 & \text { References } & 71\end{array}$ 


\section{List of Tables}

Table 3.1 - A comparison of properties of candidate materials

Table 3.2 - Hybrid test specimen thermal cycling test conditions and findings

Table 4.1 - Round 2 Specimen Characteristics Prior to Infiltration

Table 4.2 - Pre-Round 2 Processing Trials on Phase 1 Pre-Forms

Table 4.3 - Infiltration Used in First Stage of Round 2 Specimens

Table 4.4 - Processing Characteristics of Round 4 and 5 Duplex Tubes

Table 4.5 - MER Tube Characteristics After PIP Matrix Densification

Table 4.6 - Starfire and NovaTech all Composite Tubes

Table 5.1. Geometry for SCWR conditions for fuel pins with $\mathrm{SiC} / \mathrm{SiC}$ and metal cladding.

Table 5.2. Reference SCWR fuel assembly with SiC/SiC-clad fuel pins.

Table 5.3 SCWR water densities for the coolant and water rods

Table 5.4. Assembly lattice k-infinity and reactivity worth comparison for various assembly material replacements.

Table 5.5. Assembly k-infinity comparison for various assembly material replacements.

Table 5.6. Fuel rod enrichments for peak-to-average radial power profile reduction.

Table 5.7. Converged BOL SCWR water densities for the coolant and water rods.

Table 5.8. Additional data for comparing the three fuel assemblies.

Table 6.1. Surface Composition Determined by Auger Spectroscopy (atomic percent)

Table 8.1. Materials/Process Matrix for Round 6 Tubes

Table 10.1. Summary of Room Temperature Hoop Strength Tests

Table 11.1. Specimen locations for the initial irradiation period

\section{List of Figures}

Figure 3.1 Micrograph of 1st fabrication run specimen with hoop overwrap fiber winding

Figure 3.2 Micrograph of 2nd fabrication run specimen with hoop overwrap fiber winding

Figure 3.3 Four Point Displacement Loading of Round 1 Specimens

Figure 3.4 Thermal cycling testing of hybrid ceramic test specimen

Figure 4.1 Feedstock Materials for Duplex Tube Fabrication

Figure 4.2 Gamma's Duplex Tube Fiber Winding Device

Figure $4.31 / 3^{\text {rd }}$ Portion of Round 2 Fiber Pre-Forms Fabricated by Gamma

Figure 4.4 4 BP Specimens showing interlayer laminations and capping off behavior

Figure 4.5 Images of 5-2 Specimens showing internal voids and capping off behavior

Figure 4.6 One end of MER Tube \# 1 After Internal SiC CVD Coating

Figure 4.7 Opposite End of MER Tube \# 1 After Internal SiC CVD Coating

Figure 4.8 Synterials Tube Showing Outer Composite Layer and Inner Monolith

Figure 4.9 Magnified Synterials Tube Showing Composite and Monolith Layers

Figure 4.10 Starfire - NovaTech Tube Section Showing Good Matrix Infiltration

Figure 4.11 Magnification of Starfire Tube Interior Surface Showing Surface Cracking

Figure 5.1. Reference $21 \times 21$ SCWR fuel assembly showing fuel rods, water rods, control rods Figure 5.2 MCNP 1/8-assembly model of the $21 \times 21$ SCWR fuel assembly.

Figure 5.3 Axial power profile for uniform $5.0 \mathrm{wt} \%$ enrichment.

Figure 5.4 Fuel rod axial power profile for three-zone enrichment.

Figure 5.5 Comparison of reactivity letdown curves with SiC, MA596, and the PWR.

Figure 6.1 figure deleted. 
Figure 6.2. Weight loss for CVD SiC after exposure to high-temperature water.

Figure 6.3. Raman spectra of a stoichiometric $\mathrm{SiC}$ standard, the as-received CVD $\mathrm{SiC}$, and the specimen surface after 21 -day exposure to $500^{\circ} \mathrm{C}$ water.

Figure 6.4. SEM micrographs of polished cross sections of as-received CVD SiC (left), and after

21-day exposure to $500^{\circ} \mathrm{C}, 25 \mathrm{ppb} \mathrm{O}_{2}$ supercritical water (right).

Figure 6.5. SEM micrographs of surfaces for: (a) as-received CVD SiC; (b) after 7 day exposure;

(c) after 14 day exposure; and (d) after 21 day exposure.

Figure 7.1 NovaTech-Starfire All Composite Tube under Gas Pressure in Water.

Figure 7.2 Stress Strain Curve for TREX Monolith Tube

Figure 7.3 Stress Strain Curve for Sintered Monolith Tube.

Figure 7.4 Stress Strain Curve of Round 4 Duplex Tube with Coorstek Monolith and Bamboo Architecture Composite.

Figure 8.1. Process Flow for Fabrication of SiC Duplex Cladding

Figure 8.2. End Cap Configurations for Testing of Joining Technology

Figure 9.1 Overall and detail views of Advanced Clad Irradiation (ACI) in the reactor core tank.

Figure 9.2 Neutron Flux Profile in MITR-II Reactor

Figure 9.3 Typical 3 layer module, and special module for end cap specimens

Figure 9.4 Partially assembled 3 layer module, showing bottom layer of 3 SilCar samples in place on three tie rods, next to flow shroud.

Figure 10.1 Room-Temperature Hoop Strength Test Data for Four Round 6 Specimens

Figure 10.2 Room-Temperature Hoop Strength Data for Tubes using the PIP Matrix Densification Process.

Figure 10.3 Photographs of Specimens (a) C1-1 and (b) G1-1 after Room Temperature Hoop Strength Testing.

Figure 11.1 Photos of selected Round 6 specimens after irradiation in the MIT reactor.

Figure 11.2 Photo of B1-3 and the Zircaloy specimen. 


\begin{abstract}
The nuclear fuel cladding being developed in this project is a triplex cladding with an inner layer of high density monolith Silicon Carbide providing the impermeable fission gas boundary, a central layer of $\mathrm{SiC}$ continuous wound fiber composite with $\mathrm{SiC}$ matrix, providing the high strength and toughness required for in-pile service, and an outer layer of high density $\mathrm{SiC}$ monolith to serve as an environmental barrier coating. Because this SiC cladding, when fabricated with specific crystal structure, and chemical balance, is resistant to radiation damage, and retains its strength to very high temperatures (above $1500{ }^{\circ} \mathrm{C}$ ) and because it is a very hard, wear resistant material, it offers advantages over traditional metal alloys for both existing water reactors (where wear and fretting related clad failures sometimes occur) and for advanced reactors where much higher coolant temperatures (up to $1000{ }^{\circ} \mathrm{C}$ ) preclude the use of traditional metal alloys.
\end{abstract}

The SBIR project was successfully completed. By the end of the project:

(1) short lengths (10 inch) of high quality triplex clad were produced having the required diameter and thickness for direct substitution for zircaloy clad in existing light water reactors,

(2) mechanical tests performed at ORNL and at NovaTech demonstrated the clad tubes are impermeable during normal operation and can retain fission gas pressures up to 9,000 psi, more than 3 times higher than permitted with zircaloy cladding,

(3) steam exposure tests run by Argonne National Laboratory demonstrated the material will survive a design basis loss of coolant accident without corrosion or an exothermic reaction releasing hydrogen,

(4) MIT successfully designed and fabricated a new titanium based test rig for use in exposing up to $40 \mathrm{SiC}$ cladding specimens to high pressure (1500 psi), high temperature $\left(300{ }^{\circ} \mathrm{C}\right) \mathrm{PWR}$ coolant in the MITR-II test reactor

(5) A 4 month exposure test was performed under these PWR chemistry conditions, within the MITR-II reactor, demonstrating superior in-pile corrosion behavior as compared to currently used zirconium alloys. The test specimens acquired a fast neutron (>1 MEV) dose of up to $0.8 \mathrm{dpa}$ (displacements per atom) and exhibited length change of less than $0.8 \%$ which is consistent with published data at this exposure and temperature.

As a consequence of these results, the triplex fuel cladding is being considered for future application to commercial water reactors, where it has potential safety and economic benefits, and to advanced Generation IV reactors, where it may be an enabling technology to allow high temperature operation needed for nuclear hydrogen generation. 


\subsection{Introduction}

This report is submitted by Gamma Engineering as a final product of our work under a DOE SBIR program which included a Phase 1, Phase 2 and Phase 2 extension, running from June, 2002 through November, 2006. The purpose of the research was to develop and commercialize an advanced ceramic fuel cladding for use in existing and advanced nuclear reactors. Three main tasks were conducted: (1) materials and product development (2) applications engineering, and (3) performance testing and materials characterization.

The materials and product development effort involved six successive rounds of small tube fabrication, with each new round incorporating lessons learned from processing and testing the previous round. Our early work involved thicker walled tubes with pre-woven fabric, which resulted in rather large voids in the composite layer. The round 6 tubes produced near the end of the project had features close to those needed in typical commercial reactor applications including geometry, strength, temperature and radiation resistant characteristics. Manufacturing processes and micrographic characterization of the product, are presented in sections 3,4 and 8 .

Applications engineering involved a collaborative study with the Idaho National Laboratory and Westinghouse to evaluate the performance of a Generation IV supercritical water reactor with silicon carbide cladding. Results of this evaluation are presented in Section 5.

Performance testing and materials characterization tasks were performed after each round of process development, as needed to inform the subsequent round of development. Results are reported in Sections 2 through 11. In addition, a series of corrosion tests were performed to determine the behavior of the material in different types of nuclear plant coolants. These are reported in Sections 3, 6, and 11.

An important step in developing structural materials for reactor service is to determine the effect of neutron irradiation under typical reactor operating conditions on the properties and the performance of the materials and components. Costs of such testing exceeded the available funding from the SBIR Program. Consequently, DOE's SBIR Phase 2 extension covered only the costs of planning an irradiation test in the MIT research reactor, including design of the experiment and the test fixture, and fabrication of test specimens and the testing apparatus. This work is reported in Section 9. Gamma arranged for industry financing of the actual irradiation test and the post irradiation examination.

Design, safety evaluation, fabrication, and assembly of the irradiation test fixture, and fabrication of test specimens for insertion in that test fixture, was completed in May, 2006. In-pile testing of the cladding in the MIT test reactor was sponsored by the Westinghouse Electric Company, and began in May, 2006. Evaluation of interim results began in November, 2006, after termination of the DOE phase 2 financial assistance award.

Because this final report is required within 90 days of the completion of the DOE financial assistance award, it does not include many of the irradiation test results, which are still ongoing. 


\subsection{Early Research on Ceramic Fuel Cladding. (1990 - 2001)}

2.1 - NRC Sponsored Research - In 1990 the US-NRC sponsored a six-month SBIR Phase 1 study to identify promising ceramic materials that may have characteristics needed for nuclear fuel cladding applications. Gamma determined that continuous fiber ceramic composites (CFCC) could have the required characteristics. ${ }^{1}$

2.2 Gamma Internal Research - In 1992, Gamma Engineering sponsored an internal R\&D effort leading to the fabrication of several oxide based CFCC tubes by sol-gel processing, with products having dimensions similar to existing commercial LWR fuel cladding material. The US Patent Office granted a patent for this CFCC fuel clad tube. ${ }^{2}$ This preliminary work showed the potential of CFCC as fuel cladding, but failed to achieve acceptable bulk density, mechanical strength, and impermeability to fission gases.

2.3 - NERI Research Project - In August 1999, the DOE Office of Nuclear Energy awarded a NERI Research Grant to Gamma Engineering along with several collaborating organizations, aimed at developing improved alumina based continuous fiber composites that were later tested in an LWR environment and, separately a LOCA exposure test. This NERI project demonstrated that ceramic composite cladding materials fabricated to a relatively high density $(\sim 80 \%$ of the theoretical density of alumina), behaved well in an LWR reactor irradiation environment, and retained physical and chemical integrity during a typical LOCA transient to $2500{ }^{\circ} \mathrm{F}$, followed by a water quench at room temperature. However, the defects and open porosity in the composite matrix material led to a permeable structure, unable to retain fission gases in cladding application. It became clear that unless a ceramic composite structure could be developed that was impermeable to fission gases, yet still behaved like a composite (with graceful failure mode), the promise of high temperature ceramics in water cooled reactors could not be realized. ${ }^{3}$

\subsection{Phase 1 SBIR Research}

Following completion of the initial NRC research, the internal research in the early 1990's, and the NERI project based on alumina fibers and a single composite layer, Gamma realized that successful project development required a multilayered composite, to embody both the hermeticity features needed to retain fission gas, and the strength and graceful failure mode needed for robust in-pile service. We proposed, and were awarded, a new DOE Phase 1 SBIR grant to examine a multilayered cladding tube having both essential features. The results of this Phase 1 effort are reported in reference 4. We also examined other ceramic species, and chose silicon carbide, as being more resistant to radiation damage than other ceramic species. The decision was based on the many desirable properties of silicon carbide ceramics, including high melting point, low thermal expansion coefficient, high thermal conductivity and good corrosion resistance, all of which are well suited for fuel cladding applications. The table below shows selected properties of silicon carbide ceramics in comparison with other material candidates. 
Table 3.1 - A comparison of properties of candidate materials

\begin{tabular}{|c|c|c|c|c|c|c|}
\hline Material Property & $\mathrm{SiC}$ & $\begin{array}{c}\text { Zircaloy- } \\
4\end{array}$ & Al2O3 & $\mathrm{ZrO2(YTZP)}$ & Si3N4 & AlN \\
\hline Theoretical Density (gm/cm3) & 3.22 & 6.49 & 3.97 & 6.08 & 3.44 & 3.26 \\
\hline $\begin{array}{l}\text { Youngs Modulus } \\
\left(10^{6} \mathrm{psi}\right)\end{array}$ & 62 & 10.7 & 57 & 30 & 42 & 46 \\
\hline $\begin{array}{l}\text { Thermal Expansion Coefficient }\left(10^{-6} /\right. \\
\text { of })\end{array}$ & 2.7 & 3.2 & 4.9 & 5.2 & 1.5 & 2.4 \\
\hline $\begin{array}{c}\text { Thermal Conductivity } \\
\text { at room temp }\left(\mathrm{BTU} / \mathrm{hr}-\mathrm{ft}-\mathrm{O}^{\mathrm{O}}\right) /(\mathrm{W} / \mathrm{m}-\mathrm{C})\end{array}$ & $\begin{array}{l}35.2 / \\
20.3\end{array}$ & $\begin{array}{r}9.4 / \\
5.4\end{array}$ & $\begin{array}{l}7.7 / \\
4.4\end{array}$ & $\begin{array}{l}1.7 / \\
0.98\end{array}$ & $\begin{array}{l}14.1 / \\
8.15\end{array}$ & $\begin{array}{l}65.0 / \\
37.6 \\
\end{array}$ \\
\hline Melting Point $\left({ }^{\circ} \mathrm{F}\right)$ & 4900 & 3360 & 3760 & 4900 & 3450 & 3990 \\
\hline
\end{tabular}

\subsection{Processes used for Phase 1 tube development}

Commercially available product was used for the inner monolith layer, i.e., sintered monolithic SiC tubes with $0.50 "$ OD, $0.38 " \mathrm{ID},>97 \%$ theoretical density and closed porosity. Six, two foot tubes were procured. The dimensions of the procured $\mathrm{SiC}$ tubes was determined primarily by the availability of the commercial product. Properties of the material, based on data sheets provided by the manufacturer, Saint Gobain's Carborundum facility, were:

- Material trade name; Hexoloy SA SiC

- Fabricated by extrusion process with pressure-less sintering

- Dimension; 0.500 inch (+0.010"/-0.013") OD, 0.380 inch (+/- 0.020") ID, available in 6' length

- Chemical analysis; 98\% SiC with two major impurities, 6,900 ppm boron and 5,300 ppm carbon

- Density; $3.10 \mathrm{gm} / \mathrm{cm}^{3}$ ( 97\% theoretical density)

- Grain size; 4-6 microns

- Four point flexure strength at room temperature;

- Modulus of elasticity at room temperature;

- Thermal conductivity at room temperature;

$380 \mathrm{MPa}(55,000 \mathrm{psi})$

- Thermal conductivity at $400{ }^{\circ} \mathrm{C}$;

$410 \mathrm{GPa}(59,000,000 \mathrm{psi})$

$125 \mathrm{w} / \mathrm{m}-\mathrm{K}(72 \mathrm{Btu} / \mathrm{ft}-\mathrm{hr}-\mathrm{F})$

77 w/m-K (44 Btu/ft-hr-F)

- Gas permeability at room temperature;

- Chemically stable up to $1500{ }^{\circ} \mathrm{C}\left(2730{ }^{\circ} \mathrm{F}\right)$.

3.2 Monolith-Composite interface bonding material - A $\sim 0.3$ micrometer thick carbon coating was applied on the external surface of the monolith $\mathrm{SiC}$ tube by a pyrolytic decomposition/precipitation processing of propane gas. The carbon coating served as the hybrid interface bonding material. In this project, the carbon coating was applied after the fiber preform processing (i.e., after the braiding/winding of $\mathrm{SiC}$ fiber on the monolith $\mathrm{SiC}$ tube. 


\subsection{Fabrication of outer tubular composite layer}

3.3.1 Fiber material and preform fabrication: Commercially available SiC fiber was used in this project. In particular, Nicalon Ceramic Grade tows of $\mathrm{SiC}$ fiber. Each tow contains about 500 filaments of $\mathrm{SiC}$ fiber. The following is a brief summary of the physical and mechanical properties of the fiber material based on data sheet provided by Nippon Carbon Company.

- Filament size; $~ 14$ micrometer in diameter

- Fiber length; 500 meters, unspliced

- Fiber tow size; Each contains $\sim 500$ fiber filaments, $\sim 0.03 "$ in diameter, 1800DN

- Fiber density; $2.52 \mathrm{gm} / \mathrm{cm} 3$ ( 79\% theoretical density)

- Fiber tensile strength; $3.0 \mathrm{GPa}(434,000 \mathrm{psi})$

- Fiber modulus of elasticity at room temperature; $210 \mathrm{GPa}(30,400,000 \mathrm{psi})$

- Fiber thermal conductivity at room temperature; $2.97 \mathrm{w} / \mathrm{m}-\mathrm{K}(5.32 \mathrm{Btu} / \mathrm{ft}-\mathrm{hr}-\mathrm{F})$

- Fiber sizing material; Polyvinyl acetate, $1.7 \mathrm{wt} \%$, burn off in air for removal.

The fabrication of fiber preform was carried out at a fiber weaving company, Albany International Techniweave, Inc. Two types of fiber preform were selected for testing. In the first case, the preform consisted of two layers of braided fiber over the monolithic tube, which also served as the mandrel during fiber braiding. The braiding scheme consisted of a 64 fiber-tows carrier with 8 axial sites for continuous tubular preform braiding along the axial length. Two separate passes were made to achieve the two layers of fiber braiding. This preform pattern was applied on three monolithic tubes, each at 2 ' length. The fiber braiding angle was about 58 degrees from the mandrel axial direction. The average thickness of the preform was about 0.08 " for the two layers of braided fiber. It should be noted that the surface finish of the monolithic SiC tube was very smooth. As a result, the braided fiber preform on the monolithic tube was somewhat loose, and was not axially locked in position along the tube surface. During later processing steps, the fiber preform was stretched in the axial direction to ensure the braided fiber layer was tight over the monolithic tube.

In the second case, the preform consisted of one layer of braided fiber with a hoop overwrap fiber tow winding (near 90 degree to the axial direction) on the outside surface. The average thickness of the preform was about 0.06". This preform pattern was applied on two monolithic tubes, each at 2' length. In this case, the hoop overwrap maintained a tighter fiber preform on the monolithic tube.

3.3.2 Fiber surface coating material and processing - A $\sim 0.3$ micrometer thick carbon coating was applied on the fiber surface by pyrolytic decomposition/precipitation of propane gas, with batch processing of the entire hybrid fiber preform/monolithic tubes in a hot wall CVI reactor. As described above, the carbon coating was applied after the fiber preform processing, followed by buildup of the matrix material in the composite layer.

3.3.3 Composite layer matrix material and fabrication - A unique, TA\&T proprietary CVI reactor design and associated processing parameters were used to buildup the $\mathrm{SiC}$ matrix component of the composite layer. The process uses pulsed precursor gas flow in the target material for high $\mathrm{SiC}$ deposition rate and rapid densification of the composite layer.

Two processing runs were performed for $\mathrm{SiC}$ matrix material densification. In the first densification run, one braided and one hoop fiber overwrap specimen (i.e., 2 specimens) were plugged at the ends to prevent CVI deposition on the inner surface of the monolithic tube. The specimens were then CVI processed continuously for 44 hours. The initial four hours of processing consisted of a light 
pyrolytic carbon coating. The remaining 40 hours served as the matrix densification period, during which the carbon coated fiber tows were infiltrated with SiC. Upon completion of the 44 continuous hours of CVI processing, an additional nine hours of processing was then performed with elevated CVI process conditions for enhanced rate of material deposition, and to provide a dense $\mathrm{SiC}$ surface overcoat. The specimens were subsequently removed from the chamber, cut into sections, and evaluated for microstructure, density, and mechanical strength.

The second run also processed two test specimens with similar fiber preform makeup. These specimens, however, were plugged and infiltrated with SiC particles prior to CVI processing. Particle infiltration was accomplished by first pulling a vacuum on each tube in a narrow cylindrical chamber. Once the chamber was under vacuum, a SiC slurry open to the atmosphere was drawn into the chamber. The presence of the vacuum within the chamber and fiber preform allowed the SiC slurry to migrate into the open space in the preform. The chamber was then pressurized to about one atmosphere, forcing the slurry further into the channels. The specimens were removed from the chamber and the excess slurry was cleaned from the surface. The SiC particle infiltrated specimens were allowed to dry and subsequently CVI densified with $\mathrm{SiC}$ in a 50 hour continuous run, with an additional 12 hours of elevated CVI process conditions for enhanced rate of material deposition. The specimens were then removed from the chamber, cut into pertinent sections, and evaluated for microstructure, density, and mechanical strength in the same manner as the specimens in the first fabrication run.

The purpose of SiC slurry vacuum infiltration process step adopted in the second fabrication run was to reduce the internal open voids (between the braided fiber tows and windings) observed in the first development run. The CVI process infiltrated and reduced the size of the distributed open space (or voids), but was not able to eliminate them.

1) An important difference in the two fabrication runs for composite matrix densification was, in the second run, the SiC slurry infiltration was conducted before the pyrolytic carbon coating of the hybrid interface and fiber surfaces. Instead, the carbon coating was deposited on the SiC particulates precipitated on the hybrid interface and fiber surfaces. This greatly compromised the intent of the carbon coating and affected the mechanical strength of the finished product.

2) The purpose of the slurry infiltration process was to densify the composite fiber preform with $\mathrm{SiC}$ particulates. However, a sintering process step, as required to ensure desirable mechanical properties of the deposited material, would normally be conducted before further processing such as CVI densification.

The nominal dimension of the finished hybrid ceramic cladding product was $\sim 0.60$ " OD, 0.38 " ID, and 24" in length. Figure 3.1 shows a photograph of a finished hybrid ceramic cladding specimen. The ratio of the wall thickness of composite to monolith layer was about 1 to 1 for specimens with braided fiber preform. The ratio was lower (about to 0.75 to 1) for specimens with hoop fiber overwrap. The weight ratio of composite to monolith layer ranged from $0.57 / 1$ to $0.67 / 1$, with the higher number being specimens with double braided preform. The ratio of fiber loading in the composite layer (i.e., weight of fiber versus the weight of matrix material, not including the weight of monolith layer) ranged from 25 to $29 \%$.

Specific dimensions of specimens from the first fabrication run are shown below: 
1) Double layer braided fiber test specimens

$\begin{array}{lll}\text { Monolith layer: } & 0.50 " \text { OD } & 0.38 \text { " ID } \\ \text { Composite layer: } & 0.62 \text { " OD } & 0.50 " \text { ID }\end{array}$

Ratio of composite/monolith thickness: $\quad 1 / 1$

Monolith tube: $\quad 4.2 \mathrm{gm} / \mathrm{inch}$ (the 24" monolithic tube weigh 100 grams)

Monolith \& fiber preform: $\quad 5.0$ gm/inch (the 24" fiber braided tube weigh 120 grams)

CVI finished tube: $\quad 7.0 \mathrm{gm} / \mathrm{inch}$ (an 8.9" CVI finished tube weigh 62.4 grams)

Ratio of composite/monolith weight: $\quad 0.67 / 1$

Fiber weight loading in composite: $\quad 0.29 \%$

2) Braided/hoop wound specimen

Monolith layer: $\quad 0.50 "$ OD 0.38 " ID

Composite layer: $\quad 0.59$ " OD $\quad 0.50 "$ ID

Ratio of composite/monolith thickness: $\quad 0.75 / 1$

Monolith tube: $\quad 4.2 \mathrm{gm} / \mathrm{inch}$

Monolith \& fiber preform: $4.8 \mathrm{gm} / \mathrm{inch}$ (the 24" fiber braided tube weigh 115 grams)

CVI finished tube: $\quad 6.6 \mathrm{gm} / \mathrm{inch}$ (a 9.4" CVI finished tube weigh 62.4 grams)

Ratio of composite/monolith weight: $\quad 0.57 / 1$

Fiber weight loading in composite: $\quad 0.25 \%$

The dimensions of test specimens from the second fabrication run were similar to the data shown above. The surface of the hybrid specimens was relatively rough.

\subsection{Density and porosity properties}

The bulk densities of the finished test specimens ranged from 2.5 to $2.7 \mathrm{gm} / \mathrm{cc}$. The bulk density calculation included the internal, open void space in the composite layer. This represents a range of 78 to $84 \%$ of the theoretical density of $\mathrm{SiC}$ (with a fully dense value of $3.21 \mathrm{gm} / \mathrm{cc}$ ), a respectable density range for composite ceramic material, particularly considering the open voids existing in the composite layer of the fabricated test specimens. The specific gravities of the specimens (i.e., excluding the open voids in the composite layer) ranged from 2.7 to $3.0 \mathrm{gm} / \mathrm{cc}$ (or 84 to $97 \%$ theoretical density).

The open voids in the hybrid specimens (located all in the composite layer) ranged from 10 to $12 \%$, except for the braided preform specimen fabricated in the second batch, which had a noticeable lower open void content of $6.5 \%$. The reason could be a more effective matrix densification by the combined slurry infiltration, surface coating and later CVI processing of the specimen with the braided preform configuration. The hoop overwrap fiber winding provided a tight and relative dense fiber filled surface, which might have prevented effective matrix densification in the second fabrication run. Since the wall thickness of the composite and the monolith layers were about the same (i.e., both $\sim 0.06 ")$, and the monolith layer was non-porous, the estimated open void in the composite layer was about 20 to $24 \%$ (i.e., by doubling the void \% value in the bulk hybrid material). By the same reasoning, the estimated bulk densities of the composite layer of the specimens ranged from 1.9 to $2.3 \mathrm{gm} / \mathrm{cc}$ (or 59 to $72 \%$ theoretical density). Again, the bulk density data included the open voids in the composite layer. 


\subsection{Permeability properties}

The permeability of the hybrid specimens was measured by a specially designed and assembled test system. Hybrid specimens with length between 8 to 10 inches were tested at gas pressures up to 125 psi. All hybrid material specimens fabricated in this project were found to be gas impermeable.

\subsection{Microstructure characteristics}

A representative micrograph cross-sectional view of the braided preform test specimen with hoop overwrap from the first fabrication run is shown in Figure 3.1 below. The scale of the micrograph is about 0.55 millimeter per inch viewing length. The half moon shaped object at the right side is the monolithic material (the rounded boundary is caused by the circular viewing field of the optical magnifier). The hoop overwrap fiber winding can be seen at the left side.

As described above, in the second fabrication run, the specimens with fiber preform were processed with $\mathrm{SiC}$ slurry infiltration and surface coating steps prior to densification by CVI. The intent was to fill the internal voids between the fiber tows before CVI SiC matrix densification. In reality, however, most of the fine SiC particles were trapped near the surface of the fiber preform, and severely hindered the penetration of CVI process gas into the fiber preform. Figure 3.2 show representative micrographs of the test specimen with hoop overwrap. The effects of the matrix material deposition and build-up on the preform surface region can be clearly seen, particularly as compared to the micrograph views of specimens from the first fabrication run (Figure 3.1).

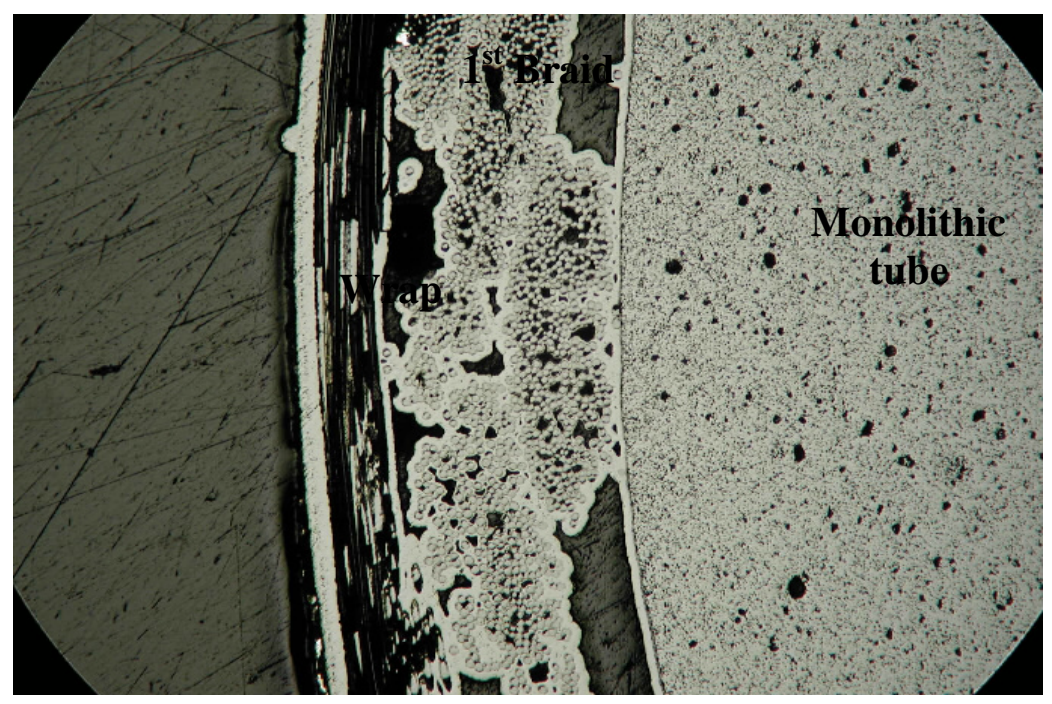

Figure 3.1 - Micrograph of 1st fabrication run specimen with hoop overwrap fiber winding 


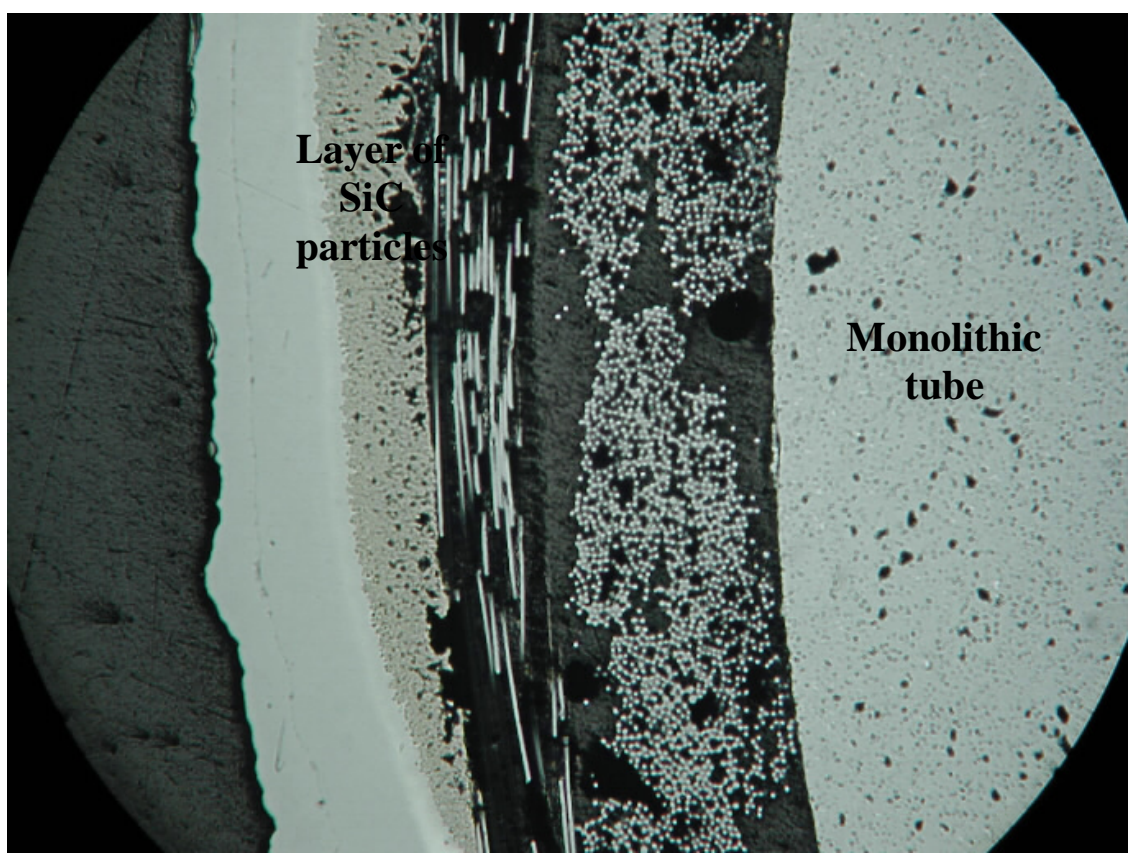

Figure 3.2 - Micrograph of 2nd fabrication run specimen with hoop overwrap winding

\subsection{Room temperature four point flexure strength tests}

Four point flexure strength tests were conducted using two inch long test specimens that were cut from the hybrid ceramic tubes. The measured data was used to compare the overall mechanical strength among different hybrid preform designs, and to evaluate the mode of failure (such as stress versus strain over test time). A direct correlation of the test results to the conventional properties such as tensile and shear strength is complex and was not attempted.

Figure 3.3 shows the four point flexure test results of the two hybrid ceramic configurations from the first fabrication run. The figure shows the peak test loads of specimens tested and typical load versus strain curves of the tests. Three monolithic tube specimens (i.e., bare $\mathrm{SiC}$ tube without the composite layer) were also tested using identical test procedure, along with eight material specimens from the second fabrication run. An analysis of the test results shows;

1) The hybrid ceramic material design significantly increased the fracture strength (here roughly represented by the peak load to material fracture) based on the results of the four point flexure tests. The increase of strength is shown in two important areas; First, as shown in Table 2 below, the average strength of the hybrid specimens is noticeably higher than the strength of the bare monolith tube (i.e., $>600 \mathrm{lbs}$ versus $\sim 400 \mathrm{lbs}$ ). Second, the failure mode of the hybrid specimens showed a ductile, metal like drop-off of strength after the peak load (see Figure 3.3), while the monolith SiC tube showed a brittle, sharp drop-off of strength resulting from the fracture of the test specimen into pieces. 


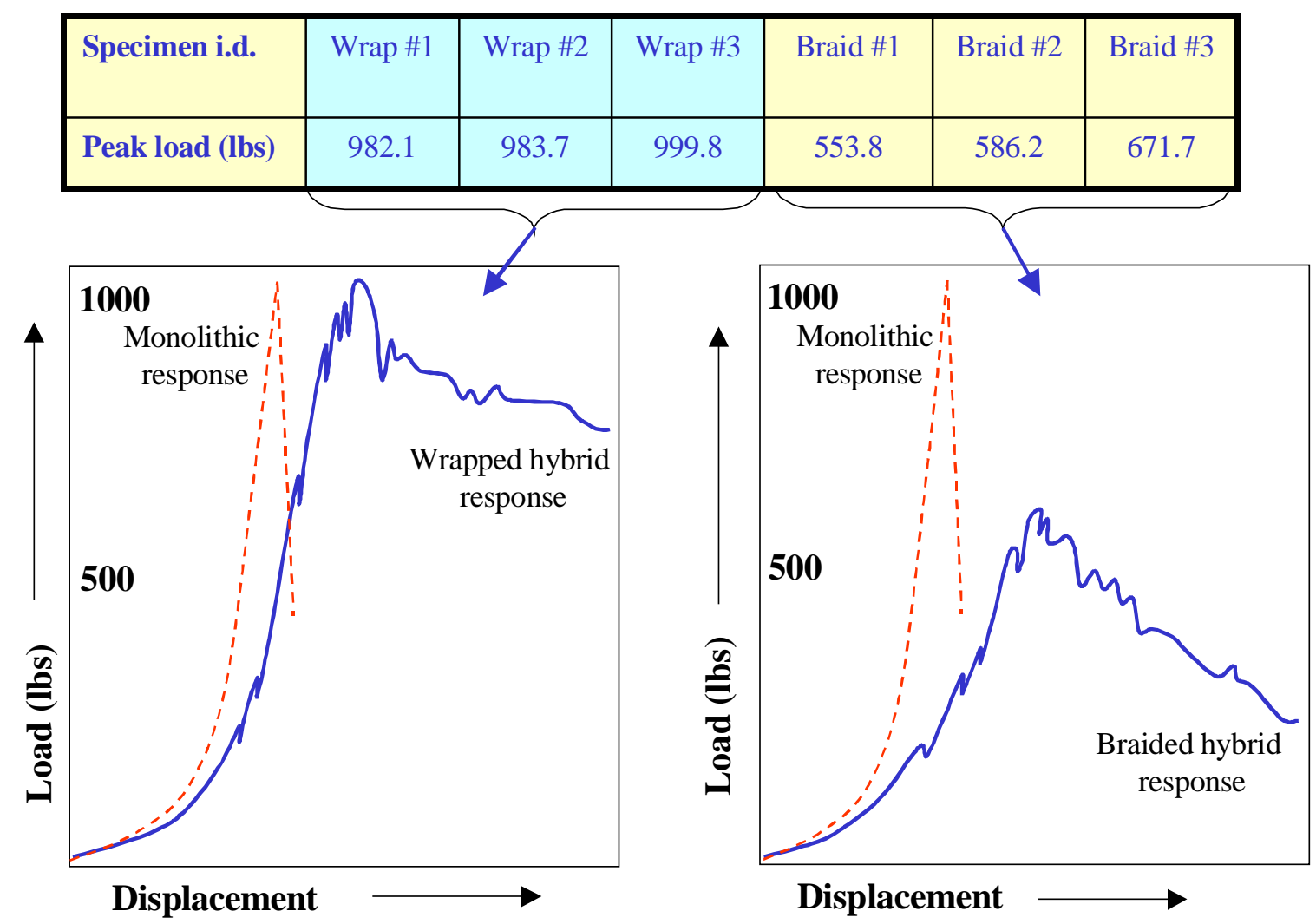

Figure 3.3 - Four Point Displacement Loading of Round 1 Specimens

\subsection{Cyclic thermal stress test results}

A three inch length of hoop fiber overwap hybrid specimen was used for the thermal cycling tests. An oxyacetylene torch was set up in the TA\&T's Ceramic Composites Laboratory with a cooling fan nearby. The ambient room temperature was $14^{\circ} \mathrm{C}\left(58^{\circ} \mathrm{F}\right)$. The tube was attached to a Type $\mathrm{K}$ thermocouple that was used to hold the sample and monitor the interior temperature in combination with an Omega multimeter. The external temperature of the test specimen above $1000^{\circ} \mathrm{C}$ was measured with a Quantum Logic two-color optical pyrometer, and external temperatures lower than $1000^{\circ} \mathrm{C}$ were measured with a Raytek Infrared thermometer. Figure 3.4 shows the test sample during a 10-minute soak heating of the thermal cyclic test.

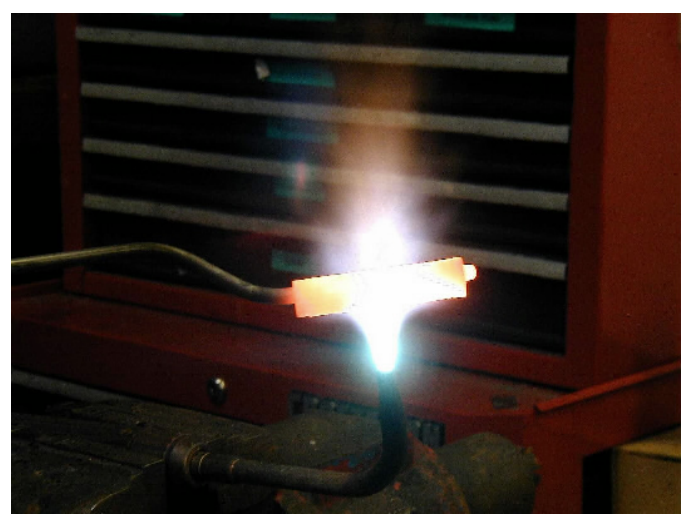

Figure 3.4 - Thermal cycling testing of hybrid ceramic test specimen 
The conditions of the thermal cycling test and results are shown in Table 3.2. The "crack" identified in the table corresponds to an occurrence in which a low audible sharp noise and/or slight twitching of the specimen was noted by the test operator. As shown in the table, no cracks were observed after the second thermal cycle of the test. The temperatures shown in the table are rough values. The thermal gradient around the diameter and along the length of the test specimen was likely severe. The post-test weight of the sample remained the same (19.3 grams). The surface of the specimen after testing was soot covered. No surface cracks were visible in the specimen after the thermal cycling test, and no debris could be dislodged by light rapping of the specimen on a hard surface. Overall, the hybrid ceramic specimen displayed exceptional thermal shock resistance.

Table 3.2 - Hybrid test specimen thermal cycling test conditions and findings

\begin{tabular}{|c|c|c|c|c|}
\hline $\begin{array}{l}\text { Thermal } \\
\text { Cycle }\end{array}$ & $\begin{array}{l}\text { Clock } \\
\text { Time }\end{array}$ & $\begin{array}{c}\text { External } \\
\text { Temperature } \\
\left({ }^{\circ} \mathrm{C}\right) \\
\end{array}$ & $\begin{array}{c}\text { Internal } \\
\text { Temperature } \\
\left({ }^{\circ} \mathrm{C}\right) \\
\end{array}$ & Observations and Remarks \\
\hline \multirow{6}{*}{1} & 10:48:00 & 1100 & 960 & $\begin{array}{l}\text { Initial } 10 \text { minute heating. Six cracks felt. } \\
\text { Shifted the tube so the end of the TC was }\end{array}$ \\
\hline & $10: 54: 00$ & 1150 & 904 & located central along the tube length. \\
\hline & $10: 56: 00$ & 1050 & 1066 & \\
\hline & 10:58:00 & 1125 & 1077 & End of 10 minute initial heating \\
\hline & 11:00:00 & 99 & 274 & Three minor cracks felt. \\
\hline & 11:00:30 & & 538 & \\
\hline \multirow[t]{2}{*}{2} & 11:02:30 & 91 & 260 & Two minor cracks felt. \\
\hline & 11:03:00 & & 586 & \\
\hline \multirow[t]{2}{*}{3} & 11:05:00 & 54 & 177 & No cracking. \\
\hline & $11: 05: 30$ & & 804 & \\
\hline \multirow[t]{2}{*}{4} & $11: 07: 30$ & 77 & 232 & No cracking. \\
\hline & 11:08:00 & 1104 & 788 & \\
\hline \multirow[t]{2}{*}{5} & 11:10:00 & 82 & 227 & No cracking. \\
\hline & 11:10:30 & & 871 & \\
\hline \multirow[t]{2}{*}{6} & $11: 12: 30$ & 93 & 221 & No cracking. \\
\hline & 11:13:00 & 1020 & 943 & \\
\hline \multirow[t]{2}{*}{7} & $11: 15: 00$ & 149 & 277 & No cracking. \\
\hline & $11: 15: 30$ & 1160 & 832 & \\
\hline \multirow[t]{2}{*}{8} & $11: 17: 30$ & 66 & 232 & No cracking. \\
\hline & 11:18:00 & 1220 & 760 & \\
\hline \multirow[t]{2}{*}{9} & 11:20:00 & 77 & 232 & No cracking. \\
\hline & $11: 20: 30$ & 1180 & 816 & \\
\hline 10 & $11: 22: 30$ & 66 & 282 & No cracking \\
\hline
\end{tabular}




\subsection{Phase 2 Development -Rounds $2-5$}

On May 17, 2003, DOE awarded Gamma Engineering Corporation a Phase 2 SBIR Financial Assistance Grant to continue the Phase 1 development of a multi-layered duplex Silicon Carbide ceramic composite for use as nuclear fuel cladding and structural material. Technical progress on the Phase 2 work has been reported in references 5, 6 and 7, and is summarized below.

4.1 Round 2 - Procurement of materials -In this task, Gamma procured fifteen 0.50" OD, 0.38 " ID, 3' length, Hexoloy SA SiC tubes manufactured by St. Gobain. Gamma also procured 0.4 kilograms of SiC Nicalon CG fiber manufactured by Nippon Carbon Co., through its US distributor, COI Ceramics. Gamma's subcontractor, CCI, procured an array of feedstock materials including precursor agents, $\mathrm{SiC}$ powder, and various process solutions/gases necessary for the $\mathrm{SiC}$ matrix densification processing of the composite layer. Figure 4.1 shows some of the procured $\mathrm{SiC}$ monolith tubes and the $\mathrm{SiC}$ fiber feedstock.

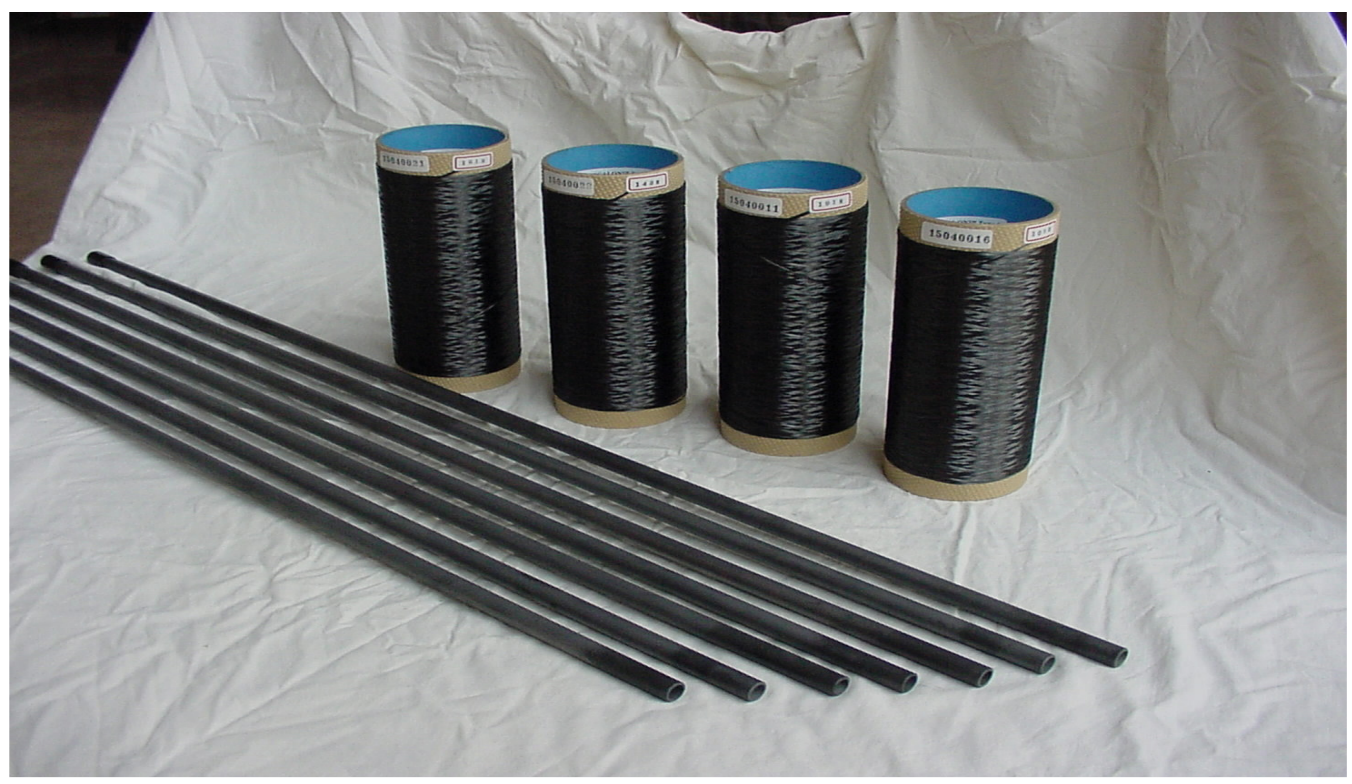

Figure 4.1 - Feedstock Materials for Duplex Tube Fabrication

\subsection{Design and operation of a fiber winding system for fabricating the SiC fiber preform of}

the composite layer - In order to provide a flexible and timely support for fabricating and evaluating the different fiber architectures and processing parameters of the $\mathrm{SiC}$ fiber preform, Gamma developed and assembled a manual driven fiber winding system for the production of the $\mathrm{SiC}$ fiber preform of the composite layer of the hybrid ceramic cladding. The resulting fiber winding system has flexible capabilities in terms of accommodating the size and shape of the monolith component, fiber preform winding angles, winding pattern, and fiber tension. A key requirement is to precisely position the fiber tows on the monolith tube, and at the same time minimize handling of the $\mathrm{SiC}$ fiber tows so as to minimize fiber damage.

Specific design and operational capabilities of the fiber winding system include: 
- Maximum length of product:

- Number of fiber tow feeder:

- Range of fiber winding angle:

- Winding sequence and pattern:

- Fiber tension during winding:
40" span for fiber winding

Two simultaneous feeders at 180 degree apart

+/- 30 to near 90 degrees from axial

direction

Back and forth at equal fiber winding angle Constant, within a range of 20 to 150 grams

Figure 4.2 shows the fiber winding system developed in this task for fiber pre-form production.

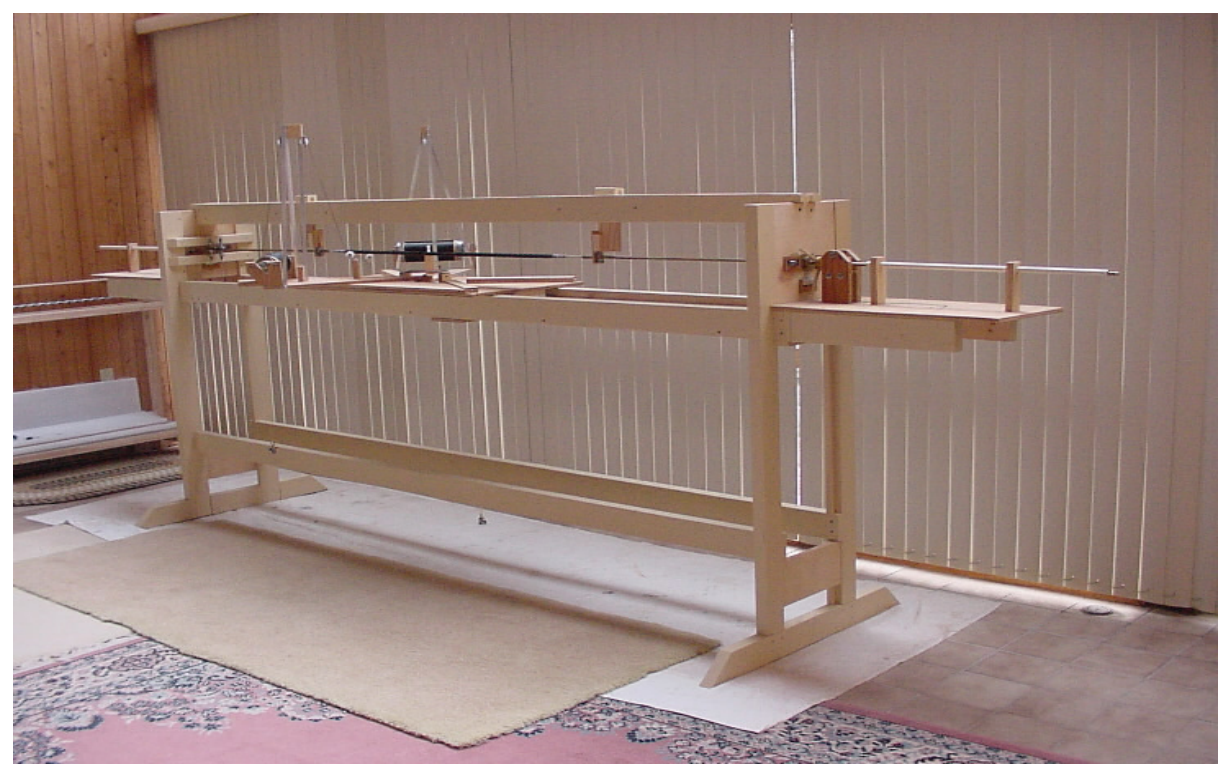

Figure 4.2 - Gamma's Duplex Tube Fiber Winding Device

4.3 Composite laver fiber pre-form "Round 2" test specimens - Five SiC fiber pre-form specimens were fabricated and delivered to TA\&T for further processing. The design configurations of the five test specimens are:

Specimen \#1: Two layers of SiC fiber winding at a +45 degree followed by a -45 degree cross winding angle, with a fiber tension at about 45 grams.

Specimen \#2: Same as \#1 specimen, but with two extra layers of SiC fiber winding on top of the base layers, and winding of the extra two layers at 50\% dense. Fiber tension; 45 grams.

Specimen \#3: Four layers of $\mathrm{SiC}$ fiber winding at a +45 degree angle followed by a -45 degree cross winding angle, with a fiber tension at about 45 grams.

Specimen \#4: Same as the \#1 specimen, but with a fiber tension at about 35 grams.

Specimen \#5: Two layers of $\mathrm{SiC}$ fiber winding with the base layer at a +45 degree winding angle and a top layer at a -45 degree winding angle, with a fiber tension at about 45 grams. 
Some specific properties of the five fiber pre-form specimens are shown in Table 4.1:

\begin{tabular}{|l|c|c|c|c|c|}
\hline & $\begin{array}{l}\# 1 \\
\text { specimen }\end{array}$ & $\begin{array}{l}\# 2 \\
\text { specimen }\end{array}$ & $\begin{array}{l}\# 3 \\
\text { specimen }\end{array}$ & $\begin{array}{l}\text { \#4 } \\
\text { specimen }\end{array}$ & $\begin{array}{l}\text { \#5 } \\
\text { specimen }\end{array}$ \\
\hline Length (ft) & 3 & 3 & 3 & 3 & 3 \\
\hline $\begin{array}{l}\text { Weight of the specimen } \\
\text { as delivered (grams) }\end{array}$ & 168.9 & 173.1 & 178.5 & 165.8 & 168.4 \\
\hline $\begin{array}{l}\text { Weight of the monolith } \\
\text { tube (grams) }\end{array}$ & 151.9 & 151.3 & 151.6 & 150.8 & 151.6 \\
\hline $\begin{array}{l}\text { Weight of carbon coating } \\
\text { on the monolith tube } \\
\text { (gm) }\end{array}$ & 0.2 & 0.2 & 0.1 & 0.2 & 0.1 \\
\hline $\begin{array}{l}\text { Estimated weight of the } \\
\text { cement at the ends (gm) }\end{array}$ & 4.6 & 5.2 & 6.3 & 3.3 & 4.7 \\
\hline $\begin{array}{l}\text { Weight of SiC fiber } \\
\text { winding (minus estimated } \\
\text { weight of the cement at } \\
\text { the two ends) (grams) }\end{array}$ & 12.2 & 16.4 & 20.5 & 11.5 & 12.0 \\
\hline $\begin{array}{l}\text { Maximum OD of fiber } \\
\text { preform (inch) }\end{array}$ & 0.53 & 0.54 & 0.55 & 0.53 & 0.53 \\
\hline $\begin{array}{l}\text { Minimum OD of fiber } \\
\text { preform (inch) }\end{array}$ & 0.52 & 0.53 & 0.54 & 0.52 & 0.53 \\
\hline
\end{tabular}

Table 4.1 - Round 2 Specimen Characteristics Prior to Infiltration

Figure 4.3 shows an end view of the five fiber pre-form specimens.

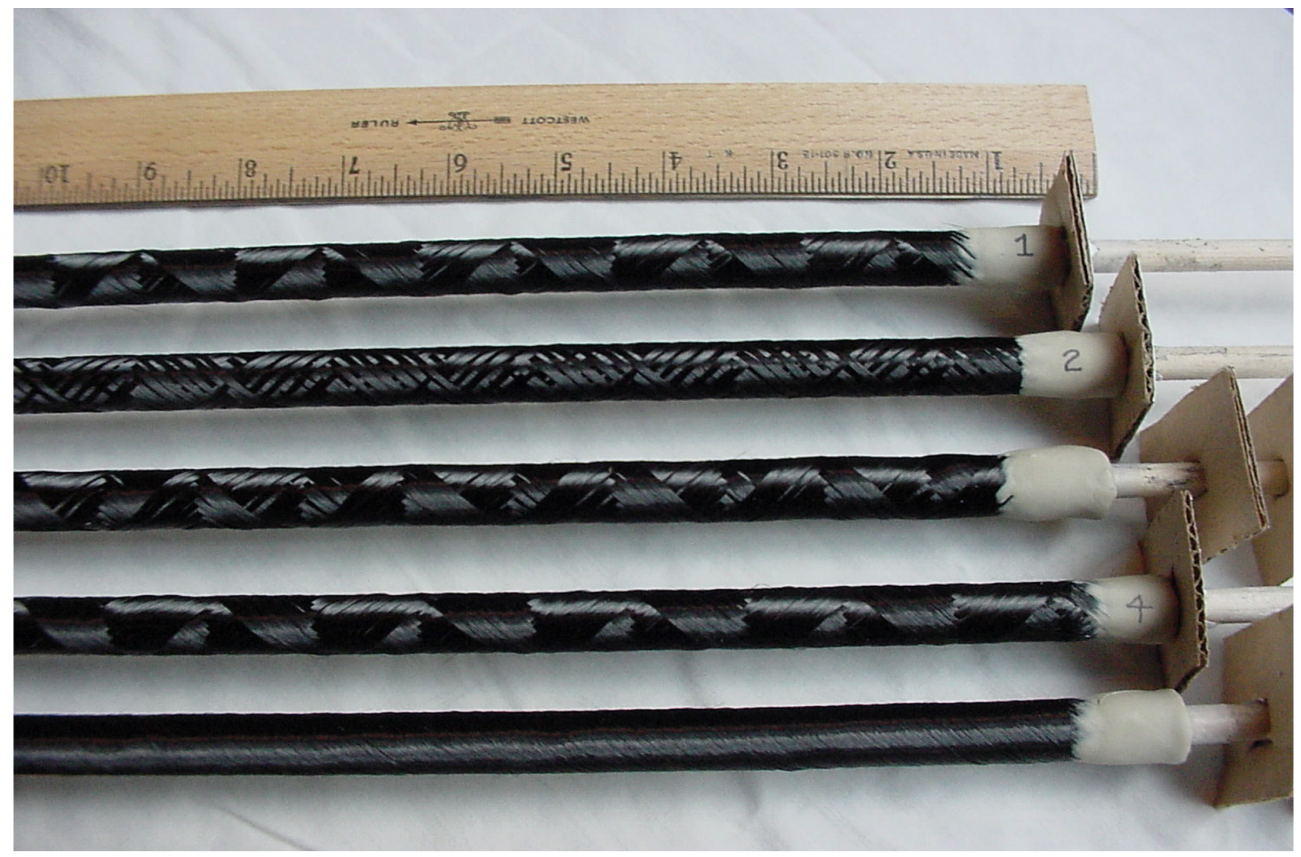

Figure 4.3 $-1 / 3^{\text {rd }}$ Portion of Round 2 Fiber Pre-Forms Fabricated by Gamma 
4.4 CCI's development work on $\mathrm{SiC}$ matrix densification of the composite laver utilizing material specimens from the Phase 1 work - Starting in July 2003, CCI conducted exploratory development work on SiC matrix densification of the composite layer utilizing the material specimens left over from the Phase 1 work. The objective was to seek more effective processing techniques and associated operating parameters for the matrix densification of the composite layer. The development work was performed on sections of a 24 " length of the material specimen with a fiber pre-form architecture of two layers of braided fiber on the monolith tube. A combination of the following five separate processing techniques/routes was made, after an initial pyrolytic carbon coating of the $\mathrm{SiC}$ fiber and the monolith tube surface:

Section 1) A total of 102 hours of SiC CVI processing;

Section 2) First with 45 hours of SiC CVI processing, followed by repeated liquid polymer precursor route of Starfire and Kion VL-20 pyrolysis;

Section 3) $\mathrm{SiC}$ ( 15 um particle size) slurry infiltration under repeated vacuum agitation, followed by 102 hours of CVI processing;

Section 4) $\mathrm{SiC}$ ( 15 um particle size) slurry infiltration under repeated vacuum, followed by 45 hours of CVI processing, then followed by repeated Starfire and Kion VL-20 pyrolysis,

Section 5) First subjected the specimen to ultrasound agitation, then with 102 hours of CVI $\mathrm{SiC}$ processing.

The open porosity of the hybrid cladding specimens after $\sim 50$ hours of CVI processing in the Phase 1 work was $\sim 24 \%$. The open porosity of the test specimens after the above five separate processing routes is shown in the table below:

\begin{tabular}{|l|c|}
\hline \multicolumn{1}{|c|}{ Composite layer SiC matrix densification processing route } & $\begin{array}{c}\text { Resulting open } \\
\text { porosity }\end{array}$ \\
\hline Phase 1 work with 50 hours of CVI processing & $\sim 24 \%$ \\
\hline Section \#1 above with 102 hours of CVI processing & $22 \%$ \\
\hline Section \#2 above with CVI and then polymer impregnation & $16 \%$ \\
\hline Section \#3 above with SiC slurry infiltration and then CVI & $19 \%$ \\
\hline Section \#4 above with slurry infiltration, then CVI, + polymer impregnation & $19 \%$ \\
\hline Section \#5 above with ultrasound agitation, then CVI processing & $26 \%$ \\
\hline
\end{tabular}

Table 4.2 - Pre-Round 2 Processing Trials on Phase 1 Pre-Forms

Based on the above findings, it appears that the resulting open porosity of the composite layer with the braided fiber pre-form architecture remains high, regardless of the different matrix densification techniques and processing parameters tested by CCI. The findings also suggest that both the polymer impregnation and the slurry infiltration steps, coupled with CVI processing could be an effective route for achieving higher SiC matrix densification.

4.5 CCI's development work on $\mathrm{SiC}$ matrix densification of the five material specimens fabricated in the Phase 2 project - Starting in November 2003, CCI performed development work on the $\mathrm{SiC}$ matrix densification of the composite layer utilizing the five material specimens described in Section 4.4 above. The objective was to identify effective processing techniques and associated operating parameters for the matrix densification of the composite layer. The five specimens, each with a different fiber pre-form architecture, were subjected to an initial 6 hours 
of pyrolytic carbon coating and then 6 hours of CVI of the SiC fiber and the monolith tube surface. The 6 hours of CVI processing was intended to firm-up the SiC fiber pre-form on the monolith tube, and to retain the fiber architecture and fiber tension during later material handling.

The five specimens were then subjected to a polymer (Starfire) impregnation processing, with the precursor solution containing $\sim 20 \mathrm{wt} \%$ of SiC particles (at about $20 \mathrm{um}$ size). Table 4.3 shows the test specimen condition after combined polymer and slurry SiC matrix densification:

\begin{tabular}{|c|c|c|c|}
\hline $\begin{array}{c}\text { TA\&T } \\
\text { Test } \\
\text { ID }\end{array}$ & $\begin{array}{c}\text { Specimen } \\
\text { type (see } \\
\text { above) }\end{array}$ & $\begin{array}{l}\text { With } \mathrm{SiC} \\
\text { polymeric/ } \\
\text { slurry step }\end{array}$ & Observation and condition of the resulting test specimen \\
\hline 11 & Type \#1 & yes & $\begin{array}{l}\text { Uniform infiltration of SiC polymer only - no particles observed. } \\
\text { Some CVI closing off of surface porosity. }\end{array}$ \\
\hline 12 & Type \#2 & yes & $\begin{array}{c}\text { Good filling of large voids with } \mathrm{SiC} \text { polymer and good penetration } \\
\text { of SiC. Relatively open structure }\end{array}$ \\
\hline 13 & Type \#3 & yes & $\begin{array}{l}\text { Filtering of } \mathrm{SiC} \text { particles on the surface. SiC polymer infiltrated but } \\
\text { CVI surface closed. }\end{array}$ \\
\hline 14 & Type \#4 & yes & $\begin{array}{l}\text { Filtering of } \mathrm{SiC} \text { particles on the surface. SiC polymer infiltrated but } \\
\text { CVI surface closed. }\end{array}$ \\
\hline 15 & Type \#5 & yes & Good SiC polymeric infiltration. Particles not visible \\
\hline 16 & Type \#1 & no & Tight weave and SiC CVI surface closing off \\
\hline 17 & Type \#2 & no & Better weave - far more open \\
\hline 18 & Type \#3 & no & SiC CVI bias towards surface - poor infiltration through depth \\
\hline 19 & Type \#4 & no & Surface closed off with CVI SiC \\
\hline 20 & Type \#5 & no & Open weave with large voids - CVI SiC appears relatively uniform \\
\hline
\end{tabular}

Table 4.3 - Infiltration Used in First Stage of Round 2 Specimens

The findings suggested the polymer impregnation processing may be an effective approach for matrix densification of the composite layer. The coupled slurry infiltration method, in this case with a largely $20 \mathrm{um} \mathrm{SiC} \mathrm{particle} \mathrm{size,} \mathrm{appeared} \mathrm{to} \mathrm{be} \mathrm{not} \mathrm{effective} \mathrm{for} \mathrm{matrix} \mathrm{phase} \mathrm{densification.}$ Considering the findings in the earlier development work, a smaller SiC particle size may be considered in the future.

The five test specimens, along with five more similar specimens but without the polymer/slurry processing, were then CVI processed for about 30 hours.

\section{$\underline{4.5}$ Rounds 3 through 5 -further process development}

In Spring, 2005, Gamma completed its evaluation of the Round 4 and 5 tubes manufactured by NovaTech and Ceramics Composites Inc. We also evaluated tubes manufactured by MER Corporation in Arizona, and by Synterials in Virginia, using alternative processes. And we compared these results to all composite tubes manufactured by NovaTech and Starfire Corporation under a separate arrangement sponsored and funded by Westinghouse. This section summarizes the processes and product configurations of these five separate development efforts. 


\subsection{Round 4 and 5 NovaTech - CCI Tubes}

Table 4.4 summarizes the main characteristics of the round 4 and 5 tubes fabricated by NovaTech for this program, and the general conditions of Chemical Vapor Infiltration that was used. . In the round 4 test series, a helical winding architecture was used that allowed for infiltration by CCI in between layers. This was intended to reduce the voids and laminations found in previous rounds. A second purpose was to examine the CVI infiltration of tubes made from fiber tows with extra sizing, $7 \%$ by weight, as compared with the normal sizing provided on fiber tows of about $1 \%$ by weight. The idea was to increase the spacing between individual fibers in a tow during winding, by virtue of the thicker sizing, and then, after burnoff, this might allow less resistance to passage of the CVI vapors into the interior of the two. Nippon Carbon, the source of the Nicalon CG fibers used in these trials, produced a separate batch with high sizing specifically for this experiment.

The round 5 series of tubes were made with the same types of Nicalon CG fibers (with two different sizings) but used the bamboo fiber architecture, with tow crossover during winding, aimed at increasing the structural integrity, and resistance to delamination, of the composite layer. There was no separate CVI infiltration between layers. As a first step in the infiltration in the CVI reactor, $\mathrm{CCI}$ infused a methane gas to provide a thin pyrolytic carbon coating on the fibers.

4.6.1 Size and Processing - The tubes infiltrated by CCI were 18 inches long. The Coorstech tubes had an ID of about 0.340 Inches and a wall thickness of .030 inches. After winding and infiltration, the tube OD was about 0.440 inches giving a total wall thickness of about .050 inches

4.6.2 Sectioning and testing - Sections of the tubes were mounted and sent to Dayton Research Center for metallography. One six inch tube was provided to Westinghouse Sweden on January 13, 2005 for insertion in a water corrosion loop.

\begin{tabular}{|c|c|c|c|c|c|c|}
\hline Image ID & $\begin{array}{c}\text { 4BM (-T or } \\
-B)\end{array}$ & $\begin{array}{c}4 \mathrm{BP}(-\mathrm{T} \\
\text { or }-\mathrm{B})\end{array}$ & 4BM & 4BP & $5-1$ & $5-2$ \\
\hline $\begin{array}{c}\text { Location } \\
\text { of section }\end{array}$ & $\begin{array}{l}\text { Top }(-\mathrm{T}) \text { or } \\
\text { Bottom (-B) }\end{array}$ & $\begin{array}{l}\text { Top (- } \\
\text { T) or } \\
\text { Bottom } \\
(-\mathrm{B})\end{array}$ & $\begin{array}{c}1 / 3 \\
\text { down } \\
\text { the } \\
\text { length }\end{array}$ & $\begin{array}{c}1 / 3 \\
\text { down } \\
\text { the } \\
\text { length }\end{array}$ & $\begin{array}{c}1 / 3 \\
\text { down } \\
\text { the } \\
\text { length }\end{array}$ & $\begin{array}{c}1 / 3 \\
\text { down } \\
\text { the } \\
\text { length }\end{array}$ \\
\hline Sizing & Regular $\sim 1 \%$ & $\begin{array}{l}\text { High } \\
7 \%\end{array}$ & $\begin{array}{c}\text { Regular } \\
\sim 1 \%\end{array}$ & $\begin{array}{l}\text { High } \\
7 \%\end{array}$ & $\begin{array}{c}\text { High } \\
7 \%\end{array}$ & $\begin{array}{c}\text { High } \\
7 \%\end{array}$ \\
\hline $\begin{array}{l}\text { Winding } \\
\text { pattern }\end{array}$ & $\begin{array}{c}\text { Helical- } 1 \\
\text { layer }\end{array}$ & $\begin{array}{l}\text { Helical- } \\
1 \text { layer }\end{array}$ & $\begin{array}{l}\text { Helical- } \\
2 \text { layer }\end{array}$ & $\begin{array}{l}\text { Helical- } \\
2 \text { layer }\end{array}$ & $\begin{array}{c}\text { Bamboo } \\
1\end{array}$ & $\begin{array}{c}\text { Bamboo } \\
2\end{array}$ \\
\hline $\begin{array}{c}\text { CVI } \\
\text { Conditio } \\
\mathbf{n}\end{array}$ & $\begin{array}{c}1015^{\circ} \mathrm{C} \\
\text { Pressure } \\
\text { pulsed to } 50 \\
\text { Torr } \\
\text { Very low gas } \\
\text { concentration }\end{array}$ & “ & “ & “ & “6 & “ \\
\hline
\end{tabular}

Table 4.4 - Processing Characteristics of Round 4 and 5 Duplex Tubes 


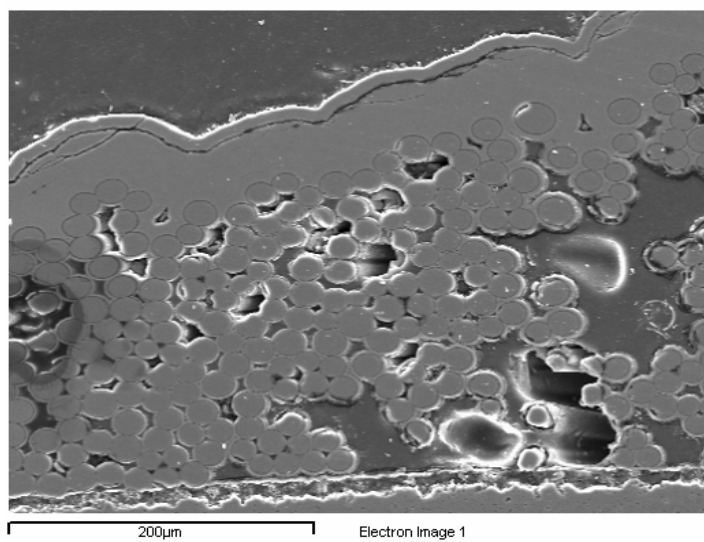

Fig 4.4 - Image of 4 BP Specimen showing interlayer laminations and capping off behavior.

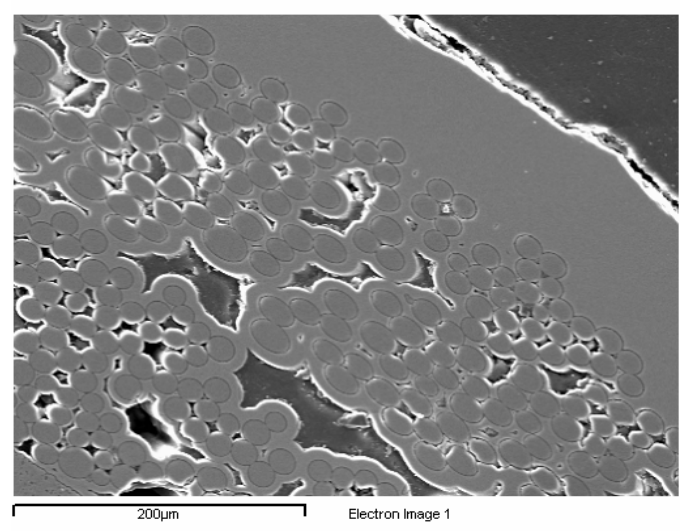

Fig 4.5 Image of 5-2 Specimen showing internal voids and capping off behavior.

All the specimens were run in the same CVI conditions. The temperatures and maximum pulsing pressure are provided. Also the runs were done under very dilute reactive gas concentrations. The exact flow rates (and therefore ratios) of gases is propriety and in truth these numbers vary for each individual reactor and setup. The gases used were MTS, hydrogen, and argon.

4.6.3 Comments on Characteristics of Round 4 and 5 Tubes. - The matrix densification of these round 4 and 5 tubes was considerably improved as compared with those in rounds 2 and 3. Furthermore, the relatively thick layer of dense $\mathrm{SiC}$ on the outer surface of the tube that resulted from the "capping off" phenomena, would provide a useful environmental barrier to minimize corrosion and wear in service. However, the extent of internal voids, especially the inter- laminar voids in the case of the round 4 helical would tubes, remained a source of concern from a long term corrosion point of view. The tubes exhibited good room temperature mechanical hoop strength characteristics, despite the internal voids. It appears that the carbon interface coating on the fibers, applied as the first step in the CVI process, has resulted in traditional composite behavior, and allowed a high degree of strain tolerance. Consequently, the basic process used in Rounds 4 and 5, with some further improvements in process techniques to assure greater penetration of the vapors prior to capping off, served as a basis for further development.

\subsection{MER Tubes}

MER tubes were fabricated in MER facilities in Tucson, Arizona under contract to Gamma. The intent was to first fabricate all composite tubes, using MER's proprietary PIP (polymer 
Infiltration and Pyrolysis) processing, and then deposit an inner layer of $\mathrm{SiC}$ via CVD on the interior of the tube to achieve hermeticity as required for this application. A final step of inside bore machining is required in order to allow loading of high tolerance urania pellets into the clad tube. For these initial trials, Gamma provided HiNicalon fibers to MER, who fabricated five short length (6 inch) tubes on graphite mandrels using hoop winding. The number of hoop wraps and PIP cycles for each tube is shown in table 4.5 below. A target of about 0.42 inch (comparable to 15 x 15 LWR fuel) was set initially, but available graphite mandrels resulted in a slightly smaller OD.

\begin{tabular}{|l|l|l|l|l|l||}
\hline $\begin{array}{l}\text { Sample } \\
\text { ID }\end{array}$ & Matrix Type & $\begin{array}{l}\text { \# Hoop } \\
\text { Wraps }\end{array}$ & $\begin{array}{l}\text { \# Infiltrations / } \\
\text { Pyrolyses }\end{array}$ & $\begin{array}{l}\text { Final } \\
\text { Weight }\end{array}$ & $\begin{array}{l}\text { Final OD } \\
\text { Before } \\
\text { Machining }\end{array}$ \\
\hline \hline 1 & $\begin{array}{l}\text { Standard SiC + } \\
\text { SiC nanoparticles }\end{array}$ & 7 & 13 & 20.84 & 0.409 \\
\hline 2 & $\begin{array}{l}\text { Higher bonding } \\
\text { strength }\end{array}$ & 4 & 13 & 20.08 & 0.405 \\
\hline 3 & Higher hardness & 6 & 13 & 20.51 & 0.409 \\
\hline 4 & Higher hardness & 7 & 13 & 19.30 & 0.403 \\
\hline
\end{tabular}

\section{$\underline{\text { Table 4.5 - MER Tube Characteristics After PIP Matrix Densification }}$}

After completion of the composite processing, and removal of the graphite mandrels, the hollow tubes were set up in a CVI reactor where a special nozzle released the CVI vapor into the interior of the tube, coating the inside with dense silicon carbide layers. Because there was significant variation of the inner layer thickness along the length, an attempt was made to acquire a machining vendor to bore out the inside hole to uniform diameter and monolith layer thickness. This attempt was unsuccessful. Finally, MER arranged for several of the tube specimens to be internally plug tested, where it was noted that failure occurred in a graceful failure mode.

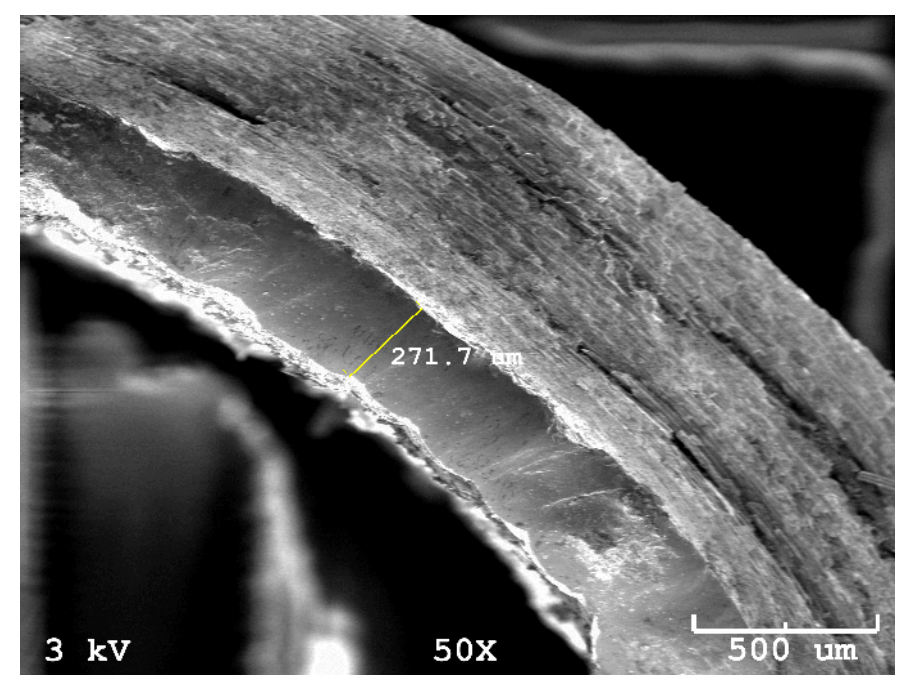

Figure 4.6 - One end of MER Tube \# 1 After Internal SiC CVD Coating 


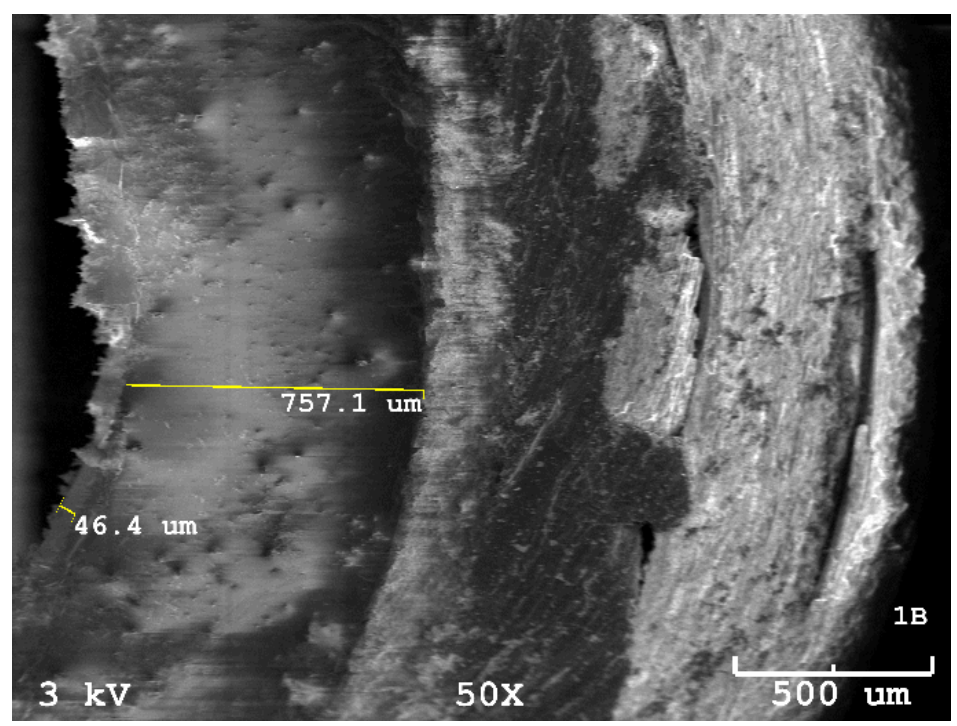

Figure 4.7 - Opposite End of MER Tube \# 1 After Internal SiC CVD Coating

Evaluation of MER process - The composite layers of the MER tubes exhibited very good matrix distribution, with minimal voids. Furthermore, the ability to deposit a thin layer of $\mathrm{SiC}$ on the inside surface of the tubes, using specialized apparatus developed by MER, was demonstrated, as shown on the above figures. With further development it is possible that the thickness variation of the $\mathrm{SiC}$ layer that was exhibited in these specimens ( from 800 microns at one end to 280 microns at the other in the example illustrated in figures 4.6 and 4.7) can be reduced. However, neither MER nor Gamma were able to identify an internal bore machining technology that could create the smooth bore, and uniform monolith layer thickness that is required for this application. Hence this approach to DUPLEX tube fabrication has been set aside.

\subsection{Synterials Tubes}

Under subcontract to Gamma, in July, 2004, Synterials acquired six 20 " graphite mandrels, and undertook to coat these with a 10 mil layer of $\mathrm{SiC}$, machine the OD, and then wind precoated fibers on the coated mandrel,, and then try several different approaches towards achieving high matrix densification.

Fibers and Coating - Synterials used Tyranno SA3 fibers. These are 7 to 8 micron fibers in 800 filaments per tow, made by UBE industries. Although stoichiometric beta phase SiC, these fibers contain up to $2 \%$ alumina. Synterials provided an interface coating of about 0.1 micron carbon, and about 0.2 microns $\mathrm{SiC}$ in a separate CVD operation, with the fiber tows re-spooled after coating. Although Gamma provided Synterials with two spools of HiNicalon $-\mathrm{S}$ for use in this process, Synterials chose to use the Tyranno SA fiber.

Synterials fabricated six tubes, three with about 10 to 12 mils of composite layer, and three with just the CVD coating, awaiting filament winding. 
Tube 1 - This was intended to be a PIP infiltrated tube. However, it ended up with too much polymer on the surface of the tube and was discarded.

Tube 2 - Wet wound the first layer with the Tyranno SA3 fibers using a Starfire polymer and < 1 micron $\mathrm{SiC}$ particles. Winding was done manually in a 90 degree hoop winding mode. A paintbrush was used during winding to apply the polymer slurry. This was followed by a PIP infiltration with Starfire polymer. Then cured and pyrolyzed. Then annealed at $1500 \mathrm{C}$ to crystallize the amorphous SiC. Then CVI'd the porous preform to fill in any voids created during pyrolysis and annealing. Then repeated with a second wet wound layer, and repeated the PIP, annealing, and CVI steps. Synterials completed one more CVI run, and then attempted graphite mandrel removal.

Tube 3 - This is the same as tube 2, except there was no wet winding or polymer infiltration. All infiltration was done by CVI. CVI was done after each of two layers.

Tubes 4, 5 and 6 - These tubes were not wound or infiltrated. The graphite mandrel was coated with 10 to 15 mil thick $\mathrm{SiC}$ overcoat, including machining. These tubes were then provided to Gamma-NovaTech for further winding and infiltration trials.

Results - The Synterials Tubes 1 and 2 were cut into short sections which were hoop strength tested at ORNL-HTML. The monolith sections failed at very low stress, although after failure, the composite layers did demonstrate ability to take additional strain and fail in a graceful failure mode. It is speculated that the method of graphite mandrel removal used by Synterials (blowing cold air into a predrilled hole in the graphite mandrel), created very high thermal stresses, and thermal shock, in the thin SiC coating, causing cracks in the monolith. As a consequence, during mechanical testing, loading of the polyurethane plug was immediately transferred to the composite layer, as the monolith layer was already cracked.

Based on these results, Gamma has concluded that the basic approach to Duplex tube fabrication suggested by the Synterials work is sound, provided that care is taken to remove the graphite mandrel without creating high thermal stresses and cracking.

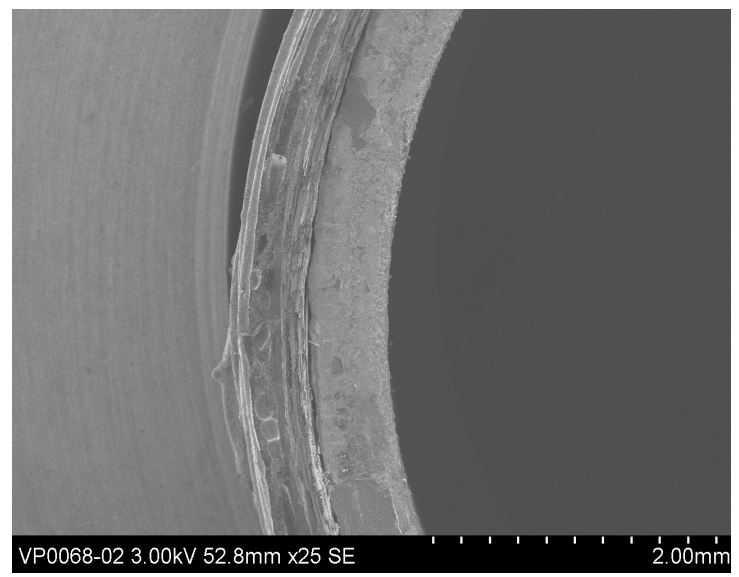

Figure 4.8 - Synterials Tube Showing Outer Composite Layer and Inner Monolith 


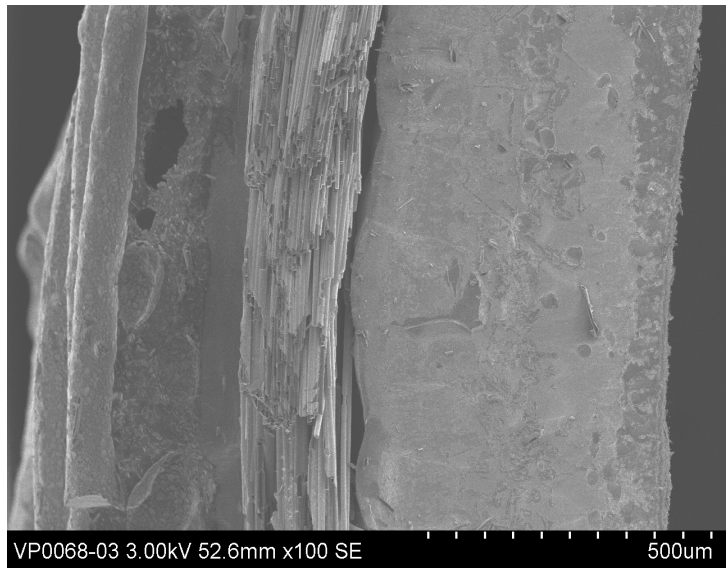

Figure 4.9 -MicroGraph of Synterials Tube Showing Composite and Monolith Layers

\subsection{Starfire - NovaTech All Composite Tubes}

Based on a suggestion from Westinghouse, Gamma arranged for Starfire Corporation, in conjunction with NovaTech fiber winding steps, to produce up to eight 12 inch long composite tubes, using Starfire's PIP process. Seven of the completed tubes were delivered to NovaTech for testing in January, 2005. Subsequently, Starfire provided 3 additional mandrels to Novatech, who wound the mandrels with bamboo weave and returned these to Starfire for infiltration. These mandrels were coated with a different release agent to facilitate mandrel removal after infiltration.

Fiber and fiber coating- Starfire provided the Tyranno SA fibers, the larger diameter (12 micron) variety. These were chosen because they were in Starfire inventory, and Starfire had an existing protocol for coating these fiber with a weak interface layer of carbon and $\mathrm{SiC}$ prior to full infiltration efforts.

Size and Processing - Size of the finished tubes were measured by NovaTech and are included in Table 4.6. Tolerances on these measurements and dimensions are $+/-.005$ inches, except SN007 which has a tolerance of $=/-.010$ inches. Processing protocol was:

1. Starfire - acquire graphite mandrels (about 14 inch) and coat with release agent

2. NovaTech - wind ten mandrels -8 with standard bamboo weave; two with alternative interweave pattern - all with two effective layers of fiber tows.

3. Starfire - apply PyC coating and $\mathrm{SiC}$ polymer coating

4. Starfire - Infiltrate with Starfire polymer, cure and pyrolize, repeat until no weight gain (about 8 times),

5. Starfire - Anneal at 1400 to $1500 \mathrm{C}$, repeat one cycle of PIP. (this was not done on tube SN008)

6. On 3 tubes - provide additional outer layer of $\mathrm{SiC}$ via PIP process 
Table 4.6 - Starfire and NovaTech all Composite Tubes

\begin{tabular}{|l|l|l|l|l|}
\hline Source & Designator & & ID-OD-t (in) & \\
\hline Starfire/NovaTech & SN001 & Bamboo-a & $.373-.42-.025$ & \\
\hline & SN002 & & $.371-.42-.025$ & \\
\hline & SN003 & & $.371-.42-.030$ & \\
\hline & SN004 & & $.370-.42-.030$ & \\
\hline & SN005 & & $.371-.42-.025$ & \\
\hline & SN006 & & $.372-.42-.025$ & \\
\hline & SN007 & Interweave & $.372-.425-.030$ & \\
\hline & SN008 & Bamboo & About the same & \\
\hline & SN009 & & & \\
\hline & SN010 & & & \\
\hline & SN011 & & & \\
\hline
\end{tabular}

After permeability testing of the Starfire impregnated tubes at NovaTech it was concluded that the composite alone cannot be relied on for gas retention. In addition the tubes failed in a brittle manner at low stress when subjected to the HTML polyurethane plug test. The permeability is an inherent characteristic of a porous matrix which results from use of the PIP process and its need to allow passages for gaseous effluents during the pyrolysis of polymers. It is speculated that the brittle mode of failure occurred because insufficient interface layer was deposited on the fibers before densifying the matrix. A cross-section of the finished starfire tubes is shown in figure 4.10 and a magnified view of the internal surface, showing matrix cracks, in figure 4.11.
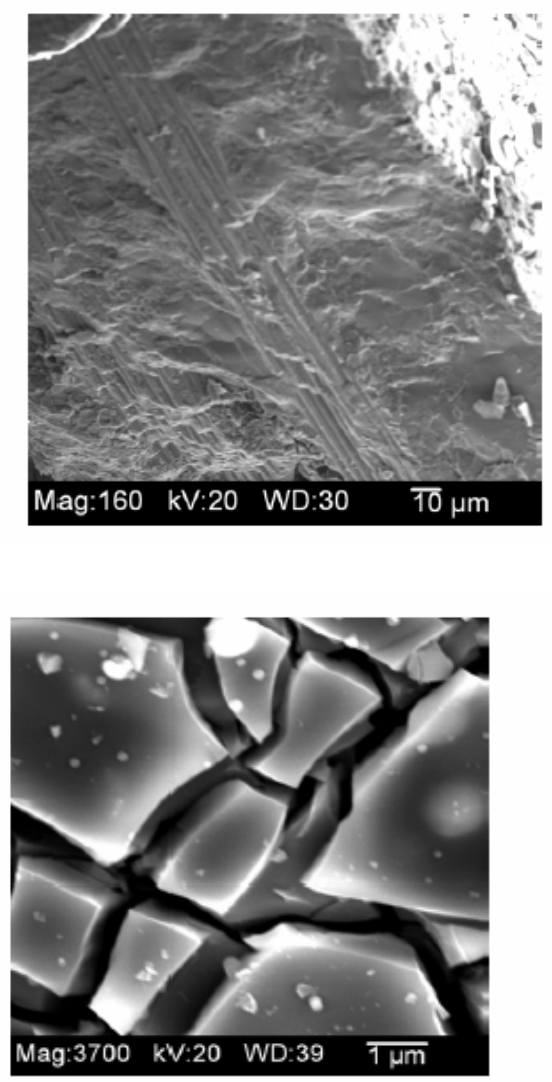

Figure 4. 45-81-2 inside surfaces
Figure 4.10 - Starfire - NovaTech Tube Section Showing Good Matrix Infiltration
Figure 4.11 Magnification of Starfire Tube Interior Surface Showing Surface Cracking 
Summary Rounds 2 - 5. It was concluded based on this preliminary processing and the mechanical testing effort described in section 7, that:

(1) Short Length SiC duplex tubes can be fabricated with radial dimensions similar to those required for some existing LWR reactor applications such as $15 \times 15$ PWR Fuel and 9x9 BWR Fuel.

(2) CCI-NovaTech Tubes - Some tubes with an internal monolith layer and external composite layer (so called "duplex" tubes) demonstrate high impermeability when pressurized up to monolith stresses of $38 \mathrm{ksi}$, and very high strain capability (above 9\%) when pressurized internally beyond the monolith fracture point. Such high strain capability offers much improved safety margins for the classical Reactivity Initiated Accident (RIA), which is a key factor limiting the burnup extension of existing zircaloy clad fuel. However, the tubes demonstrating this capability, in this program, had about twice the wall thickness of those required for current cladding application.

(3) TREX CVD Monolith Strength Characteristics - A process developed by TREX Inc. to fabricate extra strong monolith tubes via the CVD process by controlling the $\mathrm{SiC}$ crystal size and structure, provides monolith strength capability up to about $78 \mathrm{ksi}$. If applied to a duplex tube, such additional strength should allow retention of fission gas pressures above $4000 \mathrm{psi}$, allowing a safety factor of 2 on ultimate strength, assuming a monolith layer of about 15 mils, as required for direct substitution of $\mathrm{SiC}$ cladding for Zirc cladding.

(4) PIP All Composite Tubes - An alternative process to produce tubes without an internal monolith layer, via a PIP (polymer infiltration and pyrolysis) process, produced tubes with the required wall thickness, but without the hermeticity and graceful failure mode of the duplex tubes. However, these tubes had the advantage of allowing reuse of the mandrel used in pre-form fabrication, thus offering long term economic benefit. Lack of graceful failure behavior was caused by insufficient fiber interface coating, and can be overcome via improvements in the techniques used for fiber interface coatings. Lack of hermeticity may be inherent in the PIP process, which produces small gas pores or microcracks during final thermal treatment. It may be that this can be overcome only via a final internal CVD coating as was explored in another processing approach tried by the MER Corporation.

(5) MER Processing - Another alternative process to produce duplex tubes via PIP and internal CVD coating was successful in producing tubes which appeared to be hermetic (permeability testing was not possible because of the short length of tubes). However, a method for final machining of the internal monolith after final CVD was not found, despite several attempts. These tubes were strength tested also, by an alternative method, with results showing a graceful failure mode, but with monolith strength considerable less than those of the duplex tubes fabricated from winding on prefabricated monolith tubes. It is possible that the very low strength results resulted from the uneven wall thickness, and can be improved significantly if a method can be found to accurately machine the ID. 


\subsection{Application to Super-Critical Water Reactors (Gen IV Program)}

The results reported in this section have been excerpted from reference 8 - prepared by James W. Sterbentz, of the Idaho National Laboratory, as part of a work for others agreement between Gamma and INL, to support this SBIR research project.

\subsection{Selection of reference SiC and Zircaloy clad SCWR design parameters.}

As an initial step in evaluating the use of silicon carbide for the Generation IV supercritical water reactor concept, a reference silicon carbide fuel element and assembly design was selected jointly by Gamma, INEEL and Westinghouse to serve as a basis for evaluation and comparison with the reference steel cladding design. The key fuel element and fuel assembly parameters are described below:

The proposed fuel pin design is summarized in Table 5.1. The fuel system consists of LEU oxide fuel pellets clad by the $\mathrm{SiC}$ duplex cladding. The monolithic layer provides the cladding with strength and a barrier to fission product diffusion, while the composite layer imparts fracture toughness. The proposed cladding diameter and thickness are lower than that used in Gamma's early round process development work, but are larger than later developed by Gamma in round 6, and are thus conservative for this analysis. The active fuel length is assumed to be $4.27 \mathrm{~m}$, i.e., the same as for the U.S. reference SCWR with metal cladding. The cold gap width, the fission gas plenum length, the fill pressure and the linear power were selected by INEEL, and are comparable to values used in commercial PWRs.

\begin{tabular}{|l|l|l|}
\hline \multirow{2}{*}{ Parameter } & \multicolumn{2}{|c|}{ Value } \\
\cline { 2 - 3 } & Ceramic cladding design & Metal cladding design \\
\hline Fuel pin OD & $12.192 \mathrm{~mm}(0.48 \mathrm{in})$. & $10.5 \mathrm{~mm}$ \\
\hline Cladding type & SiC duplex & Stainless steel \\
\hline Monolithic SiC layer thickness & $1.016 \mathrm{~mm}(0.04$ in. $)$ & na \\
\hline Porous SiC layer thickness & $0.4064 \mathrm{~mm}(0.016$ in. $)$ & na \\
\hline Total cladding thickness & $1.4224 \mathrm{~mm}(0.056$ in. $)$ & $0.63 \mathrm{~mm}$ \\
\hline Fuel pellet OD & $9.1872 \mathrm{~mm}(0.3617$ in. $)$ & $8.78 \mathrm{~mm}$ \\
\hline Cold gap width & $80 \mu \mathrm{m}(0.003$ in. $)$ & $80 \mu \mathrm{m}$ \\
\hline Fuel composition & $\mathrm{UO}_{2}, 95 \%$ TD & $\mathrm{UO}_{2}, 95 \% \mathrm{TD}$ \\
\hline Active fuel length & $4.27 \mathrm{~m}$ & $4.27 \mathrm{~m}$ \\
\hline FG plenum length & $60 \mathrm{~cm}(23.6$ in. $)$ & $60 \mathrm{~cm}$ \\
\hline Fill pressure & $6.0 \mathrm{MPa}($ at RT $)$ & $6.0 \mathrm{MPa}($ at RT $)$ \\
\hline Average linear power & $\sim 25 \mathrm{~kW} / \mathrm{m}$ & $\sim 19 \mathrm{~kW} / \mathrm{m}$ \\
\hline Average specific power & $27.5 \mathrm{~kW} / \mathrm{kg}_{\mathrm{UO} 2}$ & $30.1 \mathrm{~kW} / \mathrm{kg}_{\mathrm{UO} 2}$ \\
\hline
\end{tabular}

na $=$ not applicable; $\mathrm{TD}=$ theoretical density; $\mathrm{RT}=$ room temperature

Table 5.1. Geometry for SCWR conditions for fuel pins with SiC/SiC and metal cladding.

With regard to the fuel assembly, it was decided to adopt a square geometry with $1.00-\mathrm{mm}$ distance between fuel rods, but with a $21 \times 21$ lattice (as opposed to $25 \times 25$ ) to maintain the same pitch of the fuel assembly with metal cladding. The cross-section and parameters of the reference $\mathrm{SiC} / \mathrm{SiC}$ cladding fuel assembly are shown in Figure 5.1 and Table 5.2. 


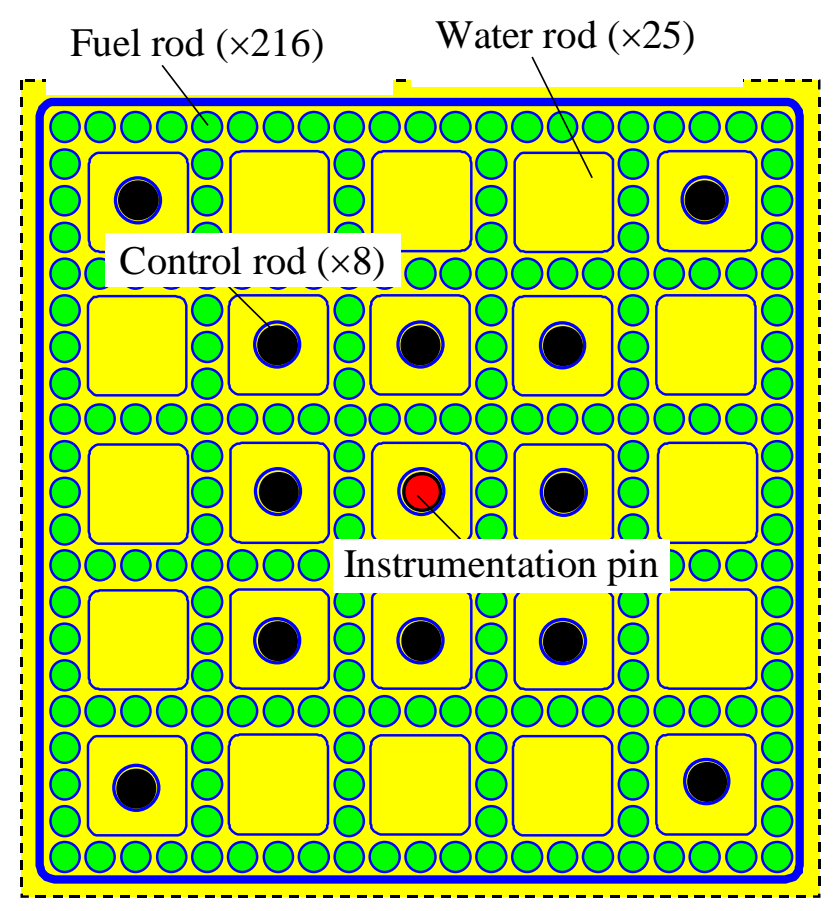

Figure 5.1. Reference $21 \times 21 \mathrm{SCWR}$ fuel assembly showing fuel rods, water rods, control rods, instrumentation pin, water rod ducts, and assembly duct

\begin{tabular}{|l|l|}
\hline \multicolumn{1}{|c|}{ Parameter } & \multicolumn{1}{c|}{ Value } \\
\hline Fuel pin lattice & Square $21 \times 21$ array \\
\hline Pitch-to-diameter ratio & 1.082 \\
\hline Number of fuel pins per assembly & 216 \\
\hline Number of water rods per assembly & 25 \\
\hline Water rod side & $39.6 \mathrm{~mm}$ \\
\hline Water rod wall thickness & $0.4 \mathrm{~mm}$ \\
\hline $\begin{array}{l}\text { Number of instrumentation rods per } \\
\text { assembly }\end{array}$ & 1 \\
\hline $\begin{array}{l}\text { Number of control rod fingers per } \\
\text { assembly }\end{array}$ & 12 (tentative) \\
\hline Number of spacer grids & 14 \\
\hline Assembly duct thickness & $3 \mathrm{~mm}$ \\
\hline Assembly side & $283 \mathrm{~mm}$ \\
\hline Inter-assembly gap & $2 \mathrm{~mm}$ \\
\hline Assembly pitch & $285 \mathrm{~mm}$ \\
\hline Average mass flux (nominal assembly) & $963 \mathrm{~kg} / \mathrm{m}^{3}$ \\
\hline H/HM & 4.56 \\
\hline Average power density & $65.5 \mathrm{~kW} / \mathrm{L}$ \\
\hline
\end{tabular}

Table 5.2. Reference SCWR fuel assembly with $\mathrm{SiC} / \mathrm{SiC}$-clad fuel pins. 
The following preliminary neutronic results have been calculated to evaluate the performance characteristics of a $21 \times 21$ supercritical water reactor (SCWR) assembly that uses silicon carbide $(\mathrm{SiC})$ for the fuel rod cladding, water rod duct, and assembly duct material. Relative to an oxide dispersion steel (ODS), such as MA956, the SiC material was expected to exhibit lower neutron absorption and hence provide considerably more assembly reactivity. This is indeed the case. $\mathrm{SiC}$ also exhibits a few other positive neutronic characteristics that should help promote its use as a SCWR fuel assembly material. Throughout the evaluation, comparison results are presented that attempt to compare the $21 \times 21$ SCWR fuel assembly with SiC clad/duct materials with a 25x25 SCWR fuel assembly with MA956 clad/duct materials, and in some cases an additional comparison is made with calculated results for a standard pressurized water reactor (PWR) fuel assembly based on a Westinghouse $17 \times 17$ fuel assembly. The $\mathrm{SiC}$ is also assumed to be used for the water rod and assembly duct material as well.

The fuel rod coolant is light water with axial density profile given in Table 5.3. The water rod also contains light water, but has a different axial density profile. The water rod water is segregated from the fuel rod coolant by the water rod duct. The coolant and water rod water axial flows are diametrically opposed; the coolant water flowing from the bottom of the core to the top, and vice versa for the water rod water.

Table 5.3. SCWR water densities for the coolant and water rods.

\begin{tabular}{|c|c|c|c|c|}
\hline Region & $\begin{array}{c}\text { Lower Elevation } \\
(\mathrm{cm})\end{array}$ & $\begin{array}{c}\text { Upper Elevation } \\
(\mathrm{cm})\end{array}$ & $\begin{array}{c}\text { Coolant Density } \\
(\mathrm{g} / \mathrm{cc})\end{array}$ & $\begin{array}{c}\text { Water Rod Density } \\
(\mathrm{g} / \mathrm{cc})\end{array}$ \\
\hline $\begin{array}{c}\text { Lower mixing or } \\
\text { reflector }\end{array}$ & -90.48 & -60.00 & 0.5649 & 0.5379 \\
\hline Gas plenum & -60.00 & 0.00 & 0.5629 & 0.5363 \\
\hline Fuel (bottom) & 0.00 & 42.7 & 0.5044 & 0.5345 \\
\hline Fuel & 42.7 & 85.4 & 0.3704 & 0.5375 \\
\hline Fuel & 85.4 & 128.1 & 0.2454 & 0.5468 \\
\hline Fuel & 128.1 & 170.8 & 0.1735 & 0.5608 \\
\hline Fuel & 170.8 & 213.5 & 0.1331 & 0.5796 \\
\hline Fuel & 213.5 & 256.2 & 0.1078 & 0.6044 \\
\hline Fuel & 256.2 & 298.9 & 0.09385 & 0.6336 \\
\hline Fuel & 298.9 & 341.6 & 0.08698 & 0.6683 \\
\hline Fuel & 341.6 & 384.3 & 0.08548 & 0.7056 \\
\hline Fuel (top) & 384.3 & 427.0 & 0.08879 & 0.7427 \\
\hline Upper reflector & 427.0 & 457.48 & 0.09171 & 0.7779 \\
\hline
\end{tabular}

\subsection{SCWR Fuel Assembly Model Development}

Based on this design and the data in Tables 5.1 and 5.2, a symmetric, 1/8-assembly, MCNP computer model was developed with fully explicit fuel rods, water rods, and assembly duct. Figure 5.2 shows a cross sectional view of the 1/8-assembly MCNP model. The SiC/SiC duplex clad material was modeled as a single clad composite material with a mean density of 2.9749 
$\mathrm{g} / \mathrm{cc}$, which is based on the monolithic and porous clad material thicknesses and densities also given in Table 5.1. This same $\mathrm{SiC}$ composite material was used for the water rod duct and assembly duct materials as well.

The fuel rods and water rods are modeled full length in the axial direction with a water reflector above the top of the active fuel region, a $60-\mathrm{cm}$ long gas plenum on the bottom of each fuel rod, and below the gas plenum at the bottom of each fuel rod, a mixing region that doubles as a lower water reflector. Figure 5.2 shows the 1/8-assembly geometry model and each component along with the fuel rod row and column coordinate label in order to identify specific fuel rods. A reflective boundary condition is applied to the three exterior planes encompassing the triangular partial assembly in order to convert the 1/8-partial assembly model into an infinite lattice of $21 \times 21$ SCWR water rod fuel assemblies.

The 427-cm active pellet stack length in each fuel pin is subdivided into 10 increments; each increment has a length of $42.7-\mathrm{cm}$. The $60-\mathrm{cm}$ length fission gas plenum beneath the bottom of the active fuel is also modeled along with a top and bottom coolant reflector with appropriate inlet and outlet water densities. The coolant channel axial lengths are also subdivided into to 10 axial volumes with appropriately assigned water densities based on Table 5.3 data. In a similar fashion, the water rod water is also modeled explicitly and subdivided into 10 axial lengths with water densities based on Table 5.3 data. The 10 axial cells for the fuel, coolant, and water rod all coincide at the same core elevations.

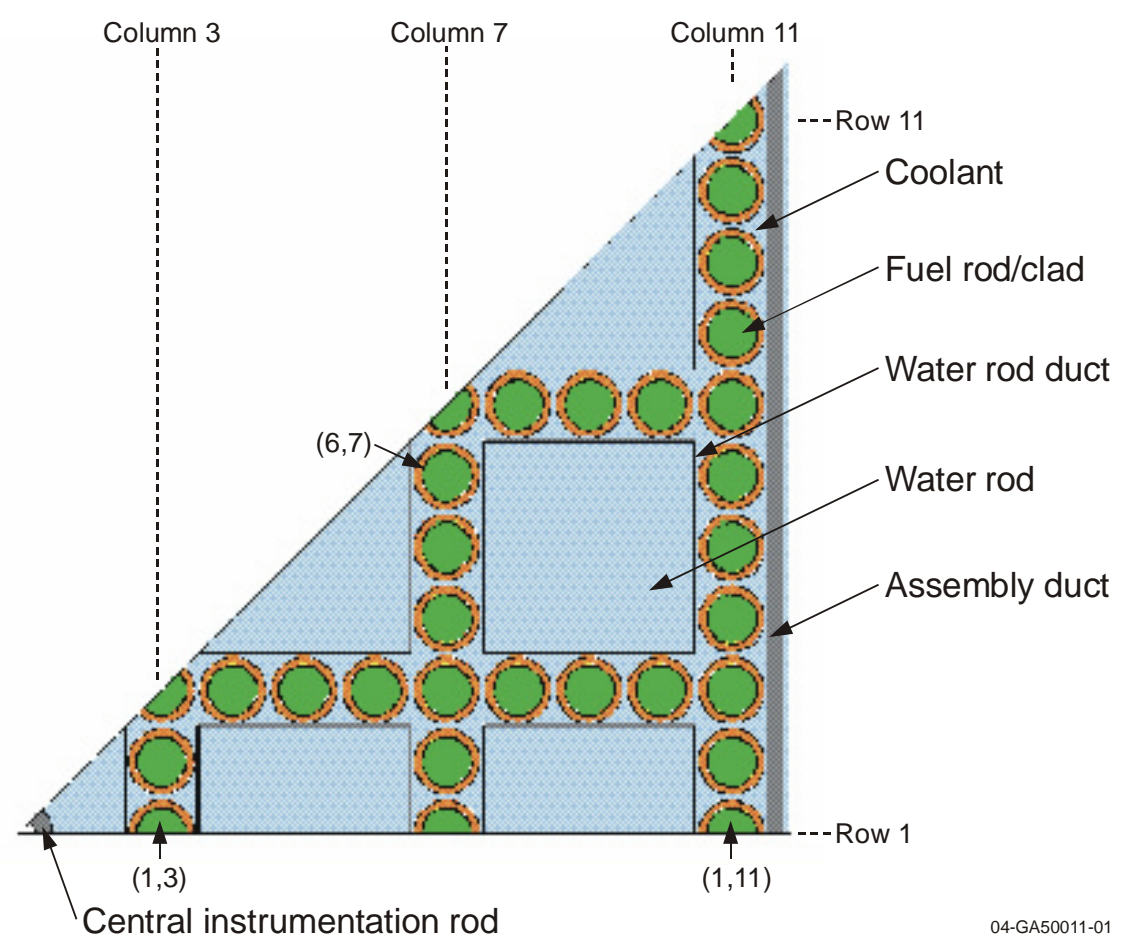

Figure 5.2. MCNP 1/8-assembly model of the $21 \times 21$ SCWR fuel assembly with SiC/SiC clad/duct materials showing the fuel rods, water rods, coolant channels, and individual fuel rod coordinate row-and-column identification numbers. 
As mentioned, the coolant and water rod axial water densities were modeled with ten equallength axial volume cells to approximate the predicted continuous water densities for the two different distributions. The neutron transport $S(\alpha, \beta)$ data libraries for the coolant and water rod water are both are assumed to be $527{ }^{\circ} \mathrm{C}$, and the average fuel temperature is assumed to be 608 ${ }^{\circ} \mathrm{C}$. These temperatures correspond to available MCNP temperature-dependent cross section libraries.

\subsection{Computer Codes}

The reactor physics computer codes MCNP, ORIGEN2, and MOCUP have been used exclusively to perform all neutronic analyses presented in this report. Details of these computer codes are presented in references $8-12$.

\subsection{Material Reactivity Comparison (SiC vs MA956)}

In order to compare the neutronic reactivity difference between MA956 and the new SiC material proposed herein, the MCNP 1/8-assembly model with MA956 clad, MA956 water rod duct, and MA956 assembly duct was used to calculate k-infinity and reactivity worths in which the MA956 material is successively replaced with $\mathrm{SiC}$. A positive reactivity gain is expected due to the lower radiative capture cross sections of silicon and carbon relative to the transition metals composing MA956. Table 5.4 presents the calculated k-infinity results for the successive material replacements of MA956 with $\mathrm{SiC}$.

Table 5.4. Assembly lattice k-infinity and reactivity worth comparison for various assembly material replacements.

\begin{tabular}{|c|c|c|c|c|c|c|c|c|}
\hline $\begin{array}{l}\text { Input } \\
\text { file }\end{array}$ & $\begin{array}{l}\text { Enrichment } \\
\text { (wt\% } \% 235 \text { ) }\end{array}$ & $\begin{array}{c}\text { Clad } \\
\text { Thk } \\
(\mathbf{m m})\end{array}$ & $\begin{array}{l}\text { Clad } \\
\text { Matl }\end{array}$ & $\begin{array}{c}\text { Water } \\
\text { Rod } \\
\text { Duct } \\
\text { Matl }\end{array}$ & $\begin{array}{c}\text { Assem } \\
\text { Duct } \\
\text { Matl }\end{array}$ & $\begin{array}{c}\text { K- } \\
\text { infinity }\end{array}$ & $\begin{array}{c}\text { rel } \\
\text { error }\end{array}$ & $\begin{array}{c}\text { Worth } \\
(\$)\end{array}$ \\
\hline sic.MA & 5.0 & 1.4224 & MA956 & MA956 & MA956 & 1.164870 & 0.0002 & --- \\
\hline sic. 1 & 5.0 & 1.4224 & $\mathrm{SiC}$ & MA956 & MA956 & 1.354373 & 0.0002 & +18.5 \\
\hline sic. $1 \mathrm{a}$ & 5.0 & 1.4224 & $\mathrm{SiC}$ & $\mathrm{SiC}$ & MA956 & 1.394881 & 0.0002 & +21.8 \\
\hline sic. $1 b$ & 5.0 & 1.4224 & $\mathrm{SiC}$ & $\mathrm{SiC}$ & $\mathrm{SiC}$ & 1.453304 & 0.0002 & +26.2 \\
\hline sic. $1 \mathrm{~d}$ & $4.85^{*}$ & 1.4224 & $\mathrm{SiC}$ & $\mathrm{SiC}$ & $\mathrm{SiC}$ & 1.450550 & 0.0002 & \\
\hline sic.MAa & 5.0 & 0.630 & MA956 & MA956 & MA956 & 1.277997 & 0.0002 & +11.7 \\
\hline
\end{tabular}

* Effective enrichment for a fuel rod with a 5.0, 4.8, and 4.7 wt\% U-235 axial distribution.

From Table 5.4, it is clear that the use of $\mathrm{SiC}$, instead of MA956, provides a significant positive reactivity advantage. This is most apparent in the material substitution of the clad, which gives a positive reactivity increase of approximately $+18.5 \$$. Additionally, the replacement of both the 
MA956 water rod and assembly ducts with $\mathrm{SiC}$ can add an additional $7.7 \$$ of positive reactivity. So there is a very large positive reactivity advantage in using $\mathrm{SiC}$ over MA956. [All reactivity values are calculated based on the formula $\left(\mathrm{k}_{2}-\mathrm{k}_{1}\right) /\left(\mathrm{k}_{1} \mathrm{k}_{2}\right)$ and an effective delayed fraction of $0.0065]$.

The data in Table 5.4 was evaluated based on the current proposed $\mathrm{SiC} / \mathrm{SiC}$ clad thickness of $1.4224 \mathrm{~mm}$. This is approximately $125 \%$ thicker than that currently proposed MA956 clad thickness of $0.630 \mathrm{~mm}$. The thinner clad wall thickness for MA956 should potentially offset the reactivity gain by the use of $\mathrm{SiC} / \mathrm{SiC}$ clad material. In attempt to assess the relative reactivity gain of the $\mathrm{SiC} / \mathrm{SiC}$ substitution and taking into consideration the difference in clad thickness, bottom row in Table 5.4 re-calculates the k-infinity for the all MA956 case with the thinner clad. Now the reactivity advantage of the $\mathrm{SiC} / \mathrm{SiC}$ is reduced to $+11.7 \$$, instead of $+18.5 \$$. This is still a substantial reactivity gain for the $\mathrm{SiC}$ material.

As a side note, the $\mathrm{UO}_{2}$ fuel was assumed to have a uniform $5.0 \mathrm{wt} \% \mathrm{U}-235$ enrichment throughout the assembly. From the axial power profile flattening study (discussed below), it was found that a 5.0\% enrichment in the bottom of the active fuel region $(0-170.8-\mathrm{cm})$, a $4.8 \%$ enrichment in the middle $(170.8-298.9-\mathrm{cm})$, and a $4.7 \%$ enrichment at the top $(298.9-427.0-\mathrm{cm})$ produced a relatively flatter axial power profile. This new enrichment profile produces an effective rod enrichment of $4.85 \mathrm{wt} \%$. Listed in row 5 of Table 5.3 is the k-infinity value associated with the $4.85 \mathrm{wt} \%$ enrichment that results in only a small reactivity loss, or approximately -20 cents.

\subsection{Coolant and Water Rod Void Reactivity}

The water in the MCNP 1/8-assembly model coolant channels and water rods was systematically voided in order to estimate the effect on the infinite assembly lattice k-infinity. The $\mathrm{UO}_{2}$ fuel is assumed to have a uniform $5.0 \mathrm{wt} \% \mathrm{U}-235$ enrichment throughout the assembly and the fuel cladding, water rod duct, and assembly duct material was assumed to be SiC. Table 5.5 gives the k-infinity results for first voiding the coolant water, then the coolant and the water rods individually, and then voiding both.

Table 5.5. Assembly k-infinity comparison for various assembly material replacements.

\begin{tabular}{|c|l|c|c|c|c|c|}
\hline $\begin{array}{c}\text { Input } \\
\text { file }\end{array}$ & $\begin{array}{c}\text { Coolant } \\
\text { Water }\end{array}$ & $\begin{array}{c}\text { Water } \\
\text { Rod } \\
\text { Water }\end{array}$ & K-infinity & $\begin{array}{c}\text { rel } \\
\text { error }\end{array}$ & $\Delta \mathbf{k}$ & $\begin{array}{c}\text { Reactivity } \\
\text { Worth } \\
\mathbf{( \$ )}\end{array}$ \\
\hline sic.1b & present & present & 1.453304 & 0.0002 & -- & -- \\
\hline sicw1 & void & present & 1.450126 & 0.0002 & -0.00318 & -0.23 \\
\hline sicw3 & present & void & 1.022154 & 0.0002 & -0.43115 & -44.65 \\
\hline sicw2 & void & void & 0.688784 & 0.0002 & -0.76452 & -117.50 \\
\hline
\end{tabular}

From Table 5.5, voiding just the coolant (loss of the coolant in the channels around the fuel rods) has only a small, but negative effect on the lattice k-infinity (approximately -23 cents). Voiding just the water rods alone produced a very strong negative decrease in the k-infinity (approximately $-\$ 44.7$ ). Voiding both the coolant and water rods drops the lattice k-infinity 
significantly, down to a very subcritical level, where the core now becomes basically an underfueled fast reactor.

If one compares the two k-infinity values in Table 5.5 between the sic. $1 \mathrm{~b}$ and sicw 3 cases, it is not readily apparent whether or not the $21 \times 21$ assembly is over-moderated or under-moderated. In order to determine whether the assembly is over-moderated or under-moderated, the water rod water density was systematically reduced in density. The resulting k-infinities monotonically decreased with decreasing water rod density and did not go through an optimal or maximum value, hence we can conclude that the assembly is under-moderated, as desired.

\subsection{Axial Power Profile and Enrichment}

Axial power profiles were calculated for each of the fuel rods in the 1/8-assembly model at BOL conditions, and for $\mathrm{SiC}$ fuel cladding, $\mathrm{SiC}$ water rod duct, and $\mathrm{SiC}$ assembly duct material. The $\mathrm{UO}_{2}$ fuel was initially assumed to have a uniform $5.0 \mathrm{wt} \% \mathrm{U}-235$ axial enrichment in each fuel rod throughout the assembly. Several individual rod power profiles for the $5.0 \mathrm{wt} \%$ case are shown in Figure 5.3. All the curves seem to exhibit a very reasonable BOL power profile shape, although the curves are not exactly centered about the midplane $(\mathrm{z} / \mathrm{L}=0.5)$. In the model, each fuel rod is divided into ten equal-length axial cell volumes and the power in each cell is averaged over the cell's volume, hence the ten axial dots per curve delineation.

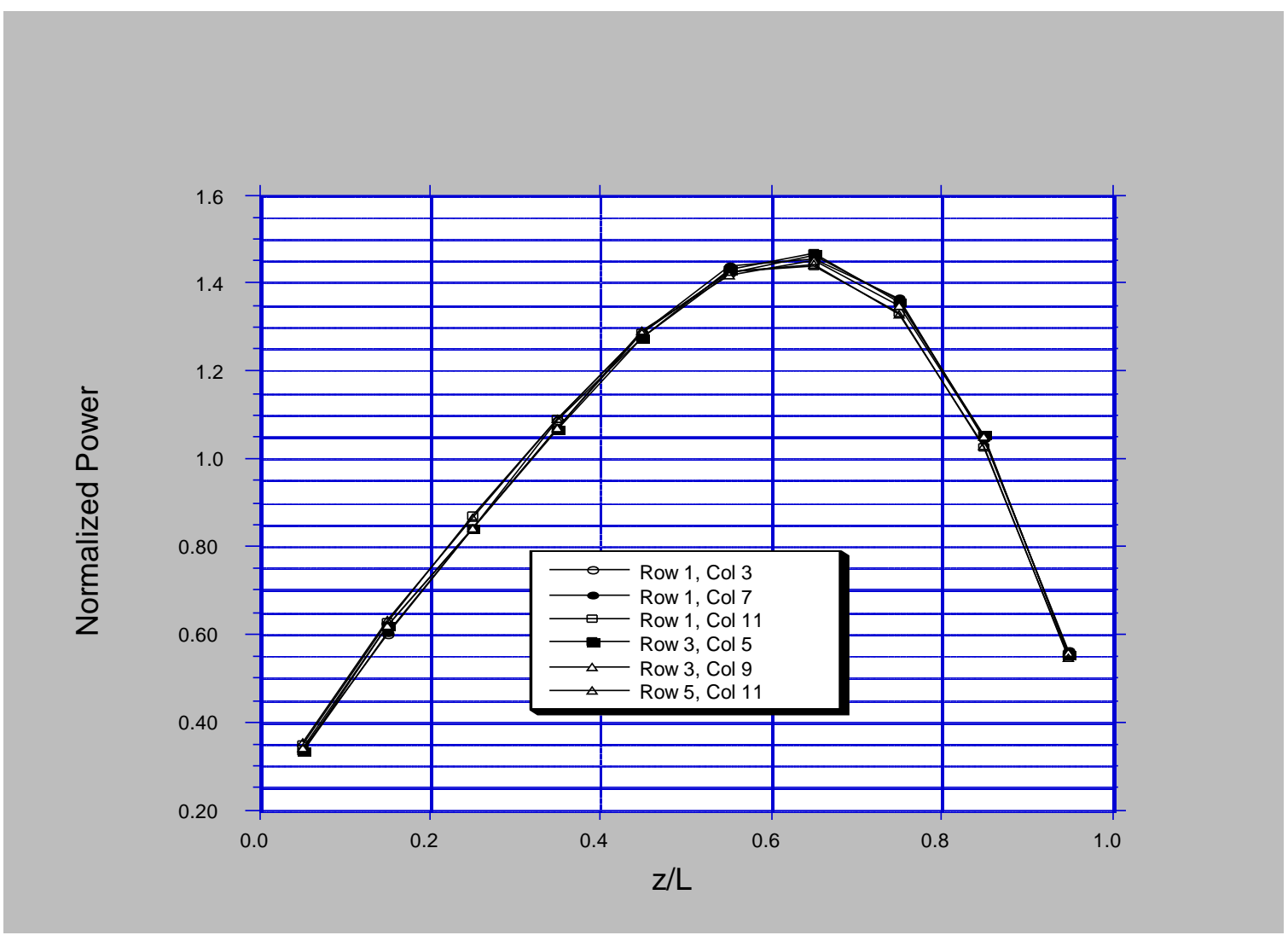

Figure 5.3. Axial power profile for uniform $5.0 \mathrm{wt} \%$ enrichment. 
The axial peak-to-average is approximately 1.45. Of particular note is the fact that all the fuel rods throughout the assembly exhibit the same axial power profile shape, i.e. rod profiles virtually overlay one another. This is indicative of a relatively long thermal neutron mean free path and low neutron absorption within the SiC SCWR fuel assembly lattice.

Despite the already reasonable axial power profile with the uniform $5.0 \mathrm{wt} \%$ U-235 enrichment, an attempt was made to center the power peak at the midplane by axial enrichment variation using the relatively coarse 10 axial segments per fuel rod. Results of this study indicate that an enrichment of $5.0 \%$ at the bottom of the active fuel region $(0-170.8-\mathrm{cm}$, or $0.0-0.4 \mathrm{z} / \mathrm{L}), 4.8 \%$ enrichment in the middle $(170.8-298.9-\mathrm{cm}$, or $0.4-0.7 \mathrm{z} / \mathrm{L})$, and $4.7 \%$ enrichment at the top (298.9-427.0-cm, or 0.7-1.0 z/L) produced a slightly flatter axial power profile with a peak-toaverage value of 1.4. Figure 5.4 shows the normalized axial power profile for several fuel rods. This axial enrichment resulted in a 1.00:0.96:0.94 relative zone enrichment ratio and an overall effective rod enrichment of $4.85 \mathrm{wt} \% \mathrm{U}-235$.

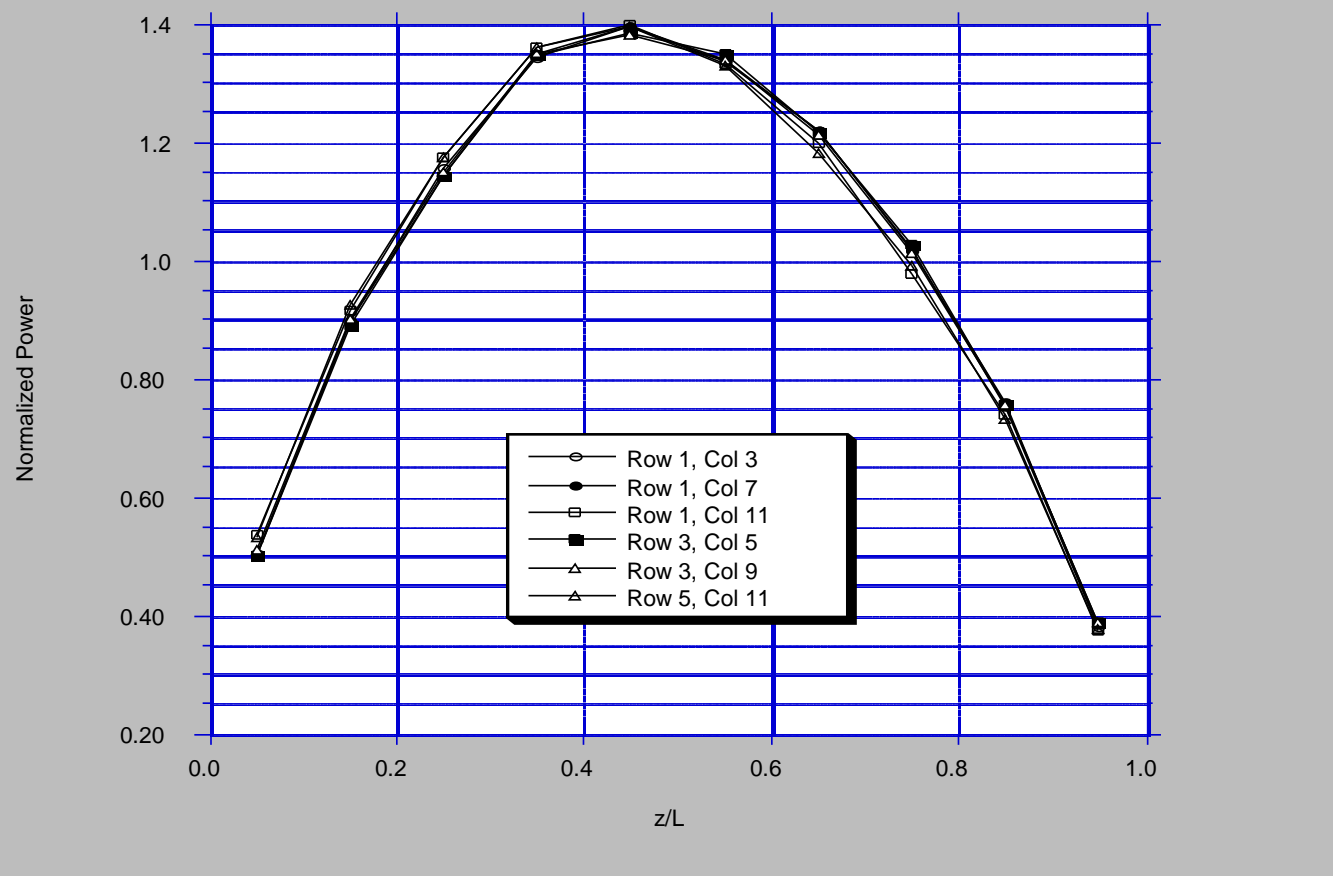

Figure 5.4 Fuel rod axial power profile for three-zone enrichment.

Again note that the fuel rods throughout the assembly exhibit the same axial power profile shape, and that the midplane peak is not exactly centered. Movement of the midplane peak was very sensitive to small axial enrichment changes - more on this issue in the depletion section. 
5.6 Radial Power Profile and Enrichment The goal of the radial fuel rod enrichment study was to make the individual fuel rod total thermal powers essentially the same across the fuel assembly. With a uniform fuel rod enrichment, fuel rods near the center of the assembly tend to have higher total powers than those near the assembly periphery and corners. The assembly fuel rod radial power profile was flattened by iteratively scaling the individual fuel rod enrichments up or down. In this manner, radial power peaking of the assembly fuel rods was reduced through selective rod enrichments. As a starting point, an initial $5.0 \mathrm{wt} \% \mathrm{U}-235$ uniform rod enrichment was assumed throughout the SCWR assembly with no axial variation. Based on the calculated rod powers, the U-235 number density in each fuel rod was adjusted in order to flatten the radial power profile. Eight iterations were required to produce a relatively flat radial power profile with the minimum-to-average and peak-to-average confined to 0.96 and 1.03 , with the exception of rod 30 at 0.94 . Table 5.6 lists the individual assembly fuel rods, their coordinate position, the final converged rod enrichments, and their associated peak-to-average value. The enrichments span from 3.0 to $8.8 \mathrm{wt} \% \mathrm{U}-235$ resulting in an overall effective rod enrichment for the SCWR assembly of approximately $4.65 \mathrm{wt} \% \mathrm{U}-235$. Note the relatively large increase in enrichment for those rods on the fuel assembly periphery and those near the assembly corners (in particular, rods in column 11 and rows 7-11).

\begin{tabular}{|c|c|c|c|c|}
\hline $\begin{array}{c}\text { Fuel Rod } \\
\text { No. }\end{array}$ & Row & Column & $\begin{array}{l}\text { Enrichment } \\
\text { (wt\% U-235) }\end{array}$ & $\begin{array}{c}\text { Radial peak to ave } \\
\text { factor }\end{array}$ \\
\hline 1 & 1 & 3 & 3.0 & 1.030 \\
\hline 2 & 1 & 7 & 3.2 & 1.006 \\
\hline 3 & 1 & 11 & 5.4 & 1.014 \\
\hline 4 & 2 & 3 & 3.0 & 0.984 \\
\hline 5 & 2 & 7 & 3.4 & 1.004 \\
\hline 6 & 2 & 11 & 5.6 & 1.007 \\
\hline 7 & 3 & 3 & 3.4 & 1.027 \\
\hline 8 & 3 & 4 & 3.2 & 1.028 \\
\hline 9 & 3 & 5 & 3.0 & 1.002 \\
\hline 10 & 3 & 6 & 3.2 & 0.982 \\
\hline 11 & 3 & 7 & 3.8 & 1.024 \\
\hline 12 & 3 & 8 & 3.6 & 0.995 \\
\hline 13 & 3 & 9 & 3.8 & 1.018 \\
\hline 14 & 3 & 10 & 4.6 & 1.013 \\
\hline 15 & 3 & 11 & 5.8 & 0.995 \\
\hline 16 & 4 & 7 & 3.6 & 1.034 \\
\hline 17 & 4 & 11 & 5.6 & 0.990 \\
\hline 18 & 5 & 7 & 3.4 & 1.016 \\
\hline 19 & 5 & 11 & 5.6 & 1.003 \\
\hline 20 & 6 & 7 & 3.6 & 0.985 \\
\hline 21 & 6 & 11 & 6.0 & 0.995 \\
\hline 22 & 7 & 7 & 4.2 & 1.007 \\
\hline 23 & 7 & 8 & 4.0 & 0.988 \\
\hline 24 & 7 & 9 & 4.2 & 1.010 \\
\hline 25 & 7 & 10 & 5.0 & 0.989 \\
\hline 26 & 7 & 11 & 6.6 & 0.997 \\
\hline 27 & 8 & 11 & 6.4 & 0.963 \\
\hline 28 & 9 & 11 & 6.8 & 0.984 \\
\hline 29 & 10 & 11 & 7.8 & 0.967 \\
\hline 30 & 11 & 11 & 8.8 & 0.942 \\
\hline
\end{tabular}

Table 5.6. Fuel rod enrichments for peak-to-average radial power profile reduction. 


\subsection{Fuel Depletion}

Two fuel depletion studies were performed for the $21 \times 21$ SCWR fuel assembly with SiC. The first fuel depletion study resulted in un-damped axial power oscillations as a function of burnup. A description of this calculation will be provided under the heading "Depletion Study No. I" below. The second SCWR depletion calculation is believed to be more accurate and reasonable, and more readily comparable to other fuel assembly depletions as described below. This second depletion study was specifically designed to achieve two goals: (1) a more stable depletion calculation under the assumption of a constant rod power and an average, uniform axial fuel rod burnup, and (2) to provide a reasonable one-to-one comparison with the depletion of a standard PWR assembly and the 25x25 SCWR fuel assembly using MA956 clad/duct materials. Reactivity letdown curves will be presented for these three reactor fuel assembly designs.

In order to limit the scope of the depletion studies, it was decided to deplete just a basic unit cell instead of the full assembly. In both models, the following conditions were assumed: (1) unrodded, (2) no burnable poisons in the lattice, and (3) a constant, rod-average linear heat generation rate. The following brief discussion describes each unit cell model in more detail.

SCWR with SiC (Depletion Study No. 1) The SCWR unit cell consisted of a water rod surrounded by 16 half and quarter fuel rods. The 4 quarter-volume fuel rods were located in the corners of the unit cell. The fuel rods were divided into 10 equal volume axial cells. As in the assembly model, the cladding and water rod duct material is $\mathrm{SiC}$. The same axial water density profiles given in Table 5.2 are used in the SCWR unit cell model for the coolant and water rod. The SCWR fuel rods are assumed to have a constant power output or constant linear heat generation rate of $25 \mathrm{~kW} / \mathrm{m}$ over the burnup calculation.

The selected axial enrichment was based on the radial and axial enrichment studies and is assumed to be the same for all 16 fuel rods in the unit cell. The bottom 4 fuel zones are assumed to have a BOL enrichment of $4.65 \mathrm{wt} \%$, the middle 3 zones $4.464 \mathrm{wt} \%$, and the top 3 zones 4.371 wt $\%$. The overall effective rod enrichment is $4.5105 \mathrm{wt} \% \mathrm{U}-235$ and this is the enrichment assumed in the PWR unit cell fuel rod.

The SCWR unit cell model, although a subset of the assembly geometry, can accurately capture the important neutron spectra information for the calculation of the neutron cross sections at each time step in the burnup calculation. Neutron cross sections are calculated in each of the 10 axial cells of segments of the fuel rods. Fission, radiative capture, $(n, 2 n)$, and $(n, 3 n)$ cross sections are calculated for 37 different actinides and 77 fission products at each burnup time step. In addition, the unit cell model is used to calculate the axial power distribution in the fuel rods.

In the case of the SCWR with SiC, after approximately $16.5 \mathrm{GWd} / \mathrm{MTU}$ (400 EFPD), the axial rod power profile began to oscillate rather wildly with each successive 30-day burnup increment. It is believed that this oscillation has some basis in actual physical phenomena rather than just numerical. The SCWR axial rod power distribution initially starts out at BOL with a reasonably symmetric shape about the fuel rod midplane. As the burnup progresses, the power distribution decreases steadily at the center of the rod and power starts to build in toward the rod ends, but not in a symmetrical manner. At around 400 EFPD, the power profile is skewed, such that the peak is significantly below the midplane causing the fuel to burn out disproportionately below the midplane. At the next burnup step, the power has now shifted to the top of the core and the

oscillations take hold permanently. Factors of 2-4 in the cell powers were observed between the 
top and bottom with peak-to-averages greater than 1.7, and minimum-to-average factors of $>4.0$. Burnup steps finer than 30-day increments can help to resolve these power oscillations, but the time and effort is beyond the scope of this work here. It should also be mentioned that during the axial enrichment study, it was also observed that the BOL power distribution seemed very unstable for seemingly very small changes in the axial enrichments. Small enrichment changes either above or below the fuel rod midplane resulted in significant movement of the peak power above or below the midplane in a rather unpredictable manner. Perhaps these power oscillations are simply the result of the asymmetry of the axial coolant and water rod water densities and in normal operation will require control rod insertion into the core (along with burnable poisons for excess reactivity) in order to control and stabilize the core burnup and power distribution over the power cycle.

SCWR with SiC (Depletion study no. 2) In order to circumvent the wild and undamped power profile oscillations seen in the first depletion study, it was decided to perform a more stable depletion calculation without the axial segmentation of the fuel rods and instead deplete a single fuel rod as a whole and uniformly with a constant axial linear heat generation rate $(25.0 \mathrm{~kW} / \mathrm{m})$. The same unit cell model was used but without the fuel rod axial segmentation. This not only simplified the depletion calculation, but also allowed for a more equal basis to compare reactivity letdown curves to the PWR and SCWR with MA956. In addition, from a previous depletion study involving the SCWR with MA956, the same converged BOL axial enrichment profile (Table 9) was used, resulting in an effective and uniform rod enrichment of $4.93 \mathrm{wt} \%$ U235. In order to further develop an equal depletion basis for the two different SCWR fuel assembly designs, the same BOL coolant water density profile (Table 9) was used in the both $21 \times 21$ SCWR fuel assembly with SiC unit cell and the 25x25 SCWR fuel assembly with MA956 unit cell. The coolant water density was then held constant throughout the depletion calculation, as was the water rod water density (both profiles per Table 5.7 data).

Table 5.7. Converged BOL SCWR water densities for the coolant and water rods.

\begin{tabular}{|c|c|c|c|c|c|}
\hline Region & $\begin{array}{c}\text { Lower } \\
\text { Elevation } \\
(\mathrm{cm})\end{array}$ & $\begin{array}{c}\text { Upper } \\
\text { Elevation } \\
(\mathrm{cm})\end{array}$ & $\begin{array}{c}\text { Coolant } \\
\text { Density } \\
(\mathrm{g} / \mathrm{cc})\end{array}$ & $\begin{array}{c}\text { Water Rod } \\
\text { Density } \\
(\mathrm{g} / \mathrm{cc})\end{array}$ & $\begin{array}{c}\mathrm{UO}_{2} \text { Enrich } \\
(\mathrm{wt} \% \\
\mathrm{U} 235)\end{array}$ \\
\hline $\begin{array}{c}\text { Lower mixing or } \\
\text { reflector }\end{array}$ & -90.48 & -60.00 & 0.5649 & 0.5379 & \\
\hline Gas plenum & -60.00 & 0.00 & 0.5629 & 0.5363 & \\
\hline Fuel (bottom) & 0.00 & 42.7 & $\mathbf{0 . 5 4 7 3 2}$ & 0.5345 & 5.0 \\
\hline Fuel & 42.7 & 85.4 & $\mathbf{0 . 4 9 6 4 7}$ & 0.5375 & 5.0 \\
\hline Fuel & 85.4 & 128.1 & $\mathbf{0 . 4 0 9 3 6}$ & 0.5468 & 5.0 \\
\hline Fuel & 128.1 & 170.8 & $\mathbf{0 . 3 0 8 6 6}$ & 0.5608 & 5.0 \\
\hline Fuel & 170.8 & 213.5 & $\mathbf{0 . 2 2 5 7 3}$ & 0.5796 & 5.0 \\
\hline Fuel & 213.5 & 256.2 & $\mathbf{0 . 1 7 0 0 9}$ & 0.6044 & 5.0 \\
\hline Fuel & 256.2 & 298.9 & $\mathbf{0 . 1 3 4 8 1}$ & 0.6336 & 4.9 \\
\hline Fuel & 298.9 & 341.6 & $\mathbf{0 . 1 1 2 6 5}$ & 0.6683 & 4.8 \\
\hline Fuel & 341.6 & 384.3 & $\mathbf{0 . 0 9 9 1 8}$ & 0.7056 & 4.8 \\
\hline Fuel (top) & 384.3 & 427.0 & $\mathbf{0 . 0 9 2 0 0}$ & 0.7427 & 4.8 \\
\hline Upper reflector & 427.0 & 457.48 & 0.09171 & 0.7779 & \\
\hline & & & & & \\
\hline
\end{tabular}


Figure 5.5 shows the reactivity letdown curve for the SCWR with SiC. A burnup of approximately $41.0 \mathrm{GWD} / \mathrm{MTU}$ can be achieved in a once-through cycle before the unit cell would drop below the critical point. The relatively high BOL k-infinity (1.4777861) is indicative of the potential to achieve relatively higher burnups and this is the case as shown in Figure 5.8 relative to the PWR and SCWR with MA956. The PWR can achieve a burnup of approximately 38.0 GWD/MTU and the SCWR with MA956 a burnup of only 31.0 GWD/MTU.

SCWR with MA 956 For comparison purposes, a depletion calculation was performed for a single fuel rod in a unit cell based on the $25 \times 25$ SCWR assembly with MA956 cladding on the fuel rods, and water rod and assembly duct material made out of MA956 as well. The effective enrichment was assumed to be $4.93 \mathrm{wt} \% \mathrm{U} 235$ and the water rod and coolant water densities are based on Table 5.9 data. Figure 5.5 shows the SCWR with MA956 reactivity letdown curve. The SCWR with MA956 can achieve a burnup of approximately $31.0 \mathrm{GWD} / \mathrm{MTU}$, substantially lower than both the SCWR with SiC and the PWR.

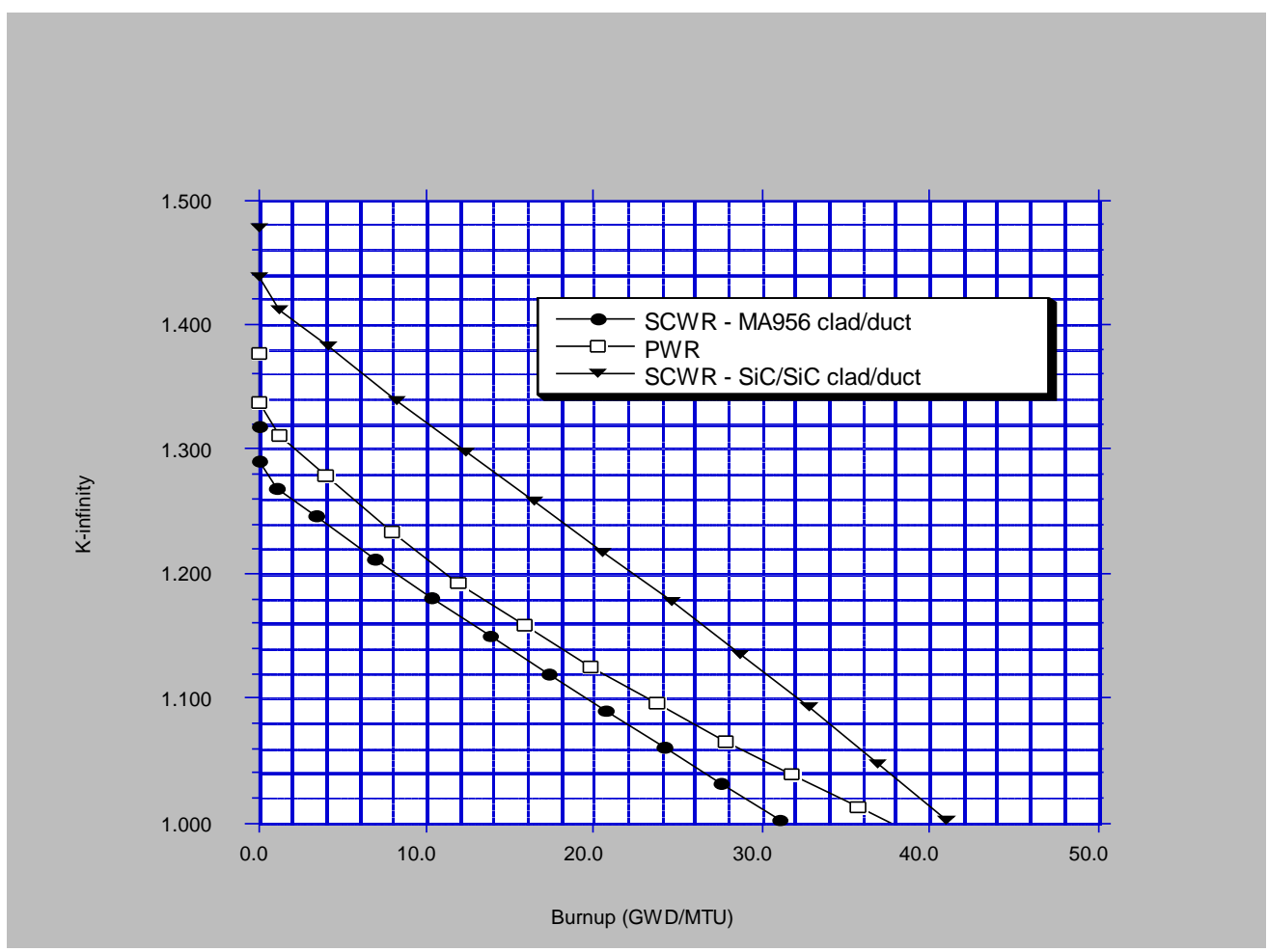

\section{Figure 5.5 Comparison of reactivity letdown curves for the SCWR with $\mathrm{SiC}$, the SCWR with MA596, and the PWR.}

The burnup comparison of the two SCWR and the one PWR fuel assemblies must be put in perspective. First, the comparison of the two SCWR assemblies is reasonable, since both operate at similar power densities. The $25 \times 25$ SCWR fuel assembly (MA956) with a $19.2 \mathrm{~kW} / \mathrm{m}$ LHGR and 300 fuel rods per assembly has a power density of the $70.4 \mathrm{~W} / \mathrm{cc}$, whereas the $21 \mathrm{x} 21 \mathrm{SCWR}$ fuel assembly $(\mathrm{SiC})$ with a $25.0 \mathrm{~kW} / \mathrm{m}$ LHGR and 216 fuel rods per assembly has a power density of the $67.4 \mathrm{~W} / \mathrm{cc}$. In addition to the greater burnup, the $21 \times 21$ assembly requires less uranium than the $25 \times 25$ fuel assembly, for example, a BOL uranium loading of only $561.6 \mathrm{~kg}$ is required 
for the $21 \times 21$ versus the substantially more $712.4 \mathrm{~kg}$ for the $25 \times 25 \mathrm{SCWR}$ fuel assembly. The superiority of the $\mathrm{SiC}$ versus the MA956 material from a neutronics standpoint is evident.

The PWR fuel assembly, with a $19.0 \mathrm{~kW} / \mathrm{m}$ LHGR, 264 fuel rods per assembly, and a BOL 467.6 $\mathrm{kg}$ U/assembly uranium loading, operates at a considerably higher power density, namely 109.5 W/cc. This is substantially higher (approximately 55-62\% higher) than either of the two SCWR fuel assemblies. This higher power density gives the PWR fuel assembly a substantial burnup and economic advantage. The specific powers for the three assemblies studied however are similar at 39.3, 34.5, and 41.1 kW/kgU for the PWR, SCWR with MA956, and the SCWR with SiC, respectively. Table 5.8 provides a summary of additional data for comparing the three fuel assemblies.

Table 5.8. Additional data for comparing the three fuel assemblies.

\begin{tabular}{|r|c|c|c|}
\hline \multicolumn{1}{|c|}{ Parameter } & PWR & $\begin{array}{c}\text { SCWR with } \\
\text { MA956 }\end{array}$ & $\begin{array}{c}\text { SCWR with } \\
\text { SiC }\end{array}$ \\
\hline No. of fuel rods & 264 & 300 & 216 \\
\hline LHGR (kW/m) & 19.0 & 19.2 & 25.0 \\
\hline Total Assembly Power (MW/assem) & 18.358 & 24.595 & 106.75 \\
\hline Assembly Volume (cc/assem) & $167,613.36$ & $349,268.92$ & $341,980.00$ \\
\hline Power Density (W/cc) & 109.52 & 70.42 & 67.43 \\
\hline BOL Uranium Mass (kg/assem) & 467.6 & 712.4 & 561.6 \\
\hline Specific Power (kW/kgU) & 39.26 & 34.52 & 41.05 \\
\hline Burnup U-235 (\%) & 62.6 & 58.9 & 75.6 \\
\hline
\end{tabular}

\section{$\underline{5.8 \text { Conclusion }}$}

Based on the limited neutronics scoping work performed herein, it can be concluded that the 21x21 SCWR fuel assembly with SiC exhibits many desirable neutronic characteristics some very similar to the 25x25 SCWR fuel assembly with MA956, but others, such as burnup better than the $25 \times 25 \mathrm{SCWR}$ fuel assembly. Use of $\mathrm{SiC} / \mathrm{SiC}$ clad and $\mathrm{SiC}$ as the duct material will produce a substantial positive reactivity gain that in turns translates into a potentially higher assembly burnup. Compared to a PWR fuel assembly of comparable uranium enrichment, the SCWR with $\mathrm{SiC}$ appears to be able to also achieve a comparable and possibly even a slightly higher burnup, 41.0 GWD/MTU versus 38.0 GWD/MTU.

In addition, the $\mathrm{SiC}$ fuel assembly lattice exhibits other desirable characteristics which include: (1) negative void reactivity upon loss of coolant and/or water rod water, (2) strong negative Doppler coefficients at BOL and solid indications that this persists as a function of burnup as well, (3) an under-moderated fuel assembly, and (4) a neutron spectra similar to, but slightly softer than both the SCWR with MA956 and a commercial PWR water reactor (due to the higher $(\mathrm{H}: \mathrm{U})$ ratio in the case of the SCWR with $\mathrm{SiC}$ ).

In the case of the SCWR with SiC, the unrodded axial and radial power profiles can be flattened through enrichment variation. For axial power flattening, a three-zone axial enrichment scheme using a relatively tight enrichment range of 4.7-5.0 wt\% U235 would suffice. A three-zone axial 
enrichment scheme was shown to produce a symmetrical axial power profile with a peak-toaverage value of approximately 1.4 for the unrodded condition. It should be noted that the axial enrichment profile was very sensitive to the coolant and water rod water axial density profiles used in the calculations. For radial power flattening, a much broader enrichment range may be required, for example, 3.0 to $8.8 \mathrm{wt} \% \mathrm{U} 235$. The higher enrichments are required for fuel rods on the periphery and corners of the assembly in order to achieve relatively constant fuel rod powers across the assembly at BOL. Because of the axial asymmetries inherent in the 21x21 SCWR fuel assembly (e.g. enrichment, coolant water density, water rod water density), control rod insertion and possibly burnable poisons will most likely be required to holddown excess reactivity in order to control burnup and eliminate any axial power oscillations in the core.

For an effective assembly enrichment of $4.93 \mathrm{wt} \%$ U235 in the $21 \times 21$ SCWR assembly with SiC as the clad and structural material, a once-through burnup of approximately $41.0 \mathrm{GWD} / \mathrm{MTU}$ could be achieved for an infinite unit cell lattice before subcriticality resulted. Relative to the $25 \times 25$ SCWR assembly with MA956 as the clad and structural material, a relative burnup of only $31.0 \mathrm{GWD} / \mathrm{MTU}$ is possible. Based on the assumed LHGRs, the $25 \times 25$ and the $21 \times 21$ fuel assemblies have comparable power densities, namely, $70.4 \mathrm{~W} / \mathrm{cc}$ and $67.4 \mathrm{~W} / \mathrm{cc}$, respectively.

In addition, for comparison purposes, a standard 17x17 commercial PWR fuel assembly was also depleted. For an assumed uniform $4.93 \mathrm{wt} \%$ U235 enrichment, the PWR fuel assembly can achieve a burnup of approximately 38.0 GWD/MTU. Although the SCWR with SiC slightly exceeds the PWR burnup or energy expenditure per unit mass of initial uranium, the PWR fuel assembly operates at a much higher power density, $109.5 \mathrm{~W} / \mathrm{cc}$ versus $67.4 \mathrm{~W} / \mathrm{cc}$, and therefore has a significant advantage over the SCWR fuel assemblies. 


\subsection{Out of Pile Corrosion Tests}

In consequence of the favorable neutronic performance of $\mathrm{SiC}$ cladding, as compared to steel cladding, as reported in Section 5, Gamma initiated a corrosion test of SiC materials in $500{ }^{\circ} \mathrm{C}$ supercritical water in collaboration with the University of Wisconsin. Gamma acquired small high purity CVD $\mathrm{SiC}$ test specimens and provided them to Wisconsin for testing in their supercritical water loop. Three specimens were tested at very low (ppb levels) of oxygen in April and May, 2004, along with a large number of metallic specimens. The specimens were removed after one, two and three weeks exposure. The $\mathrm{SiC}$ specimens had extremely low levels of weight loss. This work has been published and is reported in reference 13. It is summarized in the following section.

Hydrothermal corrosion of $\mathrm{SiC}$ has been the subject of numerous investigations [16 - 20]. Of particular interest, Hirayama, et al. found that the dissolution rate of $\mathrm{SiC}$ in water at $290^{\circ}$ is accelerated by the $\mathrm{pH}$ value and the amount of oxygen dissolved [16]. They also reported that the dissolution rate of $\mathrm{SiC}$ in an oxygenated alkaline solution follows linear kinetics whereas in an acidic solution, it approximates parabolic kinetics. Microstructural analysis revealed that corrosion occurred at the grain boundaries and that there was no evidence for the formation of a protective $\mathrm{SiO}_{2}$ layer [16].

Kim, et al. [20,21] reported that CVD SiC exhibited better corrosion resistance than reactionbonded $\mathrm{SiC}$ (RBSC) and sintered $\mathrm{SiC}$ (SSC) in water at $360^{\circ} \mathrm{C}$, that residual free silicon in RBSC was preferentially corroded and that the kinetics of corrosion followed a parabolic law, except for abrupt increases in weight loss after 7 and 10 days for SSC and CVD-SiC, respectively. Kim, et al. [20] also showed that the corrosion of RBSC was accelerated by increasing pH through the addition of small amounts of $\mathrm{LiOH}$.

Kraft, et al. [19], observed linear corrosion behavior for CVD SiC fibers (Specialty Materials Inc, Lowell, MA) in water at $200 \mathrm{MPa}$ and temperatures in the range of $400-700^{\circ} \mathrm{C}$ and concluded that no protective layer had formed on the surface of the fibers.

In this study, the corrosion behavior of $\mathrm{CVD} \mathrm{SiC}$ in deoxygenated supercritical water at $500^{\circ} \mathrm{C}$ was investigated.

\section{Experimental Procedure:}

CVD-SiC (Rohm \& Hass Company, Advanced Materials, Woburn MA) test specimens (31.75 $\mathrm{mm} \times 12.7 \mathrm{~mm} \times 0.38 \mathrm{~mm}$ ) were used in this investigation. The holes near the ends of each specimen were used to hold it in the test fixture. The specimens were polished to a 1 micron RMS surface finish. The corrosion experiment was conducted at the University of Wisconsin's Supercritical Water Test Loop facility using deionized water with an average oxygen concentration of 25 parts per billion (ppb) at $500^{\circ} \mathrm{C}$. Water pressure in the test loop was $25 \mathrm{MPa}$ and the flow rate over the specimens was approximately $1 \mathrm{~m} / \mathrm{s}$. Three $\mathrm{SiC}$ specimens were tested, one each exposed for 7 days, 14 days and 21 days. The test also included a range of metal alloys being considered for supercritical water reactor applications, and included austenitic stainless steels, nickel-base alloys, and ferritic-martensitic steels. The specimens were weighed before and after exposure to an accuracy of $0.1 \mathrm{mg}$. 
After exposure the specimens were further characterized by Raman Spectroscopy and analytical electron microscopy. Raman spectra were acquired from the surface of the samples using a Dilor XY800 Raman Microprobe (JY, Inc., Edison, NJ) with a Coherent 308C $\mathrm{Ar}^{+}$laser (Coherent Laser Group, Santa Clara, CA) operating at $5145 \AA$ and $200 \mathrm{~mW}$ output power. Light was focused using a $10 \mathrm{X}$ objective to a $\sim 10 \mu \mathrm{m}$ spot size.

Figure 6.2 shows the weight changes for the CVD-SiC coupons after exposure. Corrosion data from $\mathrm{Kim}$, et al, for $\mathrm{CVD} \mathrm{SiC}$ exposed to pure water at $360^{\circ} \mathrm{C}$ [21] has also been included. In both cases, the weight decreased with exposure time and was significantly less than that reported for SSC [21] or RBSC [20].

Kim et al. reported that preferential corrosion had occurred along the grain boundaries, revealing large columnar grains that are typical of CVD-SiC [21]. They suggested that the preferential grain boundary corrosion was likely due to the higher energy of $\mathrm{SiC}$ at the grain boundaries relative to the $\mathrm{SiC}$ within the grains and that as the corrosion reaction proceeded, sufficient amounts of $\mathrm{SiC}$ were removed from the grain boundaries resulting in the fall of grains into the water [21]. The fall of grains into the water, as opposed to dissolution of hydrolyzed SiC, was identified as the source of the abrupt increase in weight loss after the 10-day exposure.

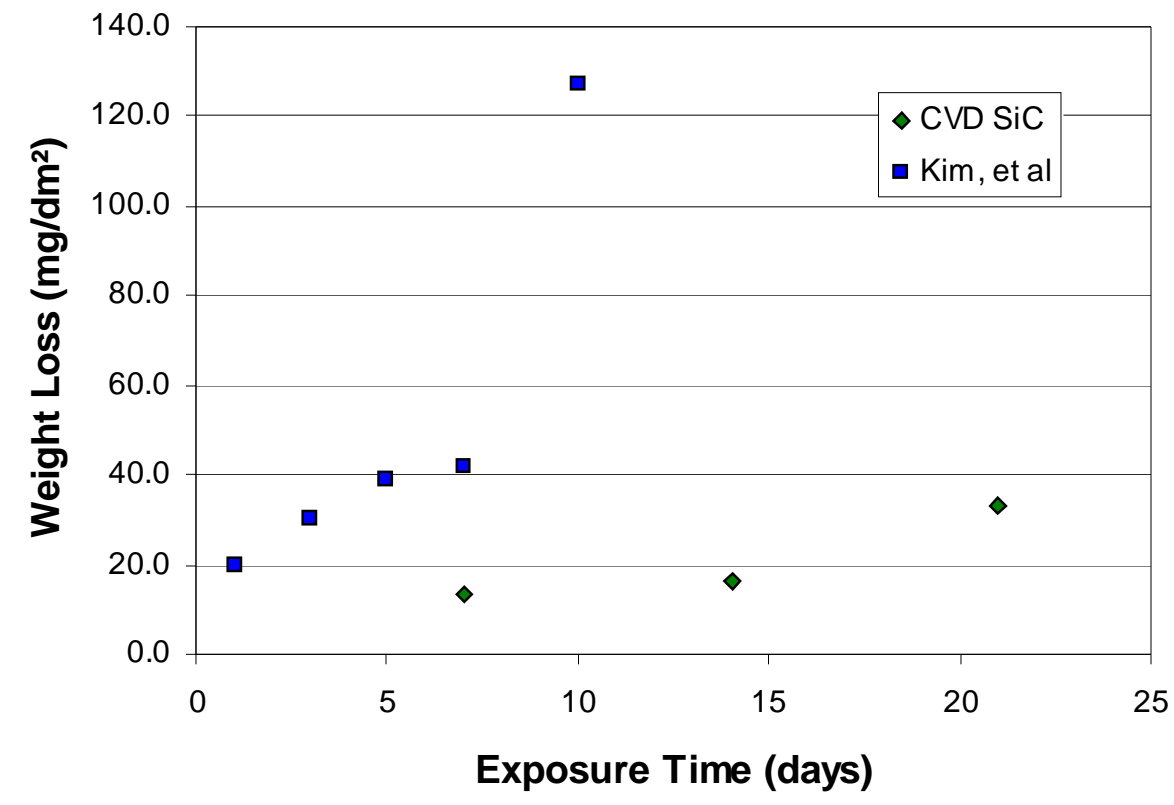

Figure 6.2. Weight loss for CVD SiC after exposure to high-temperature water.

In the present study, the amount of weight loss was much lower than that reported by Kim, et al. Moreover, the abrupt increase in weight loss reported by Kim, et al., after 10 days was not seen in the present study. This result was unexpected, given that the present study used flowing water and a higher exposure temperature, which should have accelerated corrosion/erosion rates compared to exposure in stagnant water. However, the present study utilized very low oxygen 
levels in the water, which may have suppressed corrosion. Unfortunately the limited number of data points precludes an accurate determination of the kinetics of corrosion. Nevertheless, in an attempt to elucidate the corrosion behavior observed in the present study, the exposed samples were characterized using analytical techniques.

Figure 6.3 shows Raman spectra from the surfaces of a stoichiometric $\mathrm{SiC}$ standard, the asreceived $\mathrm{CVD} \mathrm{SiC}$ and the specimen exposed to $500^{\circ} \mathrm{C}$ supercritical water for 21 days. The spectrum for the standard and as-received $\mathrm{SiC}$ showed the expected first order peaks at 800 and $970 \mathrm{~cm}^{-1}$, and second order peaks at 1540 and $1720 \mathrm{~cm}^{-1}$. No free silicon or free carbon was detected for as-received CVD-SiC. After 21 days of exposure, no measurable change in the Raman spectrum was observed, suggesting that preferential removal of silicon or carbon did not occur. Moreover, no oxygen in the form of $\mathrm{SiO}_{2}$ was detected on the surface of the specimen.

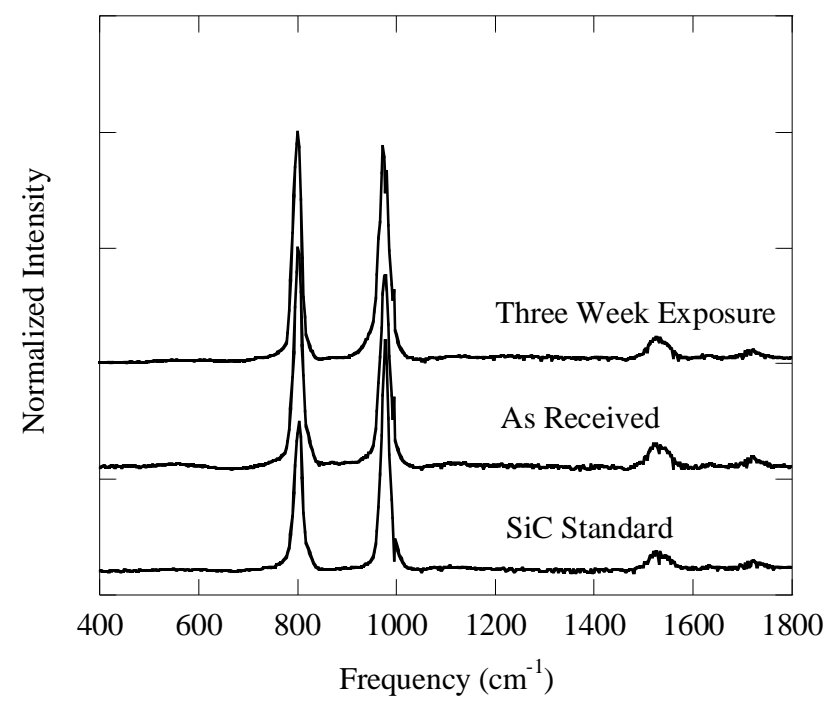

Figure 6.3. Raman spectra of a stoichiometric $\mathrm{SiC}$ standard, the as-received CVD SiC, and the specimen surface after 21-day exposure to $500^{\circ} \mathrm{C}$ water.

Figure 6.4 shows SEM micrographs of cross sections of as-fabricated CVD $\mathrm{SiC}$ and after exposure to supercritical water for 21 days. Note the large columnar grains that are typical of CVD $\beta$-SiC. After the 21-day exposure, pitting of the surface is seen at a depth of 3-5 microns.
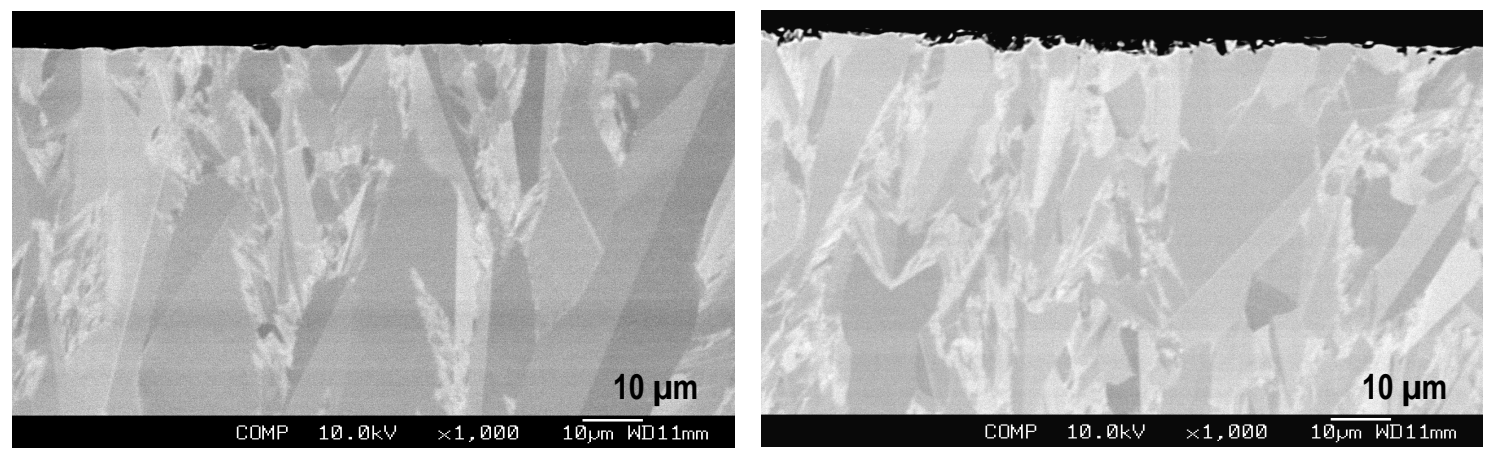

Figure 6.4. SEM micrographs of polished cross sections of as-received CVD SiC (left), and after 21-day exposure to $500^{\circ} \mathrm{C}, 25 \mathrm{ppb} \mathrm{O}_{2}$ supercritical water (right). 
Figure 6.5 shows the surface microstructure of the as-received CVD SiC, and after exposure to supercritical water for 7 days, 14 days and 21 days. The surface features on the as-received sample are the result of polishing artifacts. After exposure to supercritical water, individual $\mathrm{SiC}$ grains can be distinguished on the surface and the amount of $\mathrm{SiC}$ removed clearly increases with exposure time. These images confirm that the grain boundaries are preferentially attacked, as previously reported by Kim, et al [21]. However, Figures 6.4 and 6.5 show that while a small amount of $\mathrm{SiC}$ was removed from the grain boundaries at the surface, the depth of penetration was relatively small and there is no evidence of significant loss of surface grains.
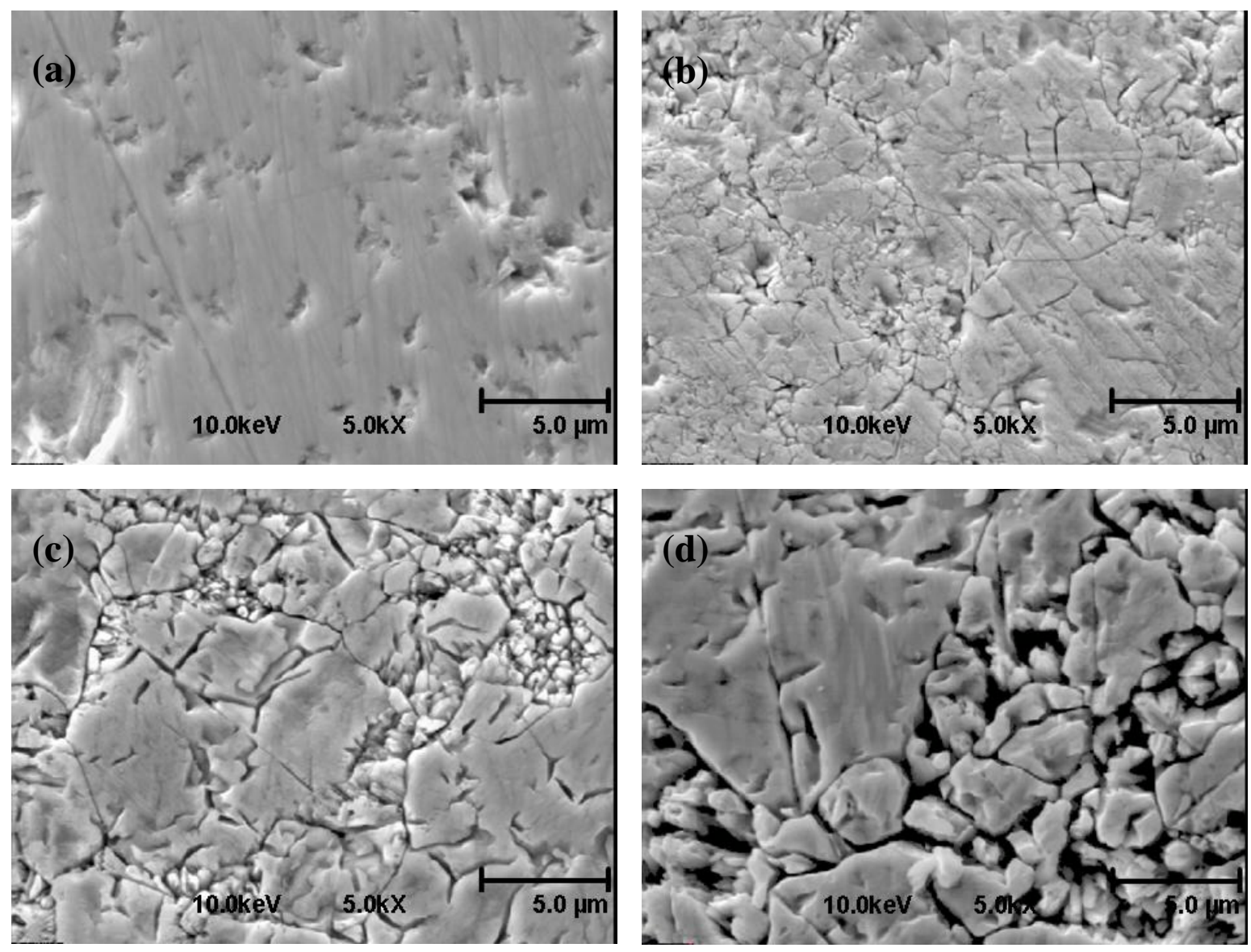

Figure 6.5. SEM micrographs of surfaces for: (a) as-received CVD SiC; (b) after 7 day exposure; (c) after 14 day exposure; and (d) after 21 day exposure.

Surface analysis by Auger spectroscopy was performed for the as-received CVD SiC and the specimens exposed to supercritical water. As shown in Table 6.1, the surface of the as-received CVD-SiC specimen contained about 48.5 atomic percent silicon, 41.3 atomic percent carbon and 10.2 atomic percent oxygen. It should be mentioned that the numbers in Table 6.1 are an average of three values from selected points representing typical surface features. For the unexposed sample, the $\mathrm{C}$ and $\mathrm{Si}$ values ranged from 35-38 at.\% and 44-52 at.\%, respectively. Likewise, the $\mathrm{C} / \mathrm{Si}$ values for the 1 week, 2 week and 3 week samples ranged from $\mathrm{C} 48-49 / \mathrm{Si} 45-46$ at.\%; C 52-68/Si 28-44 at.\%; and C 42-49/Si 47-54 at.\%, respectively. In all cases, lower C values meant 
higher Si values and vice versa. The atomic \% of oxygen was more consistent from point to point on each sample.

Table 6.1. Surface Composition Determined by Auger Spectroscopy (atomic percent)

\begin{tabular}{|c|c|c|c|}
\hline Specimen & Silicon & Carbon & Oxygen \\
\hline As-received & 48.5 & 41.3 & 10.2 \\
\hline 7 day & 45.5 & 48.2 & 6.3 \\
\hline 14 day & 37.0 & 57.9 & 5.1 \\
\hline 21 day & 50.9 & 45.4 & 3.7 \\
\hline
\end{tabular}

In general, exposure to supercritical water led to a reduction in the amount of oxygen present on the surface. The trends for $\mathrm{Si}$ and $\mathrm{C}$ tend to show a slight reduction of $\mathrm{Si}$ and slight increase of $\mathrm{C}$, except for the 3 week sample. This trend would be consistent with removal of Si from the surface via hydrolysis to form $\mathrm{Si}(\mathrm{OH})_{4}$ which dissolved into water, although more data would be required to positively identify this mechanism. The composition of the surface of the specimen exposed for 21 days shows a reduction in the oxygen content, but does not follow the trend with respect to silicon and carbon. This would indicate a different mechanism becomes important after 14 days.

Analytical chemical analysis using an Electron Microprobe confirmed that oxygen was present only on the exposed surface, and that no measurable oxide scale was present. The results of the Auger and microprobe examinations suggest that a protective oxide (or hydrated silica) layer was not present, as has been suggest by Kim, et al [21] and Hirayama, et al [16]. Rather, it is likely that $\mathrm{SiC}$ at the surface was hydrolyzed to form $\mathrm{Si}(\mathrm{OH})_{4}$ species, which were rapidly dissolved into the flowing supercritical water. In this case, a linear relationship between weight loss and exposure time would be expected. However, insufficient data exists in the present study to confirm such a relationship.

As was shown in Figure 6.2, the corrosion rate observed in the present study for CVD SiC in $500^{\circ} \mathrm{C}$ supercritical water was much lower than that reported by Kim, et al. [21], for a different $\mathrm{CVD} \mathrm{SiC}$ in $360^{\circ} \mathrm{C}$ water. The difference in corrosion rates is not fully understood, particularly given the higher temperature and flowing water conditions used for the present study. The present study, however, was carried out with very low oxygen levels (about $25 \mathrm{ppb}$ ) in the water. Kim, et al., did not specify oxygen levels for their experiment, and unless special precautions were made it is likely that somewhat higher oxygen levels were present $(>1 \mathrm{ppm})$. Higher oxygen concentrations in the water would lead to more rapid corrosion [6.4] and therefore, that could explain the differences in corrosion rates. In addition, while both studies utilized highpurity CVD SiC, it appears that differences in the microstructure, or at least orientation of the columnar grains relative to the exposed surface, existed. The columnar grains were generally oriented normal to the surface of the specimens used for the present study, while they appeared to be oriented along the surface in the $\mathrm{SiC}$ used by $\mathrm{Kim}$, et al [6.9]. Moreover, the grains in their specimens appeared to be smaller in size. This would lead to higher grain boundary area in their specimens, and a greater tendency to lose grains via erosion once sufficient corrosion of the grain boundaries had occurred. 


\section{Summary of Corrosion Studies:}

High-purity CVD $\beta$-SiC showed relatively low corrosion rates in deoxygenated supercritical water at $500^{\circ} \mathrm{C}$. The corrosion rate was much lower than that observed for sintered and reaction bonded $\mathrm{SiC}$, and it was lower than that previously reported for $\mathrm{CVD} \mathrm{SiC}$ in water at $360^{\circ} \mathrm{C}$. The present study confirmed that CVD-SiC was preferentially attacked at the grain boundaries. However, insufficient weight loss data were collected to determine if corrosion obeyed a linear or parabolic rate law. Analytical microscopy did not reveal the presence of a measurable oxide scale. As a result, it is believed that corrosion occurred via hydrolysis to hydrated silica species at the surface that were rapidly dissolved into the water. 


\section{0 - Mechanical and Permeability Tests of Round 2-5 Duplex Tubes}

\subsection{Permeability Tests at NovaTech}

Under sponsorship of Westinghouse, NovaTech developed and fabricated a permeability test apparatus to determine the gas retention capability of the round $2-5$ tubes. .

NovaTech pressure tested a NovaTech CCI round 5 duplex tube up to 150 psi with no leakage. Joints between the fixture and the tube did not permit going to higher pressure.

NovaTech tested nine all composite tubes manufactured by NovaTech and Starfire. None of these tubes could retain gas, as illustrated in Figure 7.1 below. Subsequently, NovaTech and Starfire fabricated another three tubes using improved polymer infiltration techniques and these were also tested for gas tightness. These tubes had improved gas retention characteristics, but they also began to leak at pressures of a few psi.

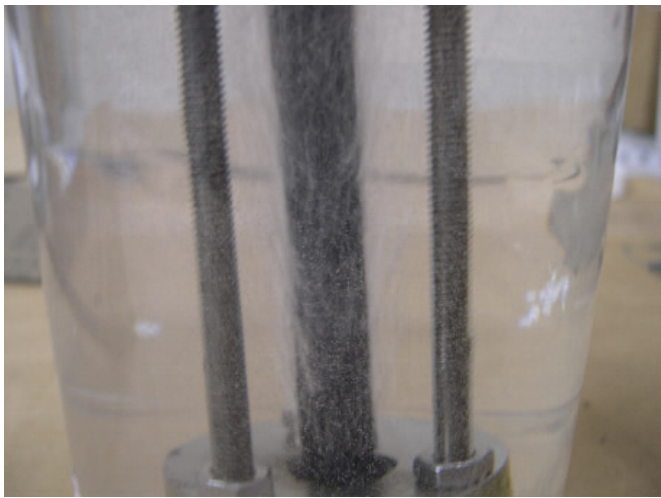

Figure 7.1 - NovaTech-Starfire All Composite Tube under Gas Pressure in Water.

7.2 Mechanical Testing at ORNL - HTML As an Oak Ridge National Laboratory HTML user, Gamma arranged for a series of hoop strength tests to be conducted on round 4 and 5 duplex tubes, on several monolith tubes, and on the all composite tubes, using an existing apparatus at ORNL. Results have been published (reference 22) and are summarized below:

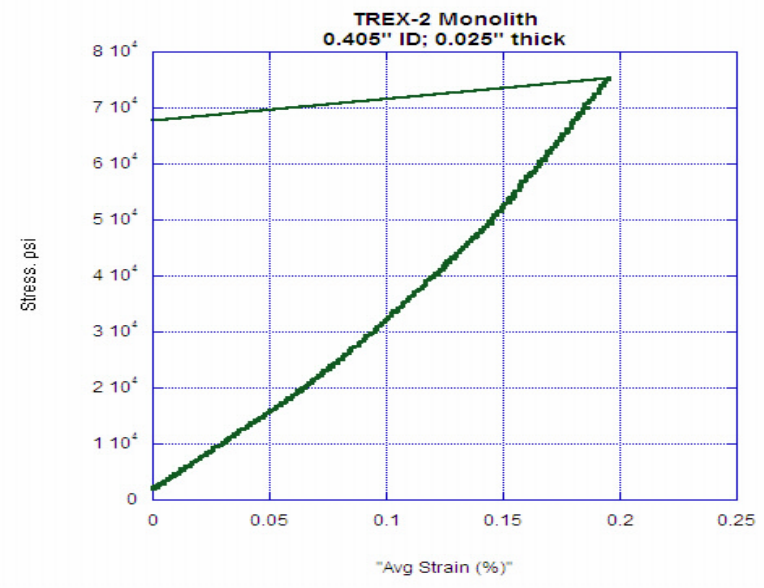

Figure 7.2 - Stress Strain Curve for TREX Monolith Tube 
As expected, the monolith tubes failed in a brittle manner, at about $0.2 \%$ strain. Figure 7.2 shows a stress strain curve for the TREX monolith tube, and figure 7.3 shows a similar curve for a St. Gobain sintered tube. The TREX tube failed at a stress level of 75,000 psi, whereas the sintered tube failed at a stress level of 38,000 psi.

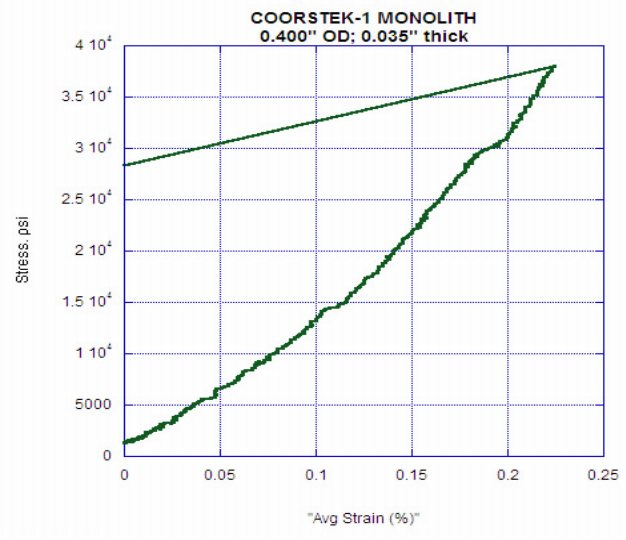

Figure 7.3 Stress Strain Curve for Sintered Monolith Tube.

The results of this testing for a typical Duplex tube, wound with bamboo architecture, is shown in Figure 7.4 below. The duplex tubes failed in a bimodal fashion. A uniform stress strain curve developed up to about $0.2 \%$ strain until the monolith failed, after which the load dropped, and the composite layer stretched out under continuing load application, to above $10 \%$ strain, whilst retaining its basic cylindrical geometry. This ability to retain its geometry out to very high strain levels may mean that the duplex tube can remain stable during more severe Loss of Coolant Accidents, and Reactivity Insertion Accidents, as compared to zirconium alloy clad fuel.

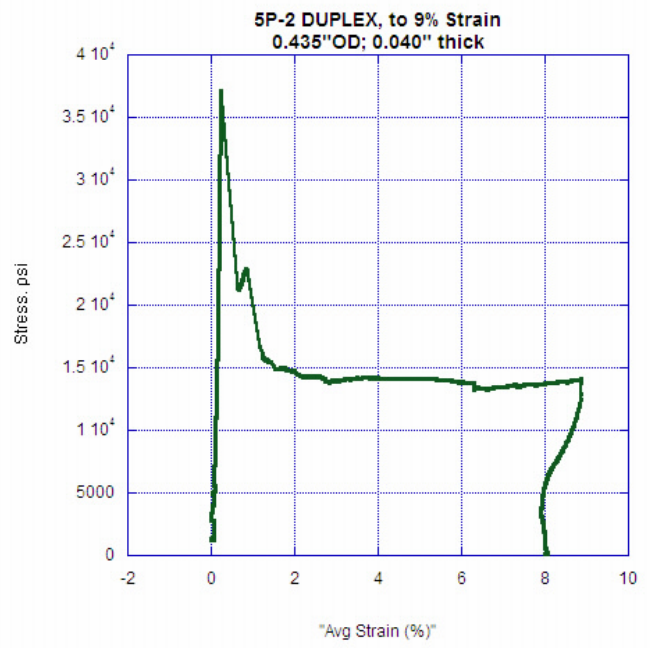

Figure 7.4 - Stress Strain Curve of Round 4 Duplex Tube with Coorstek Monolith and Bamboo Architecture Composite

Two important aspects of nuclear fuel rod cladding are its ability to withstand internal loads, and its ability to contain fission gases during the lifetime of the fuel. Internal loads can arise from a 
pressure gradient between the inside of the cladding and the external environment. Internal pressure sources include the prefill gas pressure (Helium) and the accumulation of fission gases over the life of the fuel rod. Swelling of the fuel over long periods of operation may also provide a source of pressure loads on the cladding. External pressure, at power operation, is usually higher than the internal pressure. However, during certain transient and accident scenarios, there may be a positive gradient from inside to outside, which is then a loading source for the cladding.

Another potential load arises from the reactivity-initiated accident, wherein the fuel pellet expands quickly due to the deposition of energy from the accident. The expansion could include both thermal expansion as a solid fuel pellet and expansion due to melting of some of the fuel.

These various loads are postulated in the safety review of the fuel design, and thus it is necessary to know the cladding response. The processing, and mechanical testing of various Silicon Carbide $(\mathrm{SiC})$ tubular specimens described in this report constitutes an early exploratory step in the direction of qualifying silicon carbide tubes for use as fuel cladding in a nuclear reactor. 


\subsection{Design and Fabrication of the Round 6 Tubes for Strength Testing and MIT Irradiation}

The dimensions of the Round 6 tubes closely model the required geometry for $15 \times 15$ LWR fuel, and are slightly larger than the dimensions required for fast reactor fuel and for $17 \times 17$ LWR fuel. Figure 8.1 shows the process used to fabricate the Round 6 tubes. This was the first time that $\mathrm{SiC}$ duplex tube specimens were produced with thin walls, and it was previously unclear that tubes with such dimensions could be produced. The critical innovation that enabled this success was to leave the very thin monolithic $\mathrm{SiC}$ layer on the graphite mandrel to provide support for the tube during fabrication of the composite layer. The mandrel was used as the primary support structure for the filament wind operation, and remained through deposition of the composite

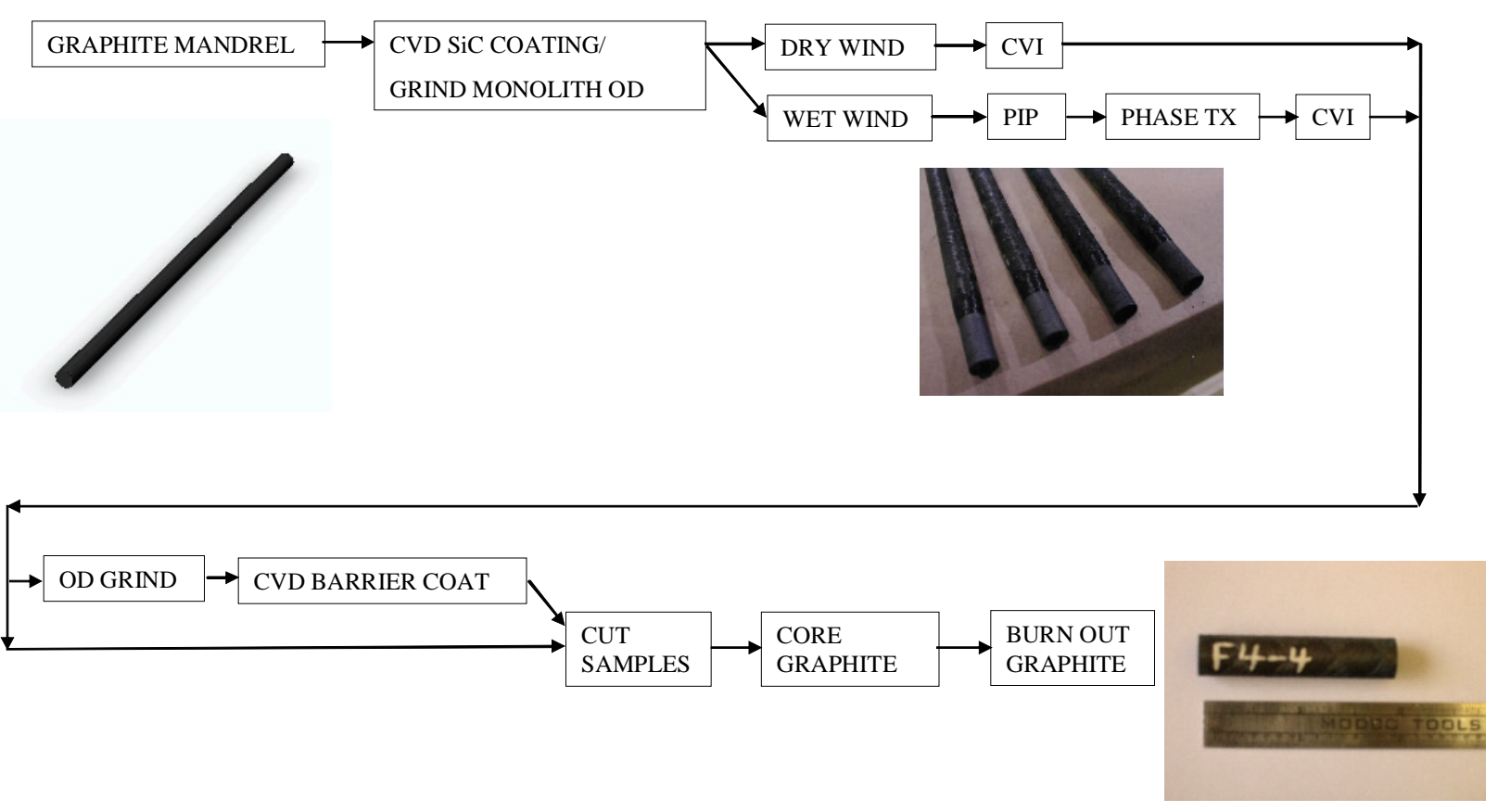

Figure 8.1. Process Flow for Fabrication of SiC Duplex Cladding

matrix and outer $\mathrm{SiC}$ environmental barrier layer. A further innovation was the introduction of the "bamboo" fiber architecture in the filament winding step. The result was a duplex tube having sufficient strength and stiffness to allow removal of the graphite mandrel by hightemperature oxidation. At this point, the tubes had adequate strength for subsequent processing and handling.

\section{$\underline{8.1 \text { Processing Protocol for Round } 6 \text { tubes }}$}

In fabricating the Round 6 tubes, decisions had to be made regarding a number of constituent materials and fabrication steps. The following sections provide an overview of the various options, and the rationale for selection of specific materials and processing routes. 


\subsubsection{Graphite Mandrel}

A key innovation that permitted successful fabrication of the Round 6 tubes was the use of a graphite mandrel as a support structure for the duplex tube throughout the fabrication process. This included the high-temperature operations related to matrix densification, and the addition of a CVD barrier coating (for selected tubes). As a result, it was essential that the graphite material selected for the mandrel have a CTE that was closely matched to that of $\beta$-SiC $\left(3.0-4.5 \times 10^{-6}\right.$ ${ }^{\circ} \mathrm{C}^{-1}$, depending on the precise composition). In addition, the graphite needed to have a relatively high purity to avoid deleterious contamination of the monolithic SiC layer. The graphite material used for the mandrel was specified by the CVD monolithic SiC supplier, based on their processing experience.

\subsubsection{Monolithic SiC}

In the fabrication of previous rounds of $\mathrm{SiC}$ tubes, NovaTech and Gamma worked with a number of firms that can produce CVD SiC structures. For example, both CoorsTek and TREX fabricated 30 mil thick, $1 / 2$ inch diameter tubes that were free standing and were used to fabricate duplex tubes in the earlier rounds of development (Rounds 3, 4 and 5). Rohm and Haas was also asked to provide tubes, but declined to bid. St. Gobain also fabricated good quality tubes for these earlier rounds but these were made from sintered $\alpha-S i C$, which was not considered suitable for service in a neutron flux environment. For the Round 6 tubes, a decision was made to procure CVD SiC monoliths from both CoorsTek, Inc. and TREX Enterprises Corporation to assure a backup source of supply, and to help determine if one source produced tubes having better properties than the other. There was also a significant difference in price, and it was believed that retaining two competitors would be beneficial in the long run. Both suppliers were limited to lengths of 8 to 12 inches, although TREX representatives stated they were working on a possible technology that would allow fabrication of much longer length tubes.

\subsubsection{SiC Fiber (and Coating)}

A number of $\mathrm{SiC}$ fibers are available and have been used to fabricate SiC-based ceramic matrix composite materials. However, the current application requires that the fiber have a high purity and be fully crystallized. SiC fibers that contain amorphous phases, or have impurities such as oxygen, are unsuitable for nuclear applications due to excessive degradation upon irradiation. At present, there are only three high-purity, fully-crystallized $\mathrm{SiC}$ fibers that are suitable for fabrication of thin-walled tubes for use as nuclear fuel cladding: 1) Hi Nicalon Type S (Nippon Carbon Co., LTD); 2) Sylramic iBN (COI Ceramics); and Tyranno SA (Ube Industries). For the Round 6 tubes, Hi Nicalon type S and Sylramic iBN fibers were used. NovaTech had previous experience with the Nicalon fiber, and felt confident that thin-wall duplex tubes could be fabricated using this fiber. NovaTech did not have prior experience with the Sylramic fiber. However, a special research grade fiber using isotopically pure Boron to reduce the absorption cross-section of the fiber coating was made available. As a result, the Sylramic fiber was used for this project. It should be noted that the Sylramic fiber has only recently become commercially available. The fiber was initially developed by NASA, using a heat treatment process on amorphous fiber produced by Dow. The fiber and fabrication process has been licensed by COI Ceramics, who initiated commercial supply in 2004. Data presented by NASA at the 2004 Cocoa Beach conference shows that the Sylramic iBN has substantially better high-temperature creep and rupture resistance as compared to Hi Nicalon Type $S$ and Tyranno SA fibers. The Tyranno SA fiber was not used for Round 6 tube fabrication, although this fiber may be suitable for nuclear fuel cladding, and has been included in numerous studies directed at $\mathrm{SiC}_{\mathrm{f}} / \mathrm{SiC}$ composites 
for fusion reactor structural applications. Irradiation studies have shown that the Tyranno fiber and $\mathrm{SiC}$ composites containing this fiber have excellent property retention. So, while the present work used the Nicalon and Sylramic fibers, it seems that all three fibers may be suitable for fabrication of duplex tubes for nuclear fuel cladding

Carefully controlled coatings on the fibers are critical to achieving the desired graceful failure behavior in ceramic composites. For $\mathrm{SiC}_{\mathrm{f}} / \mathrm{SiC}$ composites, the most common fiber coatings have been carbon and boron nitride. These materials, provide for a weak interface between the fibers and the SiC matrix. The Nicalon and Tyranno fibers are often supplied with a pyrolytic carbon coating, although they can be obtained with a BN coating. The Sylramic fiber is supplied with an in-situ BN coating that is formed during the heat treatment of the amorphous $\mathrm{SiC}$ fiber to produce the fully-crystallized fiber. It should also be noted that the Sylramic fibers can be given an in-situ processing called $\mathrm{iC}$, which leads to a thin carbon coating. This fiber is not yet commercially available. The specific coatings used in the fabrication of the Round 6 tubes depended on the matrix densification process

\subsubsection{Filament Winding for Composite Layer}

Winding of the $\mathrm{SiC}$ fibers onto the $\mathrm{SiC}$ monolithic layer was the first step to forming the composite layer of the duplex tubes. A key parameter that had to be defined for the Round 6 tubes was the fiber architecture. Some early Round 4 and 5 tubes used a helical winding without crossover architecture that resulted in tubes with high hoop strength, but relatively low flexural strength. A transition was made to all helical wound structures with fiber tow crossover for Round 6 tubes.

A number of additional parameters used for winding the composite layer depended on the fibers selected and the subsequent matrix densification method. First, the fibers can be obtained with a sizing (organic binder) applied to the fiber. The use of sizing improves that handling characteristics of the fiber, and can affect the fiber packing within the composite layer. A greater amount of sizing tends to open the space available for the infiltration of matrix material within the tows. Also, the use of sizing generally allows for higher tension to be used during the winding process. A higher winding tension generally results in a thinner composite layer with higher fiber density. The winding tension used is also influenced by the quality of the fibers, especially strength. Lower strength fibers must use lower winding tension to avoid excessive damage to the fibers within tows, or even breakage of fiber tows. In Round 5, Gamma-NovaTech tried to make some duplex tubes using fiber tows with extra thick sizing to see if that would improve the matrix density and reduce unwanted matrix porosity. It did not, so that approach was discarded.

The winding process was significantly impacted by the subsequent matrix densification method. For tubes undergoing matrix densification using chemical vapor infiltration (CVI), a dry winding method was used. The fiber was wound directly onto the $\mathrm{SiC}$ monolith without any further treatment. However, for tubes being densified by the polymer infiltration and pyrolysis (PIP) method, a wet winding process was used. The process involved "painting" the $\mathrm{SiC}$ monolith with a slurry ( $\mathrm{SiC}$ pre-polymer solution $+\mathrm{SiC}$ powder), followed by filament winding. The Nicalon fiber used for the wet winding process was pre-coated with approximately 0.2 microns of pyrolytic carbon, followed by 0.2 microns of $\mathrm{SiC}$ (applied by Synterials, Inc). Wet winding was accomplished by passing the fiber tows through a container of pre-polymer solution prior to winding the tows onto the SiC coated mandrel. The Sylramic fiber that was wet wound was not given this additional fiber coating because of insufficient time in the schedule. For the dry winding and CVI matrix densification approach, both fiber types were given a thin in-situ carbon 
coating before matrix infiltration (i.e., performed by Hyper-Therm within the CVI reactor). Additional details regarding the materials and process steps used for "wet winding" are provided below.

\subsubsection{Matrix infiltration}

Densification of the matrix was performed using the CVI process and the PIP process. While NovaTech has worked with a number of CVI suppliers in the past, CVI matrix densification for the Round 6 tubes was performed by Hyper-Therm High-Temperature Composites, Inc. (Huntington Beach, CA). Hyper-Therm performed a single CVI furnace run for all of the Round 6 tubes. Prior to matrix densification, they added a two-layer fiber coating consisting of sequentially deposited pyrolytic carbon and $\mathrm{SiC}$. The outer $\mathrm{SiC}$ coating has been shown to provide some level of oxidation/ corrosion protection to the carbon interface coating. That is, studies have shown that oxygen (or corrosive species) migrate through microcracks to the matrix, and eventually degrade the carbon interface coating. The multi-layer coating prevents these species from getting to the fiber coating.

The PIP matrix densification process involved a series of infiltration and curing steps using a $\mathrm{SiC}$ polymeric precursor (SMP-10) from Starfire Systems, Inc. After achieving the maximum matrix density using the precursor, the composite tubes were heat treated at $1500^{\circ} \mathrm{C}$ in an inert atmosphere to convert the polymer into a fully crystallized $\beta$-SiC. Since this heat treatment caused the matrix to shrink, thereby creating microcracks/voids in the matrix, a final matrix densification step involving CVI was performed by Ceramics Composites, Inc. (Millersville, MD). As part of the final CVI process, a SiC barrier coating was also applied to the PIP composite layer.

It should be noted that a review of the literature suggests that CVI and PIP matrix densification processes generally result in residual porosity levels on the order of 10-15 volume percent. This implies that the process is properly conducted, and that the exposed surface is not prematurely sealed off. Studies have also shown that techniques involving forced flow of reactants through the composite and/or the application of a temperature gradient can reduce the amount of residual porosity with the CVI process. It is unclear whether either method is appropriate for the fabrication of thin-walled tubes. A forced-flow thermal gradient process may not work for the thin walled tubes because of the thin composite layer and the presence of the inner monolith. However, it may be possible to improve matrix densification by using the graphite mandrel as a heating element, thereby creating a higher temperature on the inner surface of the composite layer. If sufficient temperature gradient can be achieved, then matrix densification would proceed from the inside toward the outer surface.

\subsubsection{Post Fabrication Machining}

As shown in Figure 2, filament winding of the composite layer results in an outer surface that contains significant texture/roughness. The affect of this surface texture on the performance of the duplex tubes as nuclear fuel cladding is unknown. Furthermore, there may be a need to have a smooth surface and/or a carefully controlled outer diameter on the tubes. To evaluate the potential for machining the duplex tubes, and to have machined specimens available for the irradiation test, three (3) tubes were machined after completing CVI matrix infiltration. One of the tubes was left in the machined state, the other two were exposed to an additional CVD process by TREX for a new barrier coating followed by final machining for a smooth outer surface. The target thickness for the TREX barrier coating was 5 mils 


\subsubsection{SiC Barrier Coating}

A dense layer of $\beta$-SiC was applied to the outer surface of the tubes by CVD to improve corrosion resistance. The coating for the tubes densified by Hyper-Therm was actually produced in the same reactor run as the matrix densification step. The amount of CVD SiC deposited on the outer surface was not precisely controlled. For the tubes densified using the PIP process, the $\mathrm{SiC}$ barrier layer was applied by CCI as part of the final CVI step. Again, the amount of $\mathrm{SiC}$ deposited on the outer surface was not precisely controlled .

\subsection{Round 6 Tubes - Materials/Process Matrix}

Table 8.1 summarizes the materials and process matrix used for the Round 6 tubes. In total, 17 duplex tubes were produced using 9 different materials/process variations. In addition, two monolithic SiC only tubes were fabricated to allow separate characterization of the CVD SiC produced by CoorsTek and TREX. The tubes produced using the CoorsTek monoliths were about 10 inches in length, while those produced using the TREX monoliths were about 8 inches in length.

Table 8.1. Materials/Process Matrix for Round 6 Tubes

\begin{tabular}{|c|c|c|c|c|c|c|c|c|c|}
\hline $\begin{array}{c}\text { Sample } \\
\text { Designation }\end{array}$ & Qty & $\begin{array}{l}\text { Monolithic Tube } \\
\text { CVD SiC }\end{array}$ & Fiber & $\begin{array}{l}\text { Pre-Wind Fiber } \\
\text { Interface Coating }\end{array}$ & Tension & Slurry & $\begin{array}{c}\text { CVI } \\
\text { Infiltration }\end{array}$ & $\begin{array}{l}\text { Post-CVI } \\
\text { Machining }\end{array}$ & $\begin{array}{l}\text { Trex CVD } \\
\text { Overcoat }\end{array}$ \\
\hline \multicolumn{10}{|l|}{ Duplex Tubes } \\
\hline$A$ & 1 & Trex .015" thick, 0.354" ID & HiNicalon-S & none & $600 \mathrm{~g}$ & $\mathrm{~N} / \mathrm{A}$ & Hyper-Therm & Yes & No \\
\hline $\mathrm{B}$ & 2 & Trex .015" thick, 0.354" ID & HiNicalon-S & none & $600 \mathrm{~g}$ & $\mathrm{~N} / \mathrm{A}$ & Hyper-Therm & No & No \\
\hline C & 2 & Trex .015" thick, 0.354" ID & HiNicalon-S & $\begin{array}{l}\text { Synterial } \\
0.2 \mu \mathrm{C}+0.2 \mu \mathrm{SiC}\end{array}$ & $600 \mathrm{~g}$ & $\mathrm{CCl}$ or NT & $\mathrm{CCl}$ & No & No \\
\hline D & 1 & Trex .015" thick, 0.354" ID & Sylramic iBN & none & $120 \mathrm{~g}$ & $\mathrm{~N} / \mathrm{A}$ & Hyper-Therm & Yes & Yes \\
\hline $\mathrm{E}$ & 1 & Trex .015" thick, 0.354" ID & Sylramic iBN & none & $120 \mathrm{~g}$ & $\mathrm{~N} / \mathrm{A}$ & Hyper-Therm & No & No \\
\hline $\mathrm{F}$ & 4 & Coorstek .015" thick, $0.350 "$ ID & HiNicalon-S & none & $600 \mathrm{~g}$ & $\mathrm{~N} / \mathrm{A}$ & Hyper-Therm & No & No \\
\hline G & 2 & Coorstek .015" thick, $0.350 "$ ID & Sylramic iBN & none & $120 \mathrm{~g}$ & $\mathrm{CCl}$ or NT & $\mathrm{CCl}$ & No & No \\
\hline $\mathrm{H}$ & 3 & Coorstek .015" thick, $0.350 "$ ID & Sylramic iBN & none & $120 \mathrm{~g}$ & $\mathrm{~N} / \mathrm{A}$ & Hyper-Therm & No & No \\
\hline I & 1 & Trex .015" thick, 0.354" ID & HiNicalon-S & none & $600 \mathrm{~g}$ & $\mathrm{~N} / \mathrm{A}$ & Hyper-Therm & Yes & Yes \\
\hline \multicolumn{10}{|l|}{ Monolith Only } \\
\hline$M$ & 1 & Coorstek .015" thick, 0.350" ID & $\mathrm{N} / \mathrm{A}$ & $\mathrm{N} / \mathrm{A}$ & $\mathrm{N} / \mathrm{A}$ & $\mathrm{N} / \mathrm{A}$ & $\mathrm{N} / \mathrm{A}$ & $\mathrm{N} / \mathrm{A}$ & $\mathrm{N} / \mathrm{A}$ \\
\hline $\mathrm{T}$ & 1 & Trex .025" thick, $0.354 "$ ID & $N / A$ & $\mathrm{~N} / \mathrm{A}$ & $\mathrm{N} / \mathrm{A}$ & $\mathrm{N} / \mathrm{A}$ & $\mathrm{N} / \mathrm{A}$ & $N / A$ & N/A \\
\hline
\end{tabular}

Note: All the Sylramic fibers had a very thin BN interface coating that was formed as part of the ATK processing.

\subsection{Joint Design and Sealing Materials}

Development of an end cap joining method was performed by Gamma Engineering. Two different end cap designs, shown in Figure 8.2, were investigated. For the initial joining trials, $\beta$ $\mathrm{SiC}$ rods and monolithic tubes were procured from TREX. The SiC tubes had a 0.418" OD and a 0.035 " wall thickness ( 0.348 " ID). End caps were fabricated by machining the $\beta$-SiC rods.

- The Type A end cap design accommodates the application of adhesive on the single step of the end cap and the OD of the end cap material that fits inside the cladding.

- The Type B end cap has a second step to locate the end cap on top of the tube while a reaction bonding process is applied. 


\section{Type A}

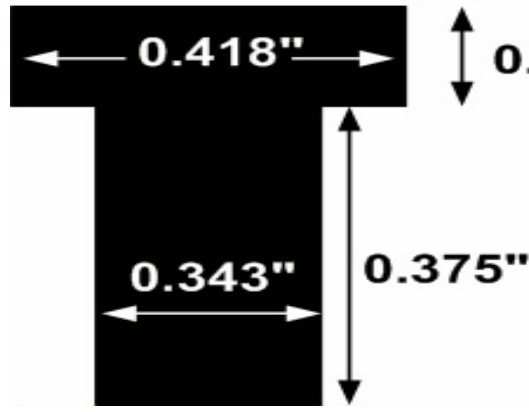

Type B

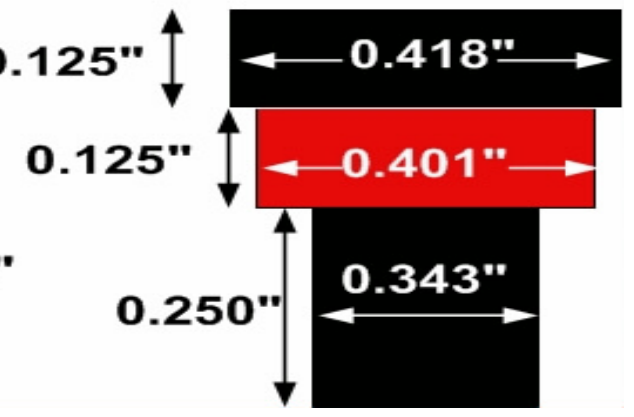

Figure 8.2. End Cap Configurations for Testing of Joining Technology

Two methods were investigated for achieving a strong, hermetic bond between the end caps and monolithic tubes. One approach used a glass sealant, while the second used a commercially available zirconia-based adhesive.

\section{Glass Bonding}

Joining of end caps to tubes was performed by Hyper-Therm using a proprietary glass. No information was provided regarding the processing parameters, and in particular the peak temperature used to melt the glass and join the components

Limited chemical analysis was performed for the glass material using XPS. Since XPS is a surface sensitive technique, care must be taken in interpreting the data, as significant amount of water and $\mathrm{CO}_{2}$ can adsorb onto the surfaces that are analyzed. The analysis suggests that the bonding material consists primarily of $\mathrm{Si}, \mathrm{Al}, \mathrm{Mg}$ and $\mathrm{O}$, with trace amounts of $\mathrm{P}, \mathrm{Ca}$ and $\mathrm{W}$.

\section{Zirconia-based Adhesive}

The zirconia-based adhesive was a commercially available material. This material has a rated service temperature of $2250^{\circ} \mathrm{C}$, compressive strength of 6,000 psi and flexural strength of 3,000 psi. Its thermal coefficient closely matches that of silicon carbide. Chemical analysis by XPS suggests that the adhesive is largely sodium silicate, with a small amount of added zirconia, presumably to adjust the CTE of the cured product. 


\subsection{Design, Fabrication and Assembly of MIT Irradiation Test Fixture}

As part of the SBIR Phase 2 extension project, MIT's Nuclear Reactor Group was assigned the task of designing an irradiation test loop to expose SilCar clad specimens to typical PWR neutron flux and chemistry conditions. The SBIR funding covered all funds needed to design and fabricate the specimen holders, modifications needed to external loop systems and components, safety analyses and operational approvals, and final assembly of the specimen holders and test specimens for insertion into the reactor. The irradiation and post irradiation examination was funded by the private sector.

\subsection{Irradiation Loop Overall Design}

The MITR-II reactor is a $5 \mathrm{MW}_{\text {th }}$ light water cooled, heavy water reflected, thermal reactor operated at atmospheric pressure and $50{ }^{\circ} \mathrm{C}$ outlet temperature. Theneutron flux in the core is similar to a commercial PWR reactor, with peak fast and thermal flux of $1 \times 10^{14}$ and $4 \times 10^{13}$ $\mathrm{n} / \mathrm{cm}^{2}$-sec respectively. The SilCar irradiation test loop and fixture is mounted in a hollow dummy fuel element in position B-3 in the middle of the core's three rings. See figure 9.1

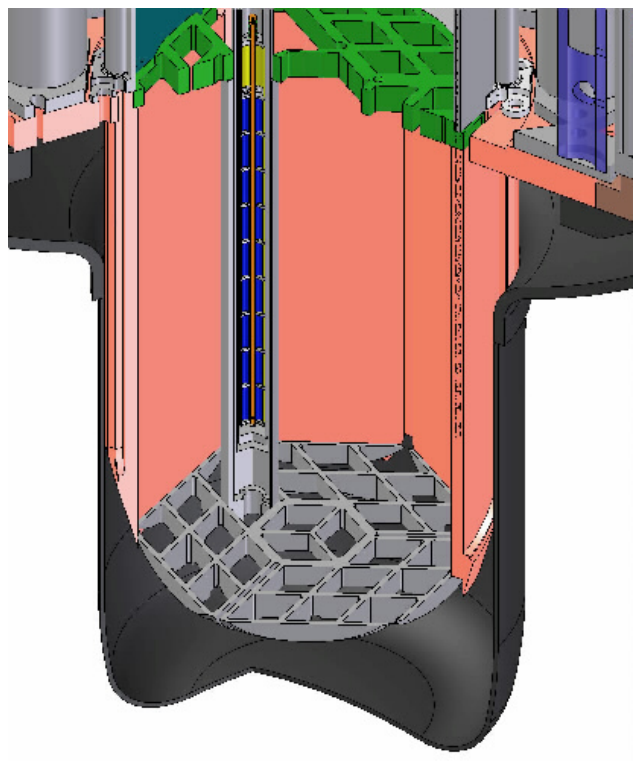

Figure 9.1 - Overall and core detail views of the Advanced Clad Irradiation (ACI) in the MITR-II reactor core tank.

The fast neutron flux axial profile, based on previous measurements at MITR-II, is shown in figure 9.2 


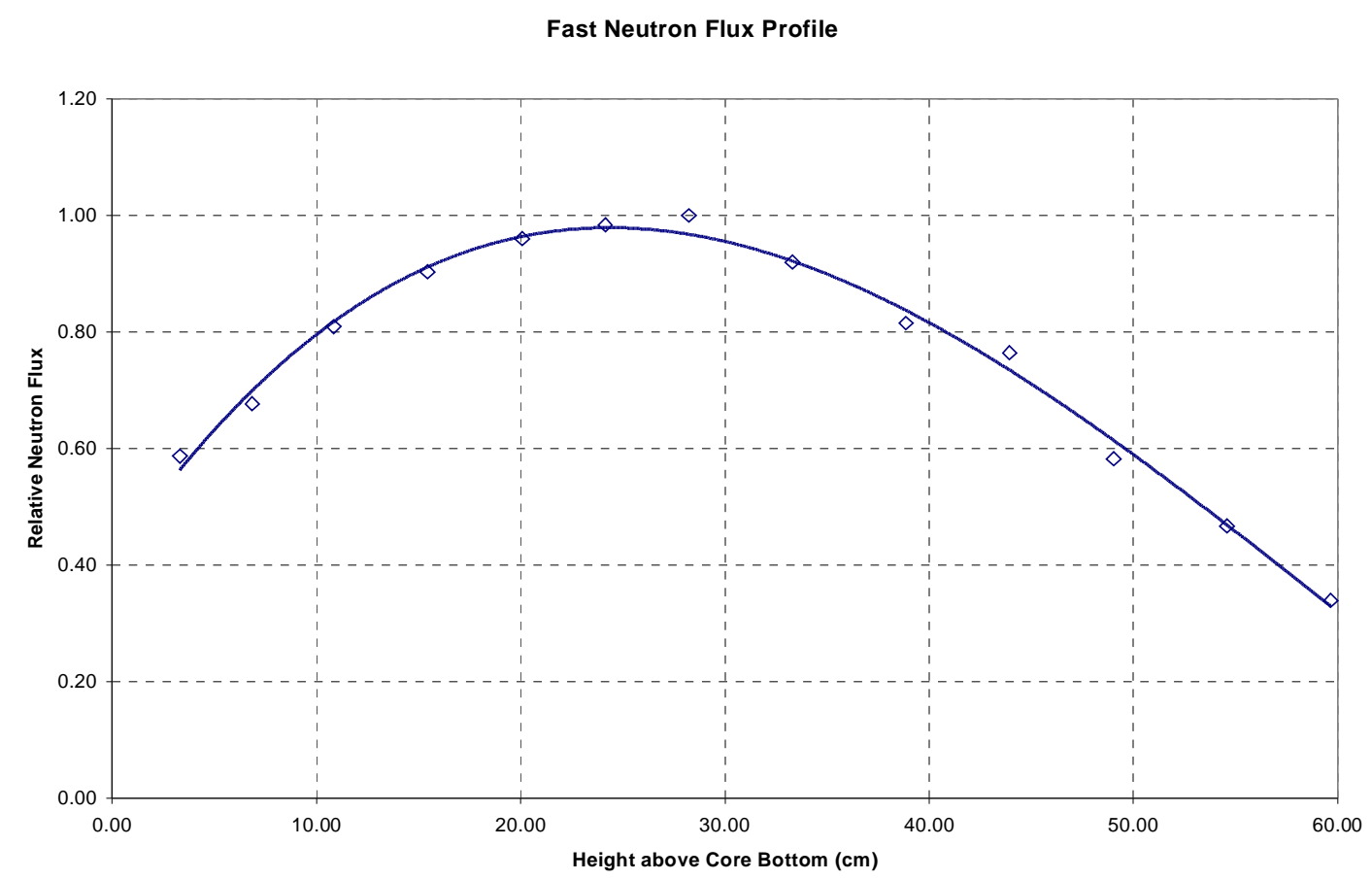

Figure 9.2 - Neutron Flux Profile in MITR-II Reactor

A closed loop is provided outside the reactor to provide the inlet water at $300{ }^{\circ} \mathrm{C}$ and $1500 \mathrm{psi}$ at a mass flow of $0.25 \mathrm{~kg} / \mathrm{sec}$. The heated portion of the loop is insulated by a $\mathrm{CO}_{2}$ gas gap, assuring a temperature drop of not more than $20{ }^{\circ} \mathrm{C}$ over the length of the in-core section.

Oxygen is removed from the circulating water by bubbling hydrogen through the coolant makeup tank. Boric acid is added to provide $800 \mathrm{ppm}$ of boron, and lithium hydroxide is added at $2.2 \mathrm{ppm}$ to provide $\mathrm{pH}$ control.

\subsection{Structural Design}

The SilCar irradiation facility consists of three main sections: the in-core assembly, the heating and flow control system, and the let-down chemistry system. Also, a data acquisition system is provided to record temperature, pressure, and chemistry parameters.

The in-core section consists of the sample assembly, autoclave and thimble. The sample assembly is made of individual modules. Each module holds 3 to 9 SilCar cladding samples, in 1 to 3 layers. An example of a 3 layer, 9 sample, module is shown in figure 9.3. The figure also shows a photograph of a 3 layer module with the SilCar samples inserted. The modules are held together by tie rods running through the center of the SilCar tubes. There are small radial holes in these tie rods to allow the coolant to flow through the center of the samples, avoiding coolant stagnation. 
The modules stack into a spine rod that hangs down from a fitting at the base of the water outlet pipe. Two feet above the in-core section is a second set of modules containing additional SilCar samples, allowing exposure to coolant chemistry, but without the neutron flux exposure.

Surrounding and in the space between each module are titanium flow shrouds which separate the flow into two channels. When the sample assembly is placed inside the autoclave, a 1.57" OD titanium tube, coolant enters the top of the autoclave, flows down around the outside of the modules, then up through the inside of each module before returning to the reactor lid. A partially assembled module showing the various components is shown in figure 9.3.

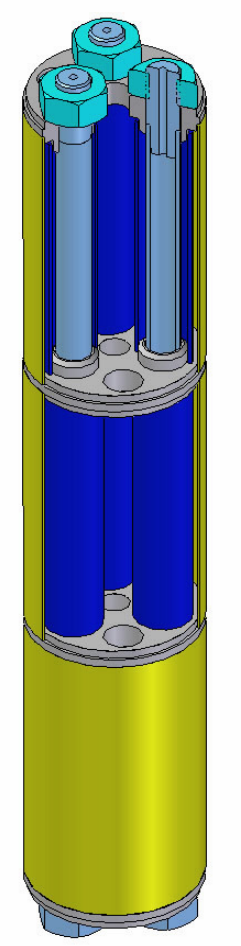

\section{"Tie" tube}

Ti Spacer

"Standard" Specimens

\section{Flow Shroud}

Figure 9.3 - Typical 3 layer module, and special module for end cap specimens

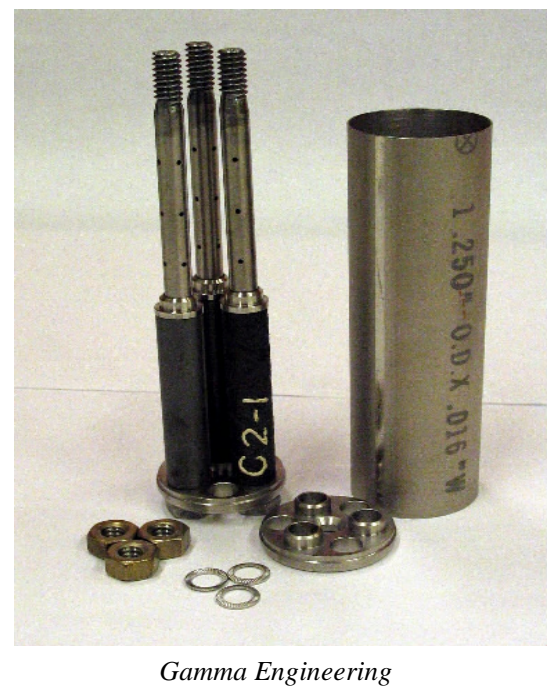

Figure 9.4 - Partially assembled 3 layer module, showing bottom layer of 3 SilCar samples in place on three tie rods, next to flow shroud. 
With respect to fast neutron irradiation damage, it has been calculated that one displacements per atom (dpa) for silicon carbide is achieved with a fast neutron fluence of about $1 \times 10^{21}$. Thus the initial MIT test period of 4 months would impart a dose of $0.8 \mathrm{dpa}$ at the center of the stack, and about $0.5 \mathrm{dpa}$ at the ends of the stack. A full year test would lead to a peak dose of $2.4 \mathrm{dpa}$, about one fourth the total dose anticipated for a fully burned up (50 gwd/t) LWR fuel. 


\subsection{ORNL Pre-Irradiation Strength Testing of Round 6 Tubes}

ORNL established a method for testing the hoop strength of the SiC duplex cladding specimens. The design of the test apparatus and the test protocol was adapted from existing capability established for testing zircaloy cladding for the DOE-NNSA MOX fuel program. Because the apparatus uses a polyurethane plug to transmit the vertical force applied by the Instron testing machine to the inner walls of the clad tube, it is limited to temperatures acceptable to the polyurethane, less than $100^{\circ} \mathrm{C}$.

As of mid June 2006, room temperature mechanical testing has been performed for ten (10) Round 6 specimens. The data for these specimens are summarized in Table 10.1. While the data is limited, it appears that the specimens fabricated with the CoorsTek monolith (Avg. $=848$ lbf; SD $=71.7 \mathrm{lbf}$ ) are slightly stronger than those fabricated with the TREX monolith (Avg. = $765 \mathrm{lbf} ; \mathrm{SD}=100.3 \mathrm{lbf}$ ). Furthermore, it appears that the tubes fabricated with the Sylramic fiber $($ Avg. $=876 \mathrm{lbf} ; \mathrm{SD}=29.5 \mathrm{lbf})$ are stronger than those fabricated with Nicalon fiber $($ Avg. $=766$ lbf; SD $=95.5 \mathrm{lbf})$.

Table 10.1. Summary of Room Temperature Hoop Strength Tests

\begin{tabular}{|c|c|c|c|c|c|c|}
\hline Specimen & Monolith & Fiber & $\begin{array}{c}\text { Matrix } \\
\text { Densification }\end{array}$ & $\begin{array}{c}\text { Date } \\
\text { Tested }\end{array}$ & $\begin{array}{c}\text { Failure } \\
\text { Load (lbf) }\end{array}$ & $\begin{array}{c}\text { Failure } \\
\text { Behavior }\end{array}$ \\
\hline F3-1 & CoorsTek & Nicalon & $\mathrm{CVI}$ & $1 / 31 / 06$ & 787 & Graceful \\
\hline F4-2 & CoorsTek & Nicalon & $\mathrm{CVI}$ & $1 / 31 / 06$ & 847 & Graceful \\
\hline H2-4 & CoorsTek & Sylramic & $\mathrm{CVI}$ & $1 / 31 / 06$ & 877 & Graceful \\
\hline H3-3 & CoorsTek & Sylramic & $\mathrm{CVI}$ & $1 / 31 / 06$ & 876 & Graceful \\
\hline F2-5 & CoorsTek & Nicalon & $\mathrm{CVI}$ & $5 / 22 / 06$ & 700 & Graceful \\
\hline E1-1 & TREX & Sylramic & $\mathrm{CVI}$ & $5 / 23 / 06$ & 868 & Graceful \\
\hline H1-1 & CoorsTek & Sylramic & $\mathrm{CVI}$ & $5 / 23 / 06$ & 890 & Graceful \\
\hline B2-1 & TREX & Nicalon & $\mathrm{CVI}$ & $5 / 23 / 06$ & 750 & Graceful \\
\hline C1-1 & TREX & Nicalon & $\mathrm{PIP/CVI}$ & $6 / 8 / 06$ & 605 & Brittle \\
\hline G1-1 & CoorsTek & Sylramic & $\mathrm{PIP/CVI}$ & $6 / 8 / 06$ & 916 & Brittle \\
\hline I1-1 & TREX & Nicalon & $\mathrm{CVI}$ & $6 / 30 / 06$ & 775 & Graceful \\
\hline A1-2 & TREX & Nicalon & $\mathrm{CVI}$ & $6 / 30 / 06$ & 553 & Atypical \\
\hline D1-1 & TREX & Sylramic & $\mathrm{CVI}$ & $6 / 30 / 06$ & 826 & Graceful \\
\hline F1-3 & CoorsTek & Nicalon & $\mathrm{CVI}$ & $6 / 30 / 06$ & 897 & Graceful \\
\hline
\end{tabular}

Load vs. strain curves for four of the specimens having their matrix densified by CVI as shown in Figure 10.1. These specimens failed in a graceful manner. That is, the load on the ram was increased to the 800-900 lbf range at which point the monolith layer failed. Afterward, the load dropped to about $200 \mathrm{lbf}$, at which point the composite layer began to carry the load. While not shown in the Figure, load bearing capability was maintained to a few percent strain at which point the test was typically terminated. Testing was not continued to higher strain levels to avoid specimen contact with the capacitance probes. 


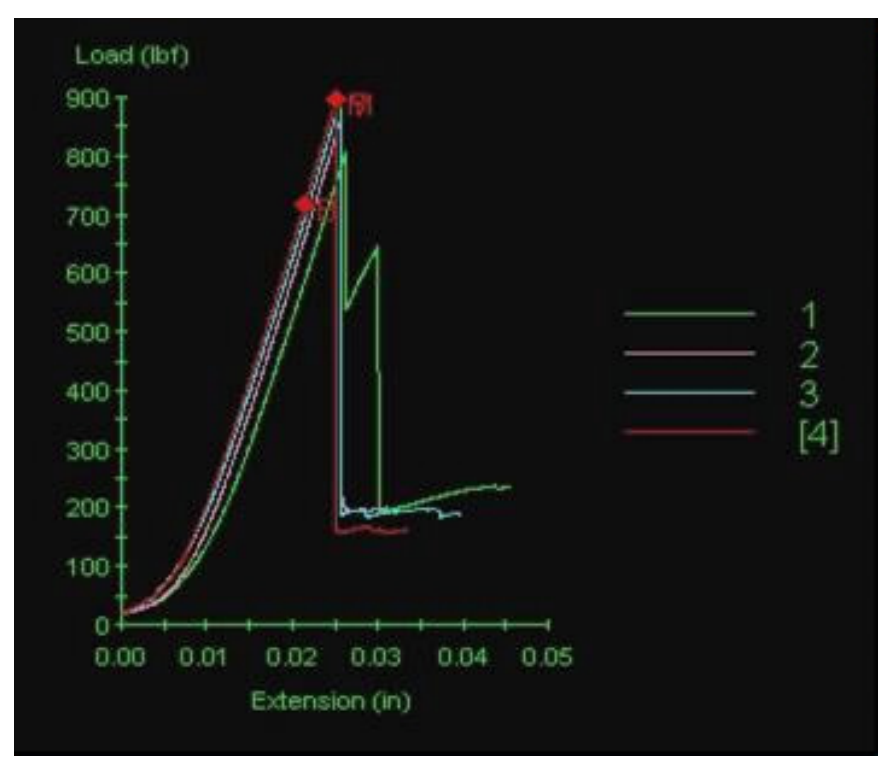

\section{Figure 10.1. Room-Temperature Hoop Strength Test Data for Four Round 6 Specimens}

Tests were performed in June 2006 for two specimens for which the composite layer was densified using the PIP process. This process involved a $1500^{\circ} \mathrm{C}$ heat treatment of the tubes, followed by final matrix densification using CVI. As shown in Figure 10.2, these two specimens yielded the highest and lowest strength values measured for Round 6 tubes, with the exception of the machined specimen (A1-2). Most important, however, is that the specimens failed in a brittle manner, as shown in Figure 10.2.

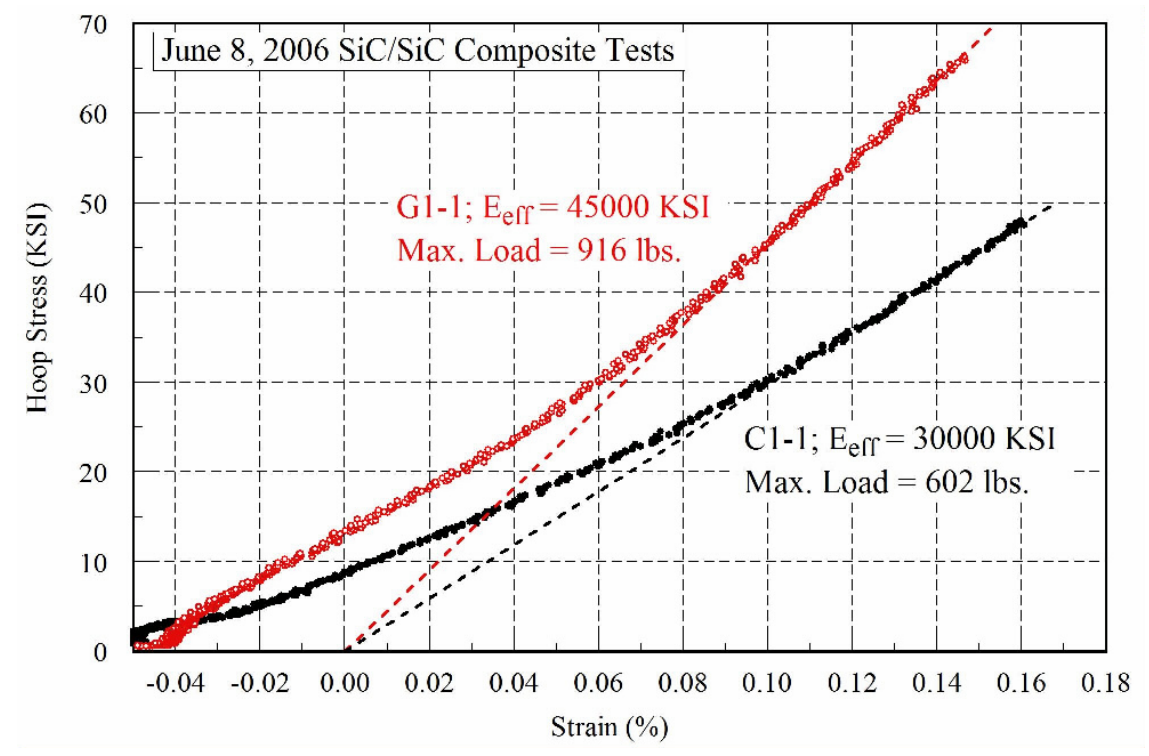

Figure 10.2. Room-Temperature Hoop Strength Data for Tubes using the PIP Matrix Densification Process. 

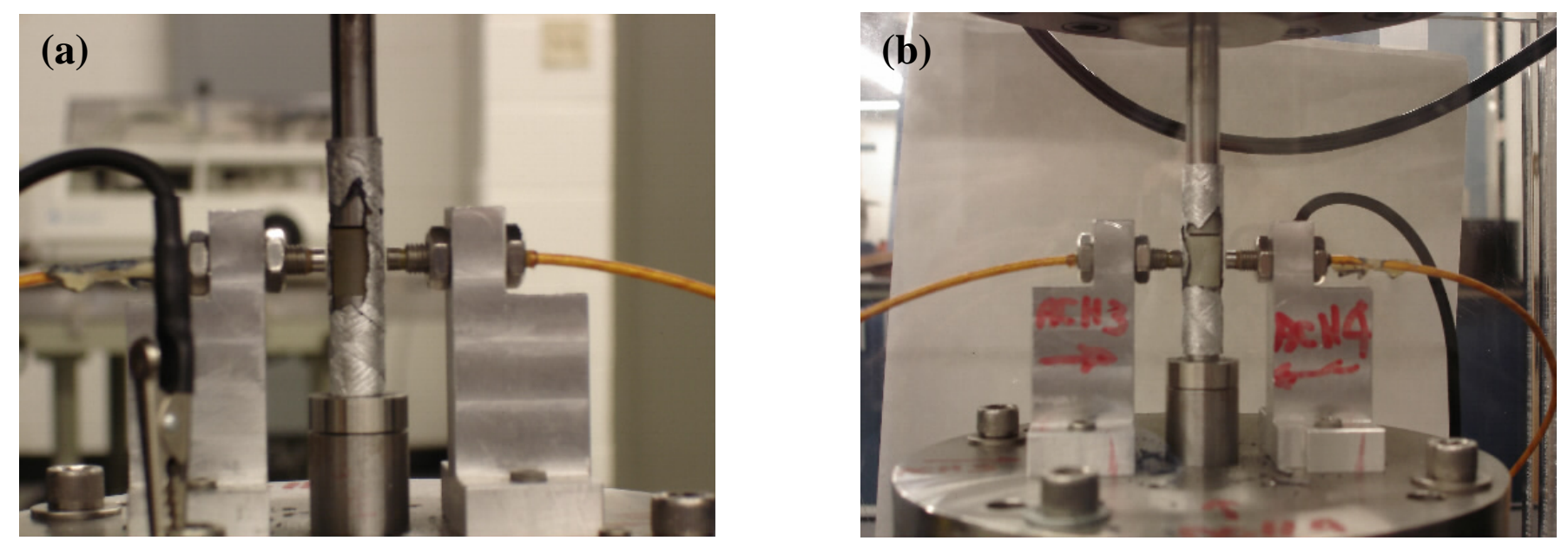

\section{Figure 10.3 Photographs of Specimens (a) C1-1 and (b) G1-1 after Room Temperature Hoop Strength Testing.}

Based on these tests, it appears that for duplex tubes made via the dry CVI process, the SiC monolith layer is capable of holding fission gas pressures up to about 9,000 psi. In addition, after initial failure at this high pressure, the outer composite layer successfully retained its geometry out to very high strain levels. This behavior was anticipated based on the mechanical properties of the two layers. Also, the test revealed that the composite layer reinforced the monolith layer and took over $30 \%$ of the internal pressure loading. This behavior was predicted by a simple stress model developed to characterize the interaction of the monolith and composite layers.

The observed mechanical properties are a significant outcome. The multi-layer SiC clad should be able to contain an internal pressure loading of about 9000 psi at room temperature, and because $\mathrm{SiC}$ does not loose its strength until $1400^{\circ} \mathrm{C}$ or higher, this fission gas retention will remain viable until well above accident temperatures. Moreover, data from the fusion program seems to indicate that this high-strength characteristic needed to retain high fission gas pressure will remain to very high dpa (dislocations per atom This, in turn, will allow fuel elements to remain robust and hermetic at very high burnup levels. 


\subsection{Privately Funded Irradiation Tests at MIT}

The initial irradiation period in the MIT Research Reactor began on May 25, 2006, and ended on October 4, 2006. The test included 24 in-core specimens and 15 out-of-core specimens. As shown in Table 11.1 below, the in-core modules included 19 Round 6 tube specimens, 3 end cap joint specimens, 1 CoorsTek monolith specimen and 1 Zircaloy specimen. The out-of-core modules included 12 Round 6 specimens, 1 Coorstek monolith specimen, 1 TREX monolith specimen and 1 Zircaloy specimen.

The tests was operated under PWR coolant conditions, with $\mathrm{T}=300^{\circ} \mathrm{C}, \mathrm{P}=1500 \mathrm{psi}$, and water chemistry controlled by adding $800 \mathrm{ppm}$ boric acid, $2.2 \mathrm{ppm} \mathrm{LiOH}$, and using a $\mathrm{H}_{2}$ overpressure (to achieve $0.4 \mathrm{ppb}$ oxygen level). It is estimated that the specimens in the central in-core modules received a fast neutron fluence of about $8 \times 10^{20} \mathrm{n} / \mathrm{cm}^{2}$ (or about $0.8 \mathrm{dpa}$ ) over the 132 day test period.

\begin{tabular}{|c|l|c|c|c|}
\hline & Position: & $\mathbf{1}$ & $\mathbf{2}$ & $\mathbf{3}$ \\
\hline \multirow{4}{*}{$\begin{array}{c}\text { In- } \\
\text { Core }\end{array}$} & tier 1 & $\mathrm{Z} 1-1$ & $\mathrm{Z} 2-1$ & $\mathrm{Z} 3-1$ \\
\cline { 2 - 5 } & tier 2 & $\mathrm{E} 1-3$ & $\mathrm{~B} 1-2$ & $\mathrm{~B} 1-4$ \\
\cline { 2 - 5 } & tier 3 & $\mathrm{H} 2-1$ & $\mathrm{~A} 1-1$ & $\mathrm{~F} 1-1$ \\
\cline { 2 - 5 } & tier 4 & $\mathrm{D} 1-2$ & $\mathrm{I} 1-2$ & $\mathrm{C} 1-3$ \\
\cline { 2 - 5 } & tier 5 & $\mathrm{I} 1-3$ & $\mathrm{D} 1-3$ & $\mathrm{C} 2-1$ \\
\cline { 2 - 5 } & tier 6 & $\mathrm{A} 1-4$ & $\mathrm{H} 3-4$ & $\mathrm{~F} 1-4$ \\
\cline { 2 - 5 } & tier 7 & $\mathrm{M} 1-2$ & $\mathrm{G} 1-3$ & $\mathrm{~N} 1-2$ \\
\cline { 2 - 5 } & tier 8 & $\mathrm{E} 1-2$ & $\mathrm{~B} 2-2$ & $\mathrm{G} 2-2$ \\
\hline \multirow{4}{*}{$\begin{array}{c}\text { Out } \\
\text { of Core }\end{array}$} & tier 9 & $\mathrm{I} 1-4$ & $\mathrm{M} 1-1$ & $\mathrm{G} 2-3$ \\
\cline { 2 - 5 } & tier 10 & $\mathrm{N} 1-1$ & $\mathrm{C} 2-2$ & $\mathrm{G} 1-4$ \\
\cline { 2 - 5 } & tier 11 & $\mathrm{F} 1-2$ & $\mathrm{H} 1-5$ & $\mathrm{C} 1-4$ \\
\cline { 2 - 5 } & tier 12 & $\mathrm{A} 1-3$ & $\mathrm{D} 1-4$ & $\mathrm{H} 2-5$ \\
\cline { 2 - 5 } & tier 13 & $\mathrm{B} 1-3$ & $\mathrm{~T} 1$ & $\mathrm{E} 1-4$ \\
\hline
\end{tabular}

Table 11.1. Specimen locations for the initial irradiation period $(M=$ CoorsTek; $\mathbf{T}=$ Trex; $\mathbf{N}=$ Zircaloy and $Z=$ end caps joints)

\subsection{Initial Characterization at MIT}

The specimens were removed from the lower in-core modules (tiers 1-4); after an appropriate cool-down period, each specimen was subjected to a visual examination, weight measurement and dimension measurements. A number of these specimens will used for additional PIE work.

Specimens from the upper-most in-core module were also examined; most of them were reinstalled into a new module (along with new specimens) for further irradiation. Specimens from the out-of-core modules were also examined; most of them were reinstalled into the module for further exposure to PWR coolant.

\section{$\underline{11.2 \text { Visual Examinations }}$}

Visual examinations were performed for all of the in-core specimens. In general, the specimens appeared to be in good shape. However, one specimen (C1-3) appeared to be severely damaged 
(as shown in Figure 11.1(a). This specimen was from the C-series tube that was fabricated using the PIP matrix densification process. The typical appearance of the remaining Round 6 specimens is illustrated in Figure 11.1(b) and Figure 11.1(c) for specimens F1-1 (CoorsTek monolith, Hi-Nicalon Type S fiber) and H2-1 (CoorsTek monolith, Sylramic IBN fiber).



(a) $\mathrm{C} 1-3$

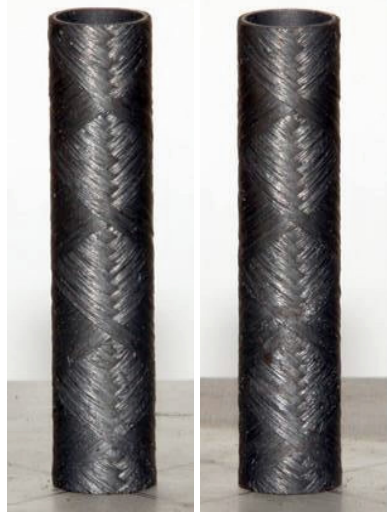

(b) F1-1

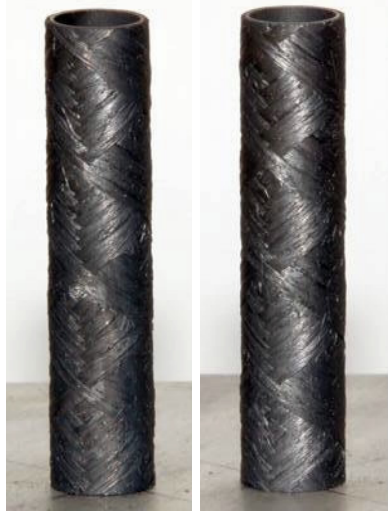

(c) $\mathrm{H} 2-1$

Figure 11.1 Photos of selected Round 6 specimens after irradiation in the MIT reactor.

Upon closer inspection of the specimens, a number of in-core and out-of core specimens (e.g., B1-3) showed an area near one end that had a different appearance than the rest of the specimen (see Figure 11.3). Initially, it was believed that the appearance of this region was due to a higher level of corrosion associated with the exposed ends of the specimens (i.e., exposing the composite layer to the coolant).

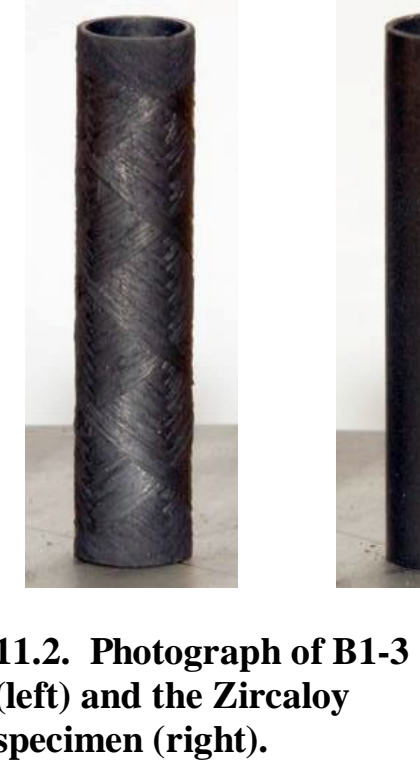

\subsection{Dimension and Weight Measurements}

Dimension and weights were measured for most of the specimens (except those in tiers 5 and 6). It should be noted that the Zircaloy specimen appeared to grow by 0.005 inches (or $0.26 \%$ ).

Subsequent to acquisition of initial weight loss data, it was realized that a significant portion of the weight loss for in reactor specimens was due to localized corrosion at the cut ends of the specimens. Consequently, a procedure was developed to correct for this condition, as such cut ends would not be exposed in a commercial reactor application. A $1 / 4$ inch ring was cut from 
several specimens, and the remaining short tube weighed and compared with previous preexposure weight calculations. The results for three in-reactor specimens are presented below.

Calculations were made to estimate the recision rates for the $\mathrm{F}$ - and $\mathrm{H}$-series specimens. The calculations are summarized in the following table:

\begin{tabular}{|l|r|r|r|r|r|r|r|r|}
\hline Sample & $\begin{array}{r}\text { Corrected } \\
\text { Pre-Irr. (g) }\end{array}$ & $\begin{array}{c}\text { Normalized } \\
\text { Post-Irr (g) }\end{array}$ & $\begin{array}{c}\text { Delta Wt. } \\
(\mathrm{mg})\end{array}$ & $\begin{array}{c}\text { Max OD } \\
(\mathrm{dm})\end{array}$ & $\begin{array}{c}\text { Length } \\
(\mathrm{dm})\end{array}$ & $\begin{array}{c}\text { Surface } \\
\text { area }(\mathrm{dm})\end{array}$ & $\begin{array}{c}\text { Surface Loss } \\
(\mathrm{mg} / \mathrm{dm})\end{array}$ & $\begin{array}{r}\text { Recision } \\
(\mathrm{microns})\end{array}$ \\
\hline $\mathrm{F} 1-1$ & 3.293 & 3.268 & -25.4 & 0.106 & 0.482 & 0.161 & -105.3 & -3.3 \\
\hline $\mathrm{H} 2-1$ & 3.754 & 3.734 & -20.0 & 0.108 & 0.483 & 0.164 & -81.2 & -2.5 \\
\hline $\mathrm{H} 2-5$ & 3.660 & 3.633 & -26.5 & 0.108 & 0.483 & 0.164 & -108.0 & -3.4 \\
\hline
\end{tabular}

As shown in the table, the estimated recision was about 3 microns for the 132 day exposure period. Extrapolation to a 4.5 year operating life results in an expected loss of about 32 microns. This is about $1 / 3$ of the typical thickness of the CVD SiC barrier coating.

\subsection{Extended Irradiation of Specimens at the MIT Research Reactor}

As of January 1, 2007, an additional test period of 5 months within the MIT Research Reactor, is underway. Reactor startup occurred on December 4, 2006. To conduct this test, new specimens were supplied to MIT to replace those removed from Tiers 1 through 4 . In addition, given the poor performance of the PIP infiltrated specimens, a decision was made to remove most of the Cand G-series specimens from the test modules. Prior to shipping the specimens to MIT, the marking material was removed from the specimens. Removal of most of the marking material was accomplished by exposing the specimens to water at $\sim 650^{\circ} \mathrm{F}$ and 2500 psi for 12 hours in an autoclave. The specimens were shipped to MIT in mid November. 


\subsection{Summary and Future Plans}

Process and Product Development - During the $4 \frac{1}{2}$ years of this extended project, Gamma and its subcontractors tried over a dozen different techniques for fabrication of the cladding tubes, starting with round 1 during our phase 1 project in 2002, and ending in round 6 in our most recent effort. Lessons from each round of fabrication and testing were incorporated in the processes used in the next round.

This final report provides only summary results from these earlier rounds. The reader is referred to the cited references for details of these early processing and testing trials.

In the latest round 6 effort, a series of twelve 10 to 12 inch long triplex tubes were fabricated by Gamma and its suppliers. These tubes had dimensions of about 0.030 inch wall thickness, and an outside diameter of about 0.410 ". These dimension are very close to those of 15 x 15 PWR fuel, thus allowing direct substitution for existing $15 \times 15$ PWR zircaloy clad fuel. They are also close to the dimension of zircaloy clad tubes used in $9 \times 9$ BWR fuel.

Because the fiber winding process is conducted on the outside of the very thin and fragile SiC monolith, it was found necessary to conduct the winding process on the monolith tubes, while the inner graphite mandrel remained in place. These graphite mandrels were burned off after the composite layer had been deposited via CVI, and the outer layer by CVD, thus giving the tubes the lateral strength needed for handling and further processing.

Mechanical Behavior of Duplex Tubes - In a collaborative effort, Gamma and ORNL researchers conducted a series of hoop strength measurements on typical $\mathrm{SiC}$ clad tubes fabricated during the course of this project. A hoop strength test device developed by ORNL as part of their MOX fuel cladding program sponsored by the NNSA was used for this work, and proved to be a valuable test method. The ORNL facilities and scientists were made available through the HTML users program at no cost to the SBIR project. We thank the DOE's Office of Renewable Energy (sponsors of the HTML) for allowing our use of these resources for this project.

The mechanical test work showed that:

1. The monolith alone cannot be relied on as fuel cladding as the monolith fails in a brittle mode. Two kinds of monoliths were tested, those fabricated by CoorsTech and those fabricated with particle reinforcement by TREX.

2. The composite alone cannot be relied on for gas retention. The permeability is an inherent characteristic of a porous matrix which results from use of the PIP process, or CVI, and the need to allow passages for gaseous effluents during the pyrolysis of polymers. It is speculated that the brittle mode of failure on the PIP tubes tested at ORNL occurred because insufficient interface layer was deposited on the fibers before densifying the matrix. Although this problem can be addressed by improved fiber coating, the porosity of the composite layer will remain, regardless of the infiltration method used.

3. The duplex tubes failed in a bimodal fashion. A typical stress strain curve developed up to about $0.2 \%$ strain until the monolith failed, after which the load dropped, and the composite layer 
stretched out under continuing load application, to above $10 \%$ strain, whilst retaining its basic cylindrical geometry. This ability to retain its geometry out to very high strain levels may mean that the duplex tube can remain stable during more severe Loss of Coolant Accidents, and Reactivity Insertion Accidents, as compared to zirconium alloy clad fuel. Further tests at high temperature, using a modified apparatus being developed under a separate STTR project, are planned to confirm this behavior.

4. The strength of the three layer triplex tube was 30 to $40 \%$ greater than strength of the monolith alone. This indicates that the combination of tightly wound composite layer, and thin outer environmental barrier layer reinforced the inner monolith layer, allowing it to retain 30 to $40 \%$ higher internal pressure $(9,000$ to $11,000 \mathrm{psi})$ as compared to the monolith layer alone. This high pressure containment capability is important in providing a high burnup capability for this new cladding, since the fission gas release will create higher internal pressures with the hotter fuel that is anticipated with silicon carbide cladding.

Joining Development - Gamma undertook several small scale joining experiments to evaluate and develop methods of joining end caps, and also joining short length tubes to make the longer lengths required for reactor service. Although we developed impermeable joints of significant load carrying capability, we found that the joints degraded during reactor exposure; further development is required.

MIT Irradiation Test - During the last year of the project Gamma conducted an irradiation test of the round 6 tubes described above. The tubes were sectioned into 1.9 inch lengths and inserted into a special titanium pressure tube designed and fabricated by MIT. The specimen holder had room for forty separate specimens, 24 within the reactor core flux region, and 16 out of the flux region, but still exposed to the $300{ }^{\circ} \mathrm{C}$ pressurized coolant that is representative of typical PWR coolant. The first phase of this test was operated for four months, representing about 0.8 dpa of fast neutron exposure, and them removed for interim examination. Nineteen specimens were replaced with fresh round 6 specimens and the fixtures were reinserted in the reactor. An additional five months of exposure is now underway, and further examination is planned in September, 2007.

Most of the specimens removed and examined after four months showed no major degradation, however a few specimens, including those infiltrated via a polymer process (PIP) were severely degraded, and contained excessive weight loss. When corrected for the end cut degradation, a condition not expected in commercial application, the material loss for the CVI impregnated triplex specimens was less than the material loss for advanced zirconium alloys. Detailed SEM examination, and additional strength tests of the irradiated specimens, is to be conducted early in 2007. 


\subsection{References}

1. NRC SBIR Phase 1 Report -"Feasibility study on use of ceramic cladding to reduce the severity of reactor accidents" US-NRC contract 04-89-099; Gamma Engineering Report 8533-1, June 30, 1990

2. United States Patent 5,182,077, January 26, 1993, Water Cooled Nuclear Reactor and Fuel Elements Therefor, Herbert Feinroth

3. Continuous fiber ceramic composite (CFCC) cladding for commercial water reactor fuel, final report; US-DOE contract DE-FG03-99SF21887; Gamma Engineering Report 41-FR, April 2001

4. SBIR Phase 1 Report "A Multi-Layered Ceramic Composite for Fuel Cladding Applications in Commercial Nuclear Reactors" Gamma Report G01-9FR, February, 2002

5. SBIR Phase 2 Technical Progress Report for the period May 17, 2003 through November 30, 2003, "A Multi-Layered Ceramic Composite for Fuel Cladding Applications in Commercial Nuclear Reactors" Gamma Report G-49-02, January 5, 2004

6. SBIR Phase 2 Technical Progress Report for the period December 1, 2003 through June 30, 2004, "A Multi-Layered Ceramic Composite for Fuel Cladding Applications in Commercial Nuclear Reactors" Gamma Report G-49-04, July 7, 2004

7. SBIR Phase 2 Technical Progress Report for the period January 1, 2005 through September 30, 2006, "A Multi-Layered Ceramic Composite for Fuel Cladding Applications in Commercial Nuclear Reactors" Gamma Report G-54-03, November 21, 2005

8. - Sterbentz, J.W.., Neutronic Evaluation of a 21x21 Supercritical Water Reactor Fuel Assembly Design with Water Rods and SiC Clad/Duct Materials; INEEL-EXT-04-02096 dated January 12, 2004

9. MCNP4B: Monte Carlo N-Particle Transport Code System," contributed by Los Alamos National Laboratory, Los Alamos, New Mexico, April 1997 and distributed as package CCC-660 by Oak Ridge National Laboratory.

10. MCNP4C Monte Carlo N-Particle Transport Code System", contributed by Los Alamos National Laboratory, Los Alamos, New Mexico, February 29, 2000 and distributed as package CCC-700 by Oak Ridge National Laboratory.

11. A. G. Croff, "ORIGEN2 - A Revised and Updated Version of the Oak Ridge Isotope Generation and Depletion Code," ORNL-5621, Oak Ridge National Laboratory, July 1980.

12. R. S. Babcock, D. E. Wessol, C. A. Wemple, S. C. Mason, " The MOCUP Interface: A Coupled Monte Carlo/Depletion System”, EG\&G Idaho, Inc., Idaho National Engineering Laboratory, presented at the 1994 Topical Meeting on Advances in Reactor Physics, Vol. III, Knoxville, TN, April 11-15, 1994. 
13. E. Barringer, Z. Faiztompkins, and H. Feinroth, T. Allen, M. Lance, H. Meyer, L. Walker, and E. Lara-Curzio "Corrosion of CVD Silicon Carbide in $500^{\circ} \mathrm{C}$ Supercritical Water" Journal of American Ceramic Society, 90 [1] 315-318 (2007)

14. E.E. Bloom, "The Challenge of Developing Structural Materials for Fusion Power Systems, "Journal of Nuclear Materials 263: 7-17 Part A, Oct 1998.

15. D. J. Senor, G. E. Youngblood, C. E. Moore, D. J. Trimble, G. A. Newsome, and J. J. Woods, "Effects of Neutron Irradiation on Thermal Conductivity of SiC-based Composites and Monolithic Ceramics,” Fusion Technology, 30 (3): 943-955 Part 2A, DEC 1996.

16. H. Hirayama, T. Kawakubo, A. Goto, and T. Kaneko, "Corrosion Behavior of Silicon Carbide in $290^{\circ} \mathrm{C}$ Water," J. Amer. Ceram. Soc., 72 [11], 2049-2053 (1989).

17. N. S. Jacobson, Y. G. Gogotsi, and M. Yoshimura, "Thermodynamic and Experimental Study of Carbon Formation on Carbides under Hydrothermal Conditions," J. Mater. Chem., 5, 595-601 (1995).

18. Y. Gogotsi, K. Nickel, D. Bahloul-Hourlier, T. Merie-Mejean, G. Khomenko and K. Skjerlie, "Structure of Carbon Produced by Hydrothermal Treatment of $\beta$-SiC Powder," J. Mater. Chem., 6[4], 595-604 (1996).

19. T. Kraft, K. G. Nickel, and Y. G. Gogotsi, "Hydrothermal Degradation of Chemical Vapor Deposited SiC Fibers,” J. Mater. Sci., 33, 4357-4363 (1998).

20. W. Kim, H. Hwang, and J. Park, "Corrosion Behavior of Reaction-Bonded Silicon Carbide Ceramics in High-Temperature Water,” J. Mater. Sci. Letters, 21, 733-735 (2002).

21. W. Kim, H. Hwang, J. Park, and W. Ryu, "Corrosion Behavior of Sintered and Chemically Vapor Deposited Silicon Carbide Ceramics in Water at $360^{\circ}$ C, ' J. Mater. Sci. Letters, 22, 581584 (2003).

22. Ross, D.F., Hendrich, W.R.. Strength Testing of Monolithic and Duplex Silicon Carbide Cylinders in Support of use as Nuclear Fuel Cladding, American Ceramic Society Composites Conference, Cocoa Beach, Florida, January, 2006.

STTR Phase 1 Final Report, "Property Measurement and Improved Strength of DUPLEX $\mathrm{SiC} / \mathrm{SiC}$ Ceramic Composites for Fast Reactor Application” DOE/NE/STTR/86243-1, November 1,2006 